\title{
DESIGN AND ANALYSIS OF A WIND ENERGY HARVESTING CIRCUIT USING PIEZOELECTRIC POLYMERS
}

\author{
A Thesis \\ presented to \\ the Faculty of California Polytechnic State University, \\ San Luis Obispo
}

\author{
In Partial Fulfillment \\ of the Requirements for the Degree \\ Master of Science in Electrical Engineering
}

by

Jameson J. Thornton

April 2011 
(C) 2011

Jameson J. Thornton

ALL RIGHTS RESERVED 


\section{COMMITTEE MEMBERSHIP}

TITLE:

Design and Analysis of a Wind Energy Harvesting Circuit Using Piezoelectric Polymers

AUTHOR:

Jameson J. Thornton

DATE SUBMITTED:

April 2011

COMMITTEE CHAIR:

Dr. Taufik, Professor

COMMITTEE MEMBER:

Dr. Dale Dolan, Assistant Professor

COMMITTEE MEMBER: Dr. Vladimir Prodanov, Assistant Professor 


\begin{abstract}
Design and Analysis of a Wind Energy Harvesting Circuit Using Piezoelectric Polymers Jameson J. Thornton

This thesis investigates a relatively new method for harvesting wind energy by using flexible piezoelectric polymers with additional sails to increase their ability to harvest wind energy. This paper also introduces a new topology deemed the "stacked buck" that allows for multiple inputs to a system with a single output. Derivations and analysis detail the workings of the "stacked buck" with a laboratory test to show a working model. This paper also reports another experiment done in a wind tunnel to analyze the capability of the piezoelectric polymers as sources to the "stacked buck" topology with measurements of the power output. The results of this thesis demonstrate that because the design is very modular, it is possible to scale the proposed wind energy harvesting system for small power applications.
\end{abstract}

Keywords: Energy, Power, Havesting, Scavenging, Power Electronics, Buck, Stacked Buck, Renewable, Piezoelectric, Wind. 


\section{ACKNOWLEDGMENTS}

First and foremost I would like to thank my advisor and teacher, Taufik. You have taught me many valuable things, and entertained my creative ideas. Thank you for keeping my research interests in mind. Without your observations I would not have known about this possible path and it would have passed by without much thought. Also thank you for all of your time and hard work as a professor, I know that all of your students greatly appreciate you. I would also like to thank my parents, Jeanne and James (from whom I get my name and my curiosity). Thank you for all the support over the years. Without you I could have never realized my dreams. This thesis is the culmination of my many years of hard work, and your many years of supporting me. I cannot thank you enough. I would also like to thank Darwin Fernandez for helping me with derivations and trouble shooting. Lastly I would like to thank the Electrical Engineering department faculty and staff for their help, as well as the Mechanical Engineering department for allowing me to use their facilities. 


\section{Table of Contents}

List of Tables ....................................................................... viii

List of Figures .......................................................................

Chapter 1 : Introduction. .......................................................................................................... 1

Chapter 2 : Background...................................................................................................... 7

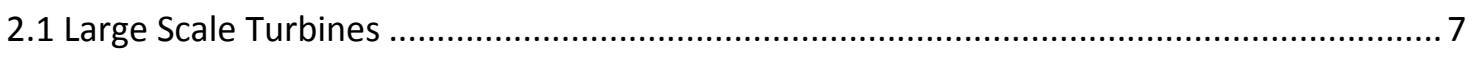

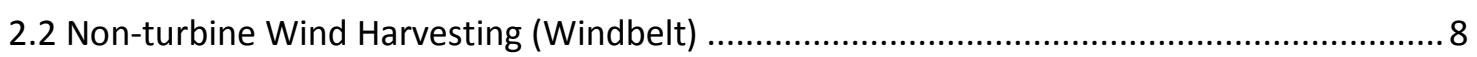

2.3 Piezoelectric Wind Generation (piezo-tree) .................................................................. 9

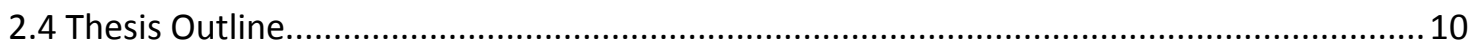

Chapter 3 : Project Overview, Design constraints............................................................. 12

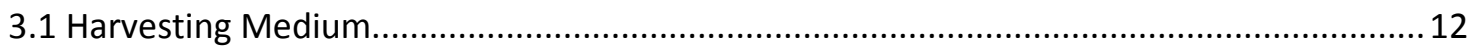

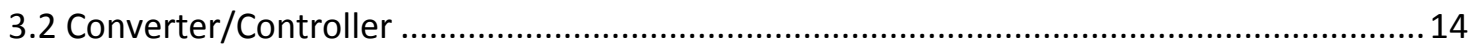

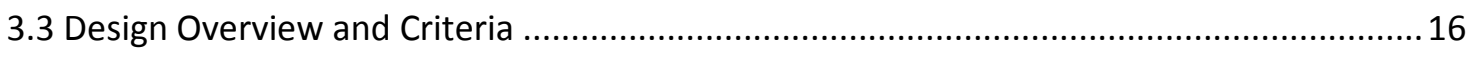

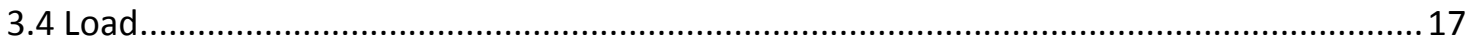

Chapter 4 : Simulation and Component Selection ............................................................. 19

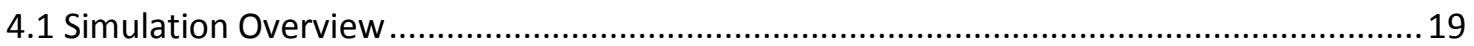

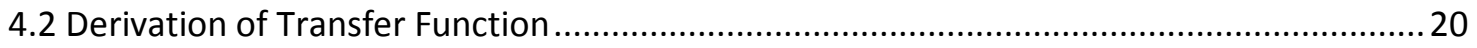

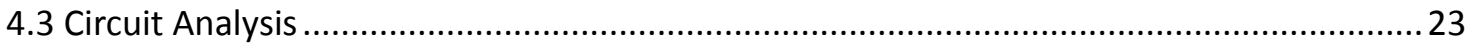

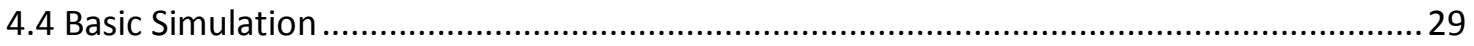

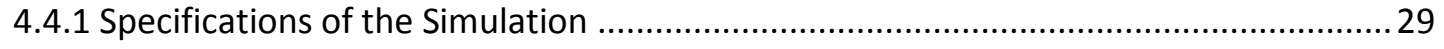

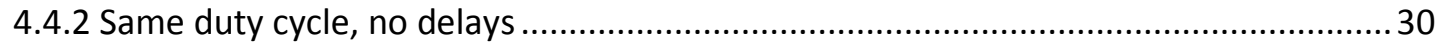

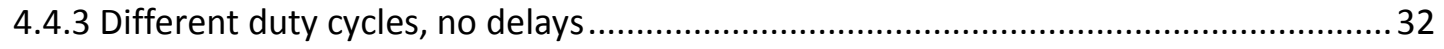

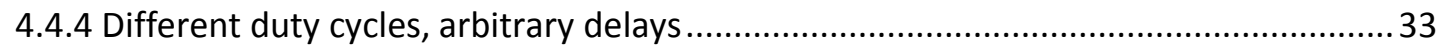

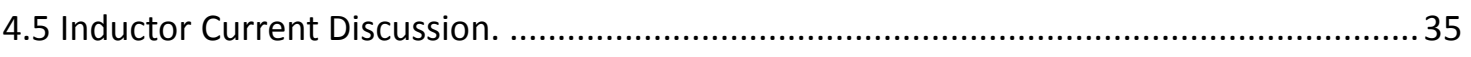

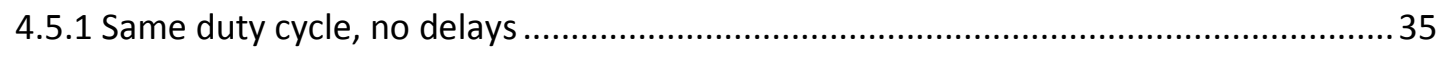

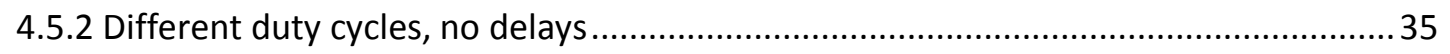

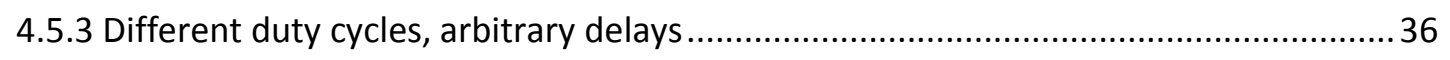

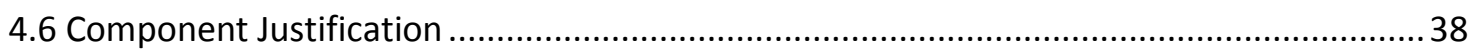

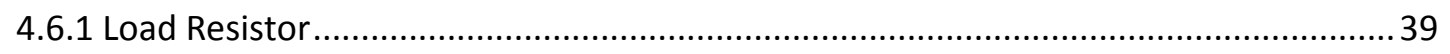

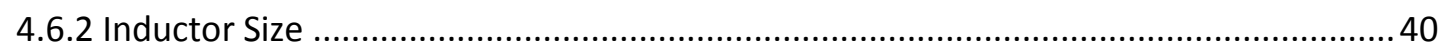

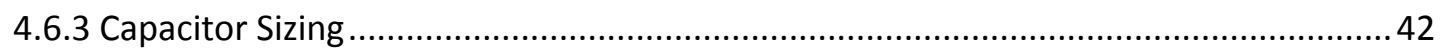

Chapter 5 : Hardware Design, Setup and Testing ............................................................. 49

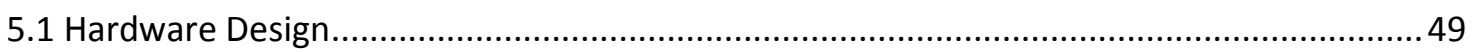

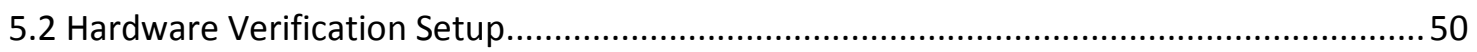

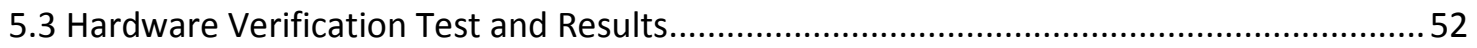


5.4 Piezoelectric Energy Harvesting Test and Results ....................................................... 70

Chapter 6 : Conclusions and Recommendations ........................................................ 83

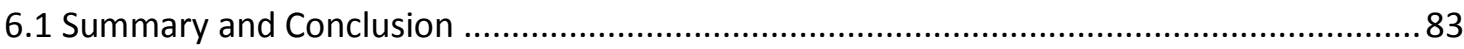

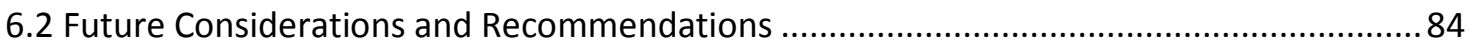

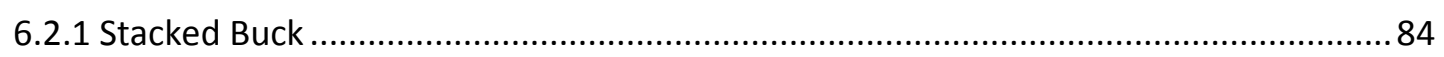

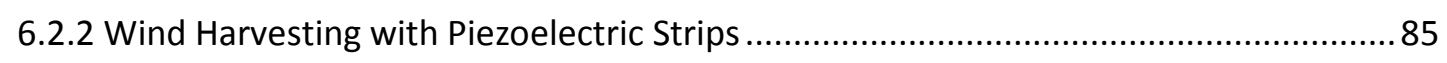

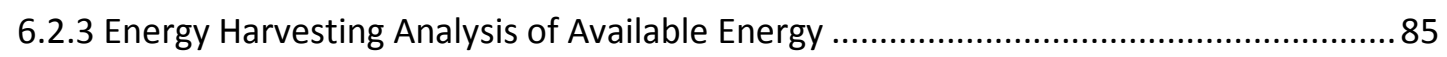

Works Cited............................................................................................................... 86 


\section{List of Tables}

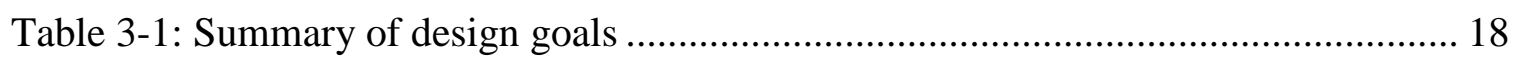

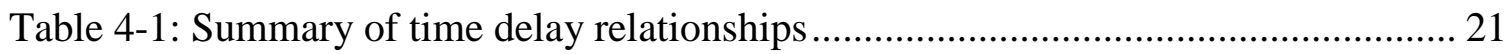

Table 4-2: Summary of component values to be used.................................................. 46

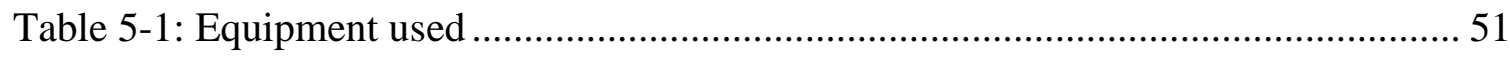

Table 5-2: Voltages measured across active stages and across the entire stack ................ 53

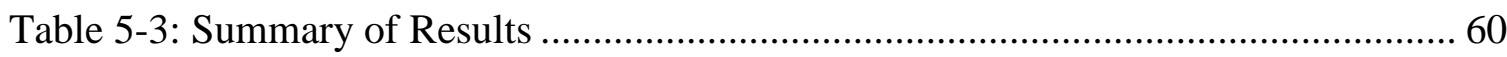

Table 5-4: Initial results for raw output of piezoelectric strips in wind tunnel.................. 72

Table 5-5: Discrete points of the piecewise voltage output............................................ 77

Table 5-6: Summary of output power data ...................................................................... 81 


\section{List of Figures}

Figure 3-1: General block diagram for energy harvesting........................................... 12

Figure 3-2: "L" configured piezoelectric wind harvester ............................................. 14

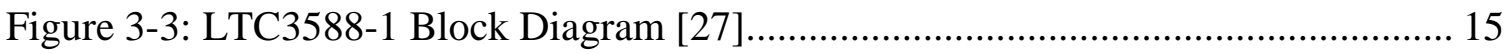

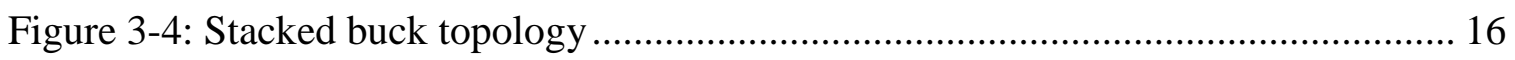

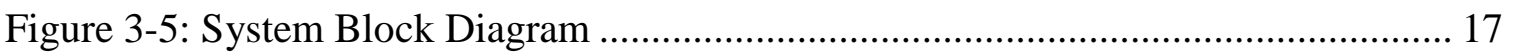

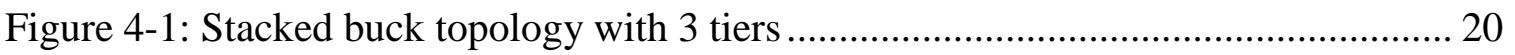

Figure 4-2: Arbitrary wave forms for switching signals............................................. 21

Figure 4-3: Current flow when all switches are conducting ........................................... 25

Figure 4-4: current flow when all switches are off ....................................................... 26

Figure 4-5: current flow when switches 1 and 3 are conducting and switch 2 is off....... 27

Figure 4-6: Currents in switches compared to inductor current for a switching period ... 28

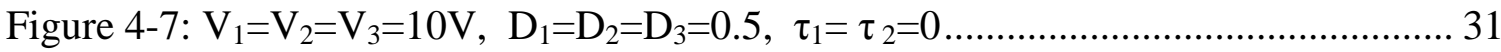

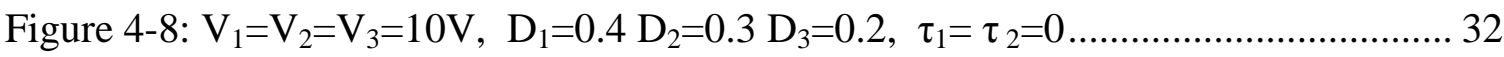

Figure 4-9: $V_{1}=V_{2}=V_{3}=10 V, D_{1}=0.8 D_{2}=0.6 D_{3}=0.3, \tau_{1}=0 \quad \tau_{2}=2 \mu s \quad \tau_{3}=3 \mu \mathrm{s}$............... 34

Figure 4-10: $V_{1}=V_{2}=V_{3}=10 V, D_{1}=0.1 D_{2}=0.3 D_{3}=0.3, \tau_{1}=0 \quad \tau_{2}=2 \mu s \quad \tau_{3}=6 \mu \mathrm{s}$............. 37

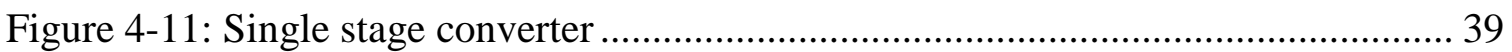

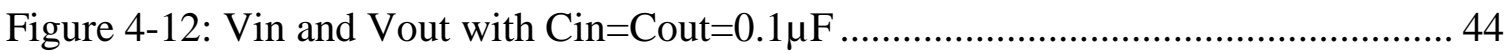

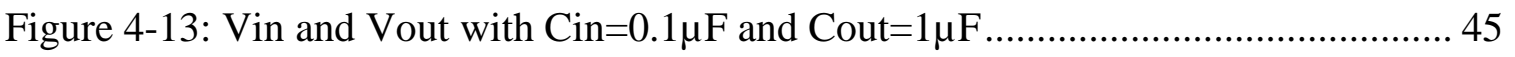

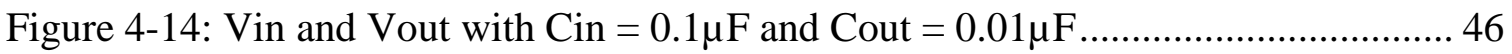

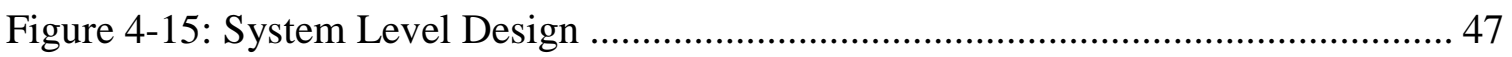

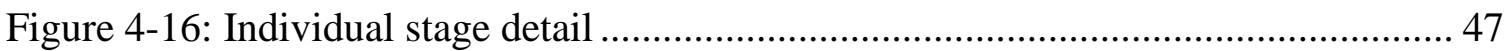

Figure 4-17: Output, 5 tiers. Cin $=0.1 \mu \mathrm{F}$, Cout $=0.01 \mu \mathrm{F}, \mathrm{L}=1 \mu \mathrm{H}$ per stage. $\mathrm{R}_{\mathrm{L}}=1 \mathrm{M} \Omega \ldots . .48$

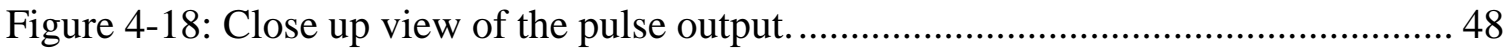

Figure 5-1: Top Copper Layer of Board Design......................................................... 50

Figure 5-2: Hardware Verification Assembly............................................................ 51

Figure 5-3: Lab Setup for Hardware Verification.......................................................... 52

Figure 5-4: Measured Across Stage E. Inputs [A,B,C,D,E] $=[0,0,0,0,10]$...................... 55

Figure 5-5: Measured Across Whole Stack. Inputs $[A, B, C, D, E]=[0,0,0,0,10] \ldots \ldots \ldots . . . .55$

Figure 5-6: Measured Across Stages B \& C. Inputs $[A, B, C, D, E]=[0,10,10,0,0] \ldots \ldots \ldots . . .56$

Figure 5-7: Measured Across Entire Stack. Inputs $[A, B, C, D, E]=[0,10,10,0,0] \ldots \ldots \ldots . . . .56$

Figure 5-8: Measured Across Stages A-C. Inputs $[A, B, C, D, E]=[10,10,10,0,0] \ldots \ldots \ldots . . .57$

Figure 5-9: Measured Across Entire Stack. Inputs $[A, B, C, D, E]=[10,10,10,0,0] \ldots \ldots . . . .57$

Figure 5-10: Measued Across A-D. Inputs [A,B,C,D,E] $=[10,10,10,10,0] \ldots \ldots \ldots \ldots \ldots \ldots . . . . . . . .58$

Figure 5-11: Measured Across Whole Stack. Inputs $[A, B, C, D, E]=[10,10,10,10,0] \ldots . . .58$

Figure 5-12: Measured Across Whole Stack. Inputs $[A, B, C, D, E]=[10,10,10,10,10] \ldots 59$

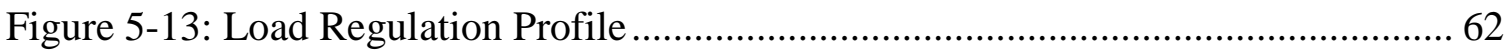

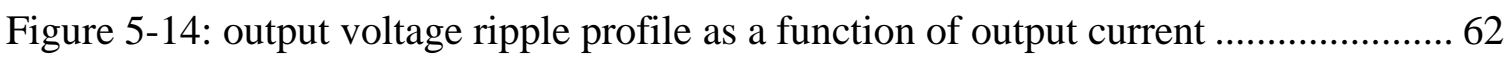

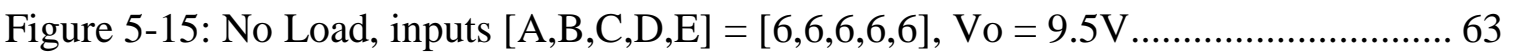

Figure 5-16: No Load, inputs $[A, B, C, D, E]=[10,10,10,10,10]$, Vo $=9.78 \mathrm{~V} \ldots \ldots \ldots \ldots \ldots . . . . . . . .63$ 
Figure 5-17: No Load, inputs $[\mathrm{A}, \mathrm{B}, \mathrm{C}, \mathrm{D}, \mathrm{E}]=[15,15,15,15,15], \mathrm{Vo}=10.4 \mathrm{~V} \ldots \ldots \ldots \ldots \ldots \ldots . . . . . . .64$

Figure 5-18: No Load, inputs [A,B,C,D,E] $=[5,7.5,10,12,15], \mathrm{Vo}=9.77 \mathrm{~V} \ldots \ldots \ldots \ldots \ldots \ldots . . . . . . .64$

Figure 5-19: Load $=400 \mathrm{ohm}$, inputs $[\mathrm{A}, \mathrm{B}, \mathrm{C}, \mathrm{D}, \mathrm{E}]=[6,6,6,6,6], \mathrm{Vo}=9.4 \mathrm{~V} \ldots \ldots \ldots \ldots \ldots . . . . . . .65$

Figure 5-20: Load $=400 \mathrm{ohm}$, inputs $[\mathrm{A}, \mathrm{B}, \mathrm{C}, \mathrm{D}, \mathrm{E}]=[10,10,10,10,10], \mathrm{Vo}=9.7 \mathrm{~V} \ldots \ldots \ldots .65$

Figure 5-21: Load $=200 \mathrm{ohm}$, inputs $[\mathrm{A}, \mathrm{B}, \mathrm{C}, \mathrm{D}, \mathrm{E}]=[6,6,6,6,6], \mathrm{Vo}=9.2 \mathrm{~V} \ldots \ldots \ldots \ldots \ldots . . . . . .66$

Figure 5-22: Load $=$ 200ohm, inputs $[A, B, C, D, E]=[10,10,10,10,10]$, Vo $=9.56 \ldots \ldots . .66$

Figure 5-23: $\mathrm{Load}=120 \mathrm{ohm}$, inputs $[\mathrm{A}, \mathrm{B}, \mathrm{C}, \mathrm{D}, \mathrm{E}]=[6,6,6,6,6], \mathrm{Vo}=6.67 \mathrm{~V} \ldots \ldots \ldots \ldots \ldots . . . . . .67$

Figure 5-24: $\mathrm{Load}=120 \mathrm{ohm}$, inputs $[\mathrm{A}, \mathrm{B}, \mathrm{C}, \mathrm{D}, \mathrm{E}]=[10,10,10,10,10], \mathrm{Vo}=6.87 \mathrm{~V} \ldots \ldots . .67$

Figure 5-25: Load $=100 \mathrm{ohm}$, inputs $[\mathrm{A}, \mathrm{B}, \mathrm{C}, \mathrm{D}, \mathrm{E}]=[6,6,6,6,6], \mathrm{Vo}=6.53 \mathrm{~V} \ldots \ldots \ldots \ldots \ldots . . . . . .68$

Figure 5-26: Load $=100 \mathrm{ohm}$, inputs $[\mathrm{A}, \mathrm{B}, \mathrm{C}, \mathrm{D}, \mathrm{E}]=[10,10,10,10,10], \mathrm{Vo}=6.9 \mathrm{~V} \ldots \ldots \ldots . .68$

Figure 5-27: Load $=1 \mathrm{Mohm}$, inputs $[\mathrm{A}, \mathrm{B}, \mathrm{C}, \mathrm{D}, \mathrm{E}]=[6,6,6,6,6], \mathrm{Vo}=9.46 \mathrm{~V} \ldots \ldots \ldots \ldots \ldots . . . . . . .69$

Figure 5-28: $\mathrm{Load}=1 \mathrm{Mohm}$, inputs $[\mathrm{A}, \mathrm{B}, \mathrm{C}, \mathrm{D}, \mathrm{E}]=[6,6,6,6,6], \mathrm{Vo}=9.71 \mathrm{~V} \ldots \ldots \ldots \ldots \ldots . . . . . . .69$

Figure 5-29: Piezoelectric Strip with Added "sail"..................................................... 71

Figure 5-30: Input Assembly with 5 Energy Harvesting Piezoelectric "sails" ................ 71

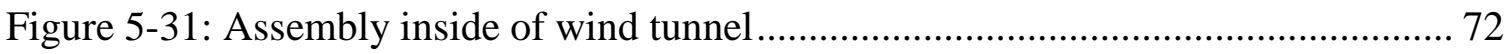

Figure 5-32: Output voltages of piezoelectric strips with varying wind speeds.............. 73

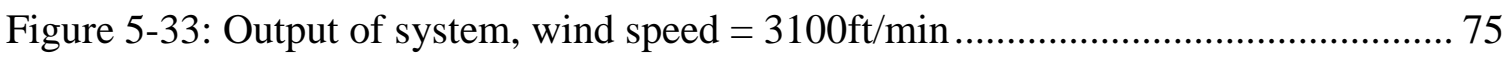

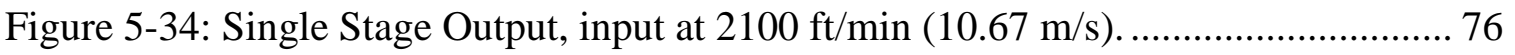

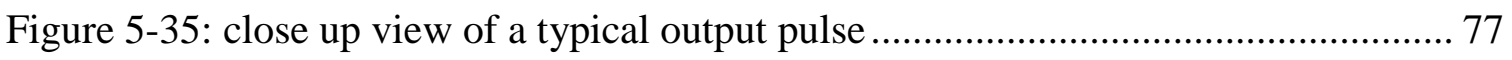

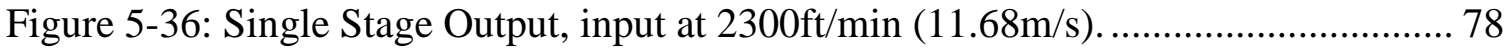

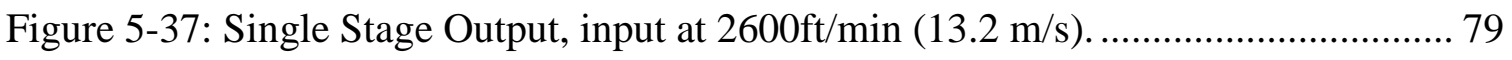

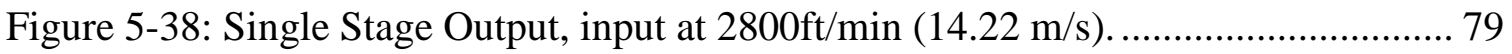

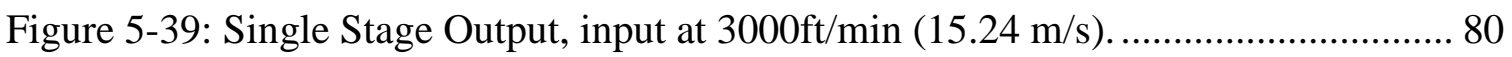

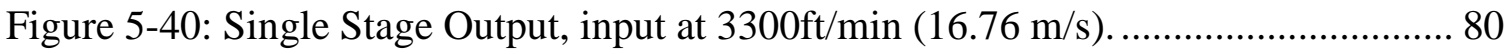

Figure 5-41: Output power as a function of wind speed.............................................. 81

Figure 5-42: Effective input voltage with rectifier and filter capacitor.......................... 82 


\section{Chapter 1 : Introduction.}

In 2009 the U.S. energy consumption profile, across all sectors, was composed of nearly $83 \%$ fossil fuels ( $37 \%$ petroleum, $25 \%$ natural gas, and $21 \%$ coal), compared to just over $8 \%$ for all renewable sources (including conventional hydro, biomass, solar, wind and geothermal) with the remaining 9\% coming from nuclear energy [1] . Focusing specifically on electric power, $67 \%$ of energy came from fossil fuels, $11 \%$ from renewables, and the remaining 22\% from nuclear [2]. (100\% of nuclear power generated went into the electric power sector.) While the use of petroleum as an energy source is largely kept to the transportation sector, it demands some extra attention as it has been the source of many key points that ultimately help lead to more conservative environmental, pollution control, and eventually energy producing policies.

The transportation sector accounted for $28.5 \%$ of energy consumed in 2009, just behind electric power at $40.5 \%$. However, the transportation sector relies almost exclusively on petroleum products. In 1973, after the U.S. had supported Israel in the Arab-Israeli war, OAPEC used its influence over oil exports to refuse to export oil to the U.S. This later became known as "the oil weapon" [3]. This had a profound effect on the American people who relied heavily on the automobile and was in some case forced to wait hours just to fill up their vehicle's gas tank. It became clear to America that they were dependent on foreign oil. While usage of petroleum has continued to increase over the year, production in the U.S. has been decreasing, leading to a growing need to import from other countries [4]. In 2009 the U.S. imported nearly 29\% of its overall energy 
supply, nearly all of this importation being petroleum [1]. [5] projects that "U.S.

petroleum consumption met by net imports is projected to rise from 52 percent in 2000 to 64 percent in 2020.” This is all from the America's desire for freedom of transportation which leads to another important factor: pollution. The most familiar form of pollution for those who live in large urban areas (especially southern California) is air pollution in the form of smog.

The California Air Resources Board [6] states that smog first occurred in 1943 in Los Angeles where visibility was only 3 blocks. Many reports mention of irritation to residents are attributed to smog. Initially this mysterious smog was unknown in source. Initial thoughts were that the smog must be from obvious thick smoke coming from the industrial sector. In 1947 California Governor Warren signed into law the Air Pollution Control Act. This was meant to investigate and mitigate the sources of this smog. It wasn’t until 1963 that the First Federal Clean Air Act was put into place.

While measures were taken to lessen the amount of particulate matter that was generated by industrial sources, this only decreased smog marginally. It wasn't until the 1960's that scientists began to realize that the beloved automobile might be a large contributor. Eventually additional regulations were put into place to monitor and limit emissions from vehicles, slowly at first, limiting only obvious particulate matter and hydrocarbon emissions. But eventually these regulations began to include things like Nitrous Oxides, Carbon Monoxide, and Sulfur producing compounds. It wouldn’t be until the late 90's and early 2000's that scientist began to suspect that Carbon Dioxide might be a culprit in potential climate change, and that automobiles were once again blamed to 
be a large contributor. In 2006 AB 32 was signed, "The first-in-the-world comprehensive program of regulatory and market mechanisms to achieve real, quantifiable, costeffective reductions in greenhouse gases." California has been a very progressive state in terms of pollution reduction, and perhaps in a related tone in producing clean energy. However [7] reminds us that as recent as 2005, 9600 people die each year from airpollution caused ailments, compared to 3200 each year in car crashes, and 2000 each year die of homicide. While great gains have certainly been made, there is still much work to do. This brings us to energy production on the utility scale, more specifically to the events and progressive moves that have lead to the current drive to greatly increase the amount of energy produced by clean and renewable sources.

California has a long energy history, which is detailed greatly in [8], and is largely recognized as being very progressive in its energy policies in the last few years. Some of this progressiveness came from the need to reduce pollution which inevitably led to discovering sources of the pollution which was largely a byproduct of energy use (in automobiles, industrial plants, or in utility scale electric generation). In the late 1990's legislation went into effect in California that would eventually lead to the 2000-2001 energy crisis with rolling blackouts and soaring energy prices. This was due to easy, yet legal, manipulation of the energy markets by just a handful of energy suppliers in that the retail price (paid by consumers) was fixed, but the wholesale price (paid by utilities) fluctuated greatly and could not be passed on by utilities. This caused the utility companies to go bankrupt. [8] echoes an opinion held by this author for a need of energy source diversification that is easily seen in a passage on page 79 . 
"When the price of natural gas goes up, the cost of electricity from these power plants increases dramatically. Experience has shown us that it is never good to depend primarily on a single source of fuel to generate electricity. As in an investment portfolio, diversity is necessary to hedge against risks."

As was mentioned before, California is known for its very progressive energy policies, and has set a mandate that $20 \%$ of electricity generated must come from renewable sources by 2010, and that this must be increased to 33\% by 2020 [9] . But where will all of this renewable energy come from? Simply put, energy harvesting. From [10] "Energy harvesting (also known as power harvesting or energy scavenging) is the process by which energy is derived from external sources (e.g., solar power, thermal energy, wind energy, salinity gradients, and kinetic energy), captured, and stored.” While it is not explicitly in the definition given here, energy harvesting is almost always renewable as it is the process of gathering energy from surroundings, rather than using a limited fuel to harness energy. The one exception would be biomass. Biomass is considered renewable in that the fuel can be grown, or continuously produced. However since it is a more active approach to harnessing energy it is not considered, in the author's opinion at least, to be energy “harvesting”. Harvesting tends to imply a more passive approach in that a device or process is put into place such that energy is harnessed with little human intervention (with the exceptions of humans effectively being the energy source as will be presented later).

Obvious forms of energy harvesting would be some of the typical renewable energy sources such as solar, geothermal, wind, and tidal. However there are other sources of energy harvesting that are not widely viewed as a renewable energy resource. 
One source of energy harvesting that may prove successful, and obvious once realized, is harvesting energy from exercise equipment. CSU San Bernadino has implemented 20 exercise machines capable of generating 50Wh from a 30 minute workout [11] . Some research has been done at Cal Poly, San Luis Obispo, [12] and [13], further investigating additional applications and improvements to the general area of energy harvesting from exercise machines. There are other applications of harvesting energy from humans beyond the obvious work out at the gym. [14] Estimates that while walking as much as $67 \mathrm{~W}$ are wasted that could potentially be harvested. Practical designs have even been made by Brother Industries, a Japanese company, to utilize low power vibrations from human hand motions to power some small electronics [15] . Brother Industries has designed small dynamos inside of AA and AAA battery sized packages that would allow a consumer to use these inside some electronics, such as a TV remote control as per their example demo, that would eliminate the need to replace or even recharge batteries. Their product works by using the movement of a small magnet, caused by shaking a device, that induces charge on coils that are wrapped around the body of the 'battery' thus allowing the device to run for a period of time due to the energy exerted by the user into the device

This thesis however is focused primarily on energy harvesting from wind. Why wind? There are several reasons; the first of which is that wind was one of the first sources of energy harvested by human civilization, "Windmills first appeared around 200B.C. in Persia and possibly as long ago as 1700B.C. in Babylon and China.” [16]. This shows that man has intuitively known the power available in the wind for many centuries. It was probably not well understood until much later that wind is caused by 
temperature and pressure differentials caused by uneven heating of the earth's surface from the sun. The energy of the wind is proportional to air density, mass of air, cross sectional area to be harvested, and proportional to the cube of wind velocity. Few phenomena have a cubic relation, so this shows that faster winds speeds have dramatically increasing energy available. Also, "wind power is the fastest growing alternative energy source today. It grew by almost 70\% between 1997 and 2000.” [3]. In 2009 10,000 MW of new capacity of wind energy was installed, a 40\% increase from 2009 [17] . This accounts for 39\% of all new generation for 2009. It is clear that wind energy harvesting is on the rise, such interest will likely spawn further research and information about optimizing energy available from the wind as well as making it more and more cost effective. 


\section{Chapter 2 : Background.}

Many people are probably aware of the typical, large, wind turbines that likely comprise just about all of the wind harvesting today, but there are a couple of other wind harvesting mechanisms aside from the large commercial turbines. Below, this thesis will discuss three types of wind harvesting mechanisms and some advantages and disadvantages of each. These three types are; large wind turbines, the bladeless "windbelt”, and a newer technique that will use piezoelectric materials to harvest wind energy.

\subsection{Large Scale Turbines (Utility Scale Power)}

These turbines are the ones that most people are familiar with. When you envision wind energy most often the windmill style, large, three bladed turbines come to mind. The basic idea behind this type of technology is that wind passing through the blades will cause them to rotate, which in turn will rotate a shaft creating a changing flux which eventually generates electricity much like a typical generator. These turbines often require some power electronics for conditioning and frequency control as the different wind speeds will cause the blades to spin faster or slower.

Some of the advantages of this type of technology are that it is already established, ratings for a single large turbine are in the range of megawatts, and an energy density of $2.5 \mathrm{~W} / \mathrm{Kg}$, which is about an order of magnitude higher than the soon to be proposed piezoelectric method [18].

Some disadvantages of this technology are that even a single turbine requires large capital cost and this type of turbine technology is very difficult to get below about 
$50 \mathrm{~W}$ as the friction and losses make it very impractical [19]. This also relates to a necessary wind speed for operation, a typical minimum wind speed for a large turbine to begin generating is around $6 \mathrm{~m} / \mathrm{s}$ [20]. Additionally there is the need for maintenance of gears and moving parts. If the turbines are located in remote locations this can be problematic, especially since the gears are almost always at the top of the tower which requires extra care and safety precautions. To utilize the turbines one needs large amounts of land that are often not used for anything else. Some older wind farms (such as the one at Altamont pass) pose a danger to birds of prey, and can result in bird deaths [3]. This results in the need for environmental studies to be performed to minimize impacts to birds. Also, some people find these large wind farms to be an eyesore and are subject to disapproval by NIMBY movements.

\subsection{Non-turbine Wind Harvesting, “Windbelt” (Modest-Consumer Scale Power)}

The "windbelt", created by Shawn Frayne, is a device that does not use rotating blades but instead uses turbulent vibrations caused by wind rushing over a mylar ribbon that translates this vibration to oscillate a small magnet that creates flux in coils and thereby generates electricity $[19,21,22]$. Frayne's aim was to create a renewable source of energy that poor families in Haiti could use to power small lights rather than using kerosene lamps.

Advantages of this technology are that there is no need for maintenance as there are no bearings, gears, or other complex moving parts. This technology is modular on the 100-1000 Watt level and can be scaled with relative ease. The windcell (comprised of 1 
meter by 1 meter set of windbelts) can generate up to $100 \mathrm{~W}$ and costs about $\$ 1 / \mathrm{W}$. this technology can also harvest energy at wind speeds lower than typical turbines.

Some disadvantages to this technology are that the power levels are a few orders of magnitude lower than large turbines. This design uses rare earth magnets that may become scarcer if large scale production were introduced. This design does not operate effectively for wind speeds below $2 \mathrm{~m} / \mathrm{s}$. The windcell has a rigid frame that may prove too bulky for some energy harvesting applications as it is about 1 meter in length, but can be reduced in size.

\subsection{Piezoelectric Wind Generation (piezo-tree)}

A brief description of the piezoelectric effect is in order. Piezoelectricity, as defined by [23], "is the ability of some materials (notably crystals...) to generate an electric field or electric potential in response to applied mechanical strain.”

Piezoelectric materials can also be made into flexible strips that will generate voltage when bent. [24] did a comparison of several types of piezoelectric materials, and their ability to harvest energy from vibrations and stated that “, the MFC [macro fiber composite] uses an interdigitated electrode pattern that capitalizes on the higher $d 33$ piezoelectric coupling coefficient, which means the device is more efficient in converting energy between the mechanical and electrical domains. For these reasons the MFC could be an ideal candidate for use as a power harvesting device.”

Directly from [18] “...their advantage remains in their robust solid-state, low-cost, lowmaintenance and scalable construction.” And also from [25] the idea of aesthetically pleasing wind power is introduced, and carried further by [18]. This may be applicable 
for a scenario where the power output is scaled up considerably, and might be envisioned as a tree where the "leaves" are the piezoelectric strips. In many applications however the strips are small enough to be distributed or hidden from view if the specific application permits or demands it.

Of course there are disadvantages to this system as well. These include low power density, about $0.29 \mathrm{~W} / \mathrm{Kg}$, and low absolute power rating around $300 \mu \mathrm{W}$ per strip at 8 m/s wind speed [18]. At an estimated \$2/piezo strip this comes out to several thousand \$W . Clearly this technology with its current level of output and economics is not suitable for medium or large scale generation. However, pricing trends for emerging technologies show that as consumers and industry adopt these new technologies prices dramatically decrease. The price of large scale commercial wind turbines have decreased by a factor of 3 to $4(\$ 4000 / \mathrm{kW}$ to about $\$ 1200 / \mathrm{kW})$ from the early 1980 ’s to today [30]. Also in the world of microelectronics and micro-scale systems of Radio Frequency Identification (RFID) tags a price drop of at least 10 times has occurred, or is predicted to occur since their price in 2004 [31]. This tells us that while the initial price of this first custom system appears to be prohibitive, we should expect within reason that market trends along with further research and maturing technology will also bring a price decrease for such a system.

\subsection{Thesis Outline}

This thesis will discuss using flexible piezoelectric polymer strips to generate energy from wind via vibrational flapping. The concept of acquiring energy from piezoelectric polymers was seen in [18], but this thesis will go more into the practicality 
and power electronics aspects of harvesting energy, as well as new configuration to do so. The motivations for exploring this energy harvesting technology are that it is yet to be largely developed, and that is has the added aesthetically pleasing potential. It is also hoped that this technology will be able to harvest energy at wind speeds that are too low for the other wind harvesting technologies to utilize.

The remainder of the thesis will be laid out as follows: chapter 3 will detail design constraints, methodology of the test procedure and experimental aims. Chapter 4 will cover a new proposed topology, simulation and some derivations for this new topology, as well as reasons for this newly proposed topology as it relates to this thesis. Chapter 5 will go into detail about the experimental tests, and the results. Chapter 6 will discuss these results and how they compared with our expectations, as well as discuss where the results can take us, and make recommendations for further testing of similar experiments. 


\section{Chapter 3 : Project Overview, Design constraints.}

Since this thesis is more a proof of concept than a performance evaluation, many simplifications have been made for convenience sake, rather than scrutinized for maximum or optimal performance. The general idea of this project is to harvest wind energy in a new way using piezoelectric strips. This raw energy will then be converted and conditioned to something more usable and will be applied to a load. The general block diagram for this is below in Figure 3-1.

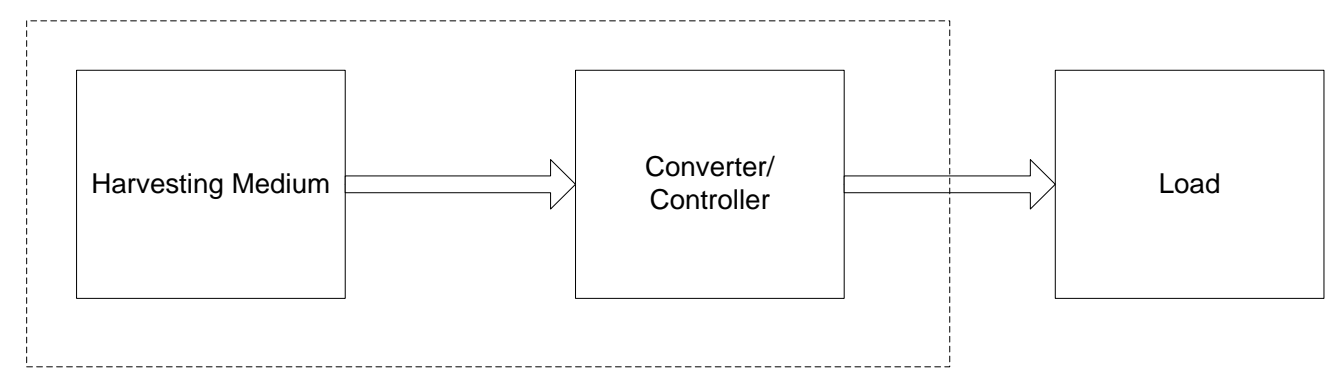

Figure 3-1: General block diagram for energy harvesting

The major components are the harvesting medium, and the converter/controller. This thesis will discuss a bit about the harvesting medium, but will focus primarily on the convert/controller.

\subsection{Harvesting Medium}

The medium to harvest wind energy for this thesis will be piezoelectric strips. The specific piezo-strip used is a Meas-Spec LDT0, with dimensions of 25mm x 13mm [26]. This strip was chosen out of convenience more than for specific performance. Things to consider here are that piezoelectric materials are capable of giving off high voltages, but generally very low currents (often 10 's $-100 \mathrm{~V}$ and in the range of $\mathrm{nA}-\mu \mathrm{A}$ ). 
The harvesting device will be configured as in Figure 3-2 with wind also as shown in Figure 3-2. The additional "sail" is largely just to increase the effective area to capture more wind. The purpose of the "L" shape comes from findings in [18] which showed that this configuration yields higher power output than a more in-line configuration, about 4-5 times more based solely on orientation. The wind causes a kind of bending vibrational motion of the piezoelectric strip (in this case in and out of the page). Initial tests show a voltage output of about $4 \mathrm{~V}$ in a modest breeze. This corresponds with roughly $1 \mathrm{uW}$ per strip (based on a "load" of $10 \mathrm{M} \Omega$ oscilloscope). Of course higher wind speeds hold more energy and will thus provide large input to our harvesting device. The higher wind speeds correlate to larger deflections (and correspondingly larger voltages) as well as slightly higher frequencies. 


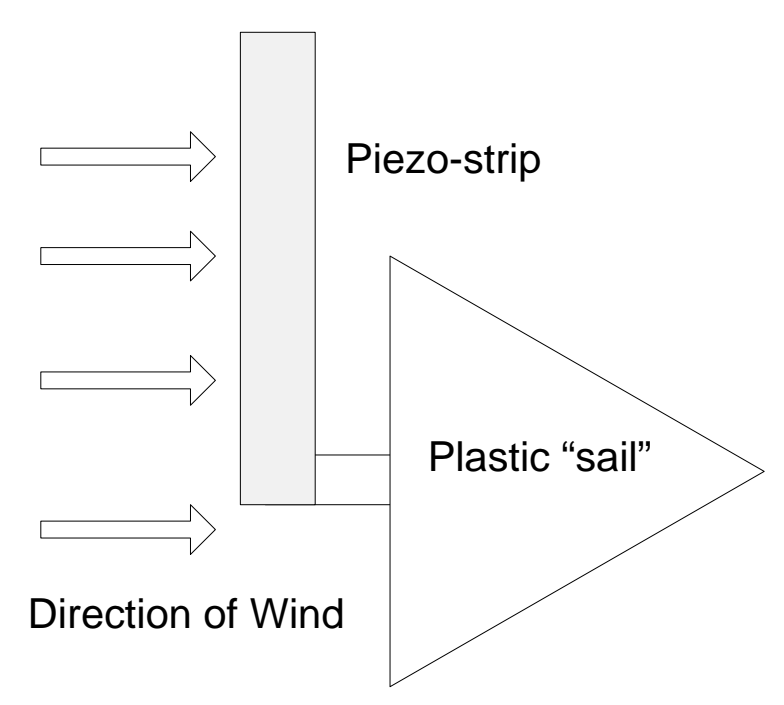

Figure 3-2: "L" configured piezoelectric wind harvester

Difficulties may arise if the energy output from a single strip is too low to turn on the converter section. This may result from a threshold voltage cutoff, or may result from the very low current generated from the piezoelectric material.

\subsection{Converter/Controller}

The specific DC-DC converter that will be used is the LTC3588-1 as found in Linear Technology's article entitled "Piezoelectric Energy Harvesting Power Supply" [27]. Referring to Figure 3-3, this single chip has a built in bridge rectifier, and

synchronous buck control, as well as built in FET's and feedback voltage sensing logic. It is designed to take in an AC signal (up to $20 \mathrm{~V}$ at which point it utilizes a shunt diode) from a piezoelectric device, rectify it, store the energy on an input capacitor, and when the voltage level is met it will send this energy to the output via its buck control. It is capable of output of 1.8, 2.5, 3.3, or 3.6V depending on selections of certain pin voltages. It can supply up to $100 \mathrm{~mA}$. Bridge rectifier losses are typically $400 \mathrm{mV}$ at $10 \mathrm{uA}$. The LTC3588-1 has undervoltage lockout thresholds between $4 \mathrm{~V}$ and $5 \mathrm{~V}$ depending on the 
output voltage selected, with lower outputs having lower input thresholds. For this reason it will be most desirable to select a $1.8 \mathrm{~V}$ output.

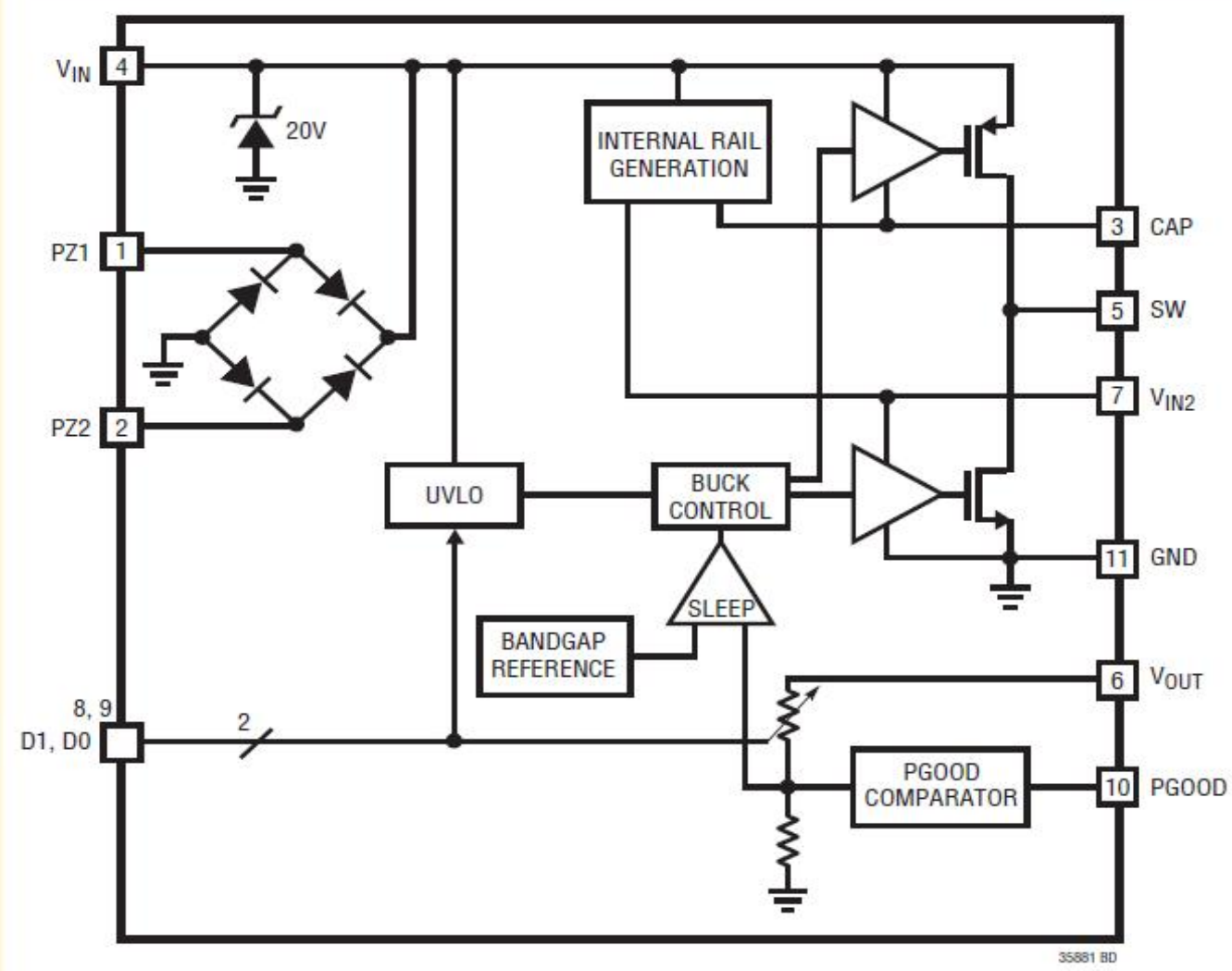

Figure 3-3: LTC3588-1 Block Diagram [27]

Two issues arise with this simple setup: one being that at most we can get $3.6 \mathrm{~V}$ out of this chip without trying to add a boost converter. The other problem being that only one piezoelectric strip can be used as an input at a time, or else the AC signals (which cannot be assumed in phase) will likely interfere destructively, decreasing total energy input. The obvious solution to the second problem is to have multiple strips with an equal number of chips. But this does not solve our first problem of lower output voltage (with the assumption that we want a higher voltage output to utilize). A proposed solution to this is one major point of this thesis and is to introduce a new topology 
currently deemed the "stacked buck". This will be described in greater detail in chapter 4, but as a brief preview the idea is to use the unfiltered output of a single buck as the reference of the next, effectively stacking them in an almost series combination as in Figure 3-4. This will allow us multiple inputs as well as an increase in voltage output.

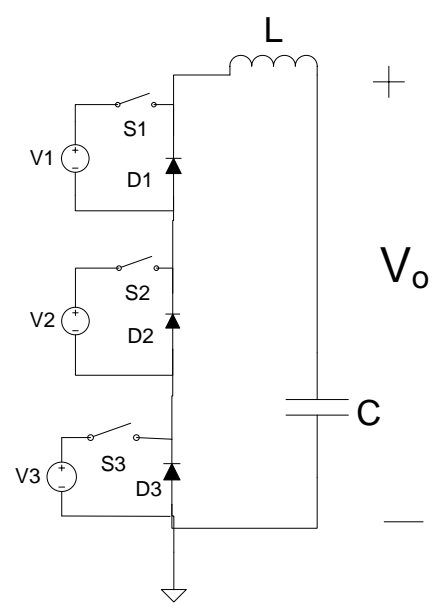

Figure 3-4: Stacked buck topology

\subsection{Design Overview and Criteria}

The two major components described above will be used in a configuration as in Figure 3-5 with an output filter and load. The piezo-strips will be configured in a harvesting array to allow all of them to harvest incoming wind energy. The wind energy will be generated by a wind tunnel with wind speeds ranging from $1 \mathrm{~m} / \mathrm{s}$ up to $30 \mathrm{~m} / \mathrm{s}$ to test a wide range of possible conditions ranging from very light breeze, to strong storm like conditions The hope here is to have a wider effective range than traditional turbines who can only operate between about 3 m/s and 20m/s [28]. Each piezo-strip will then be fed into a single LTC-3588. These unfiltered outputs will then be combined in the "stacked buck" topology to be detailed in chapter 4. This combined output will then pass through a filter to a load. 
This experiment will measure total output power for various wind speeds and will not concern itself with efficiency as any energy harvested is considered a gain over no energy harvested. In this area low efficiency is not considered "wasteful" as much as lack of production. The procedure will also measure output voltage primarily to verify operation of the proposed new "stacked buck" more than as a measure of the system's performance.

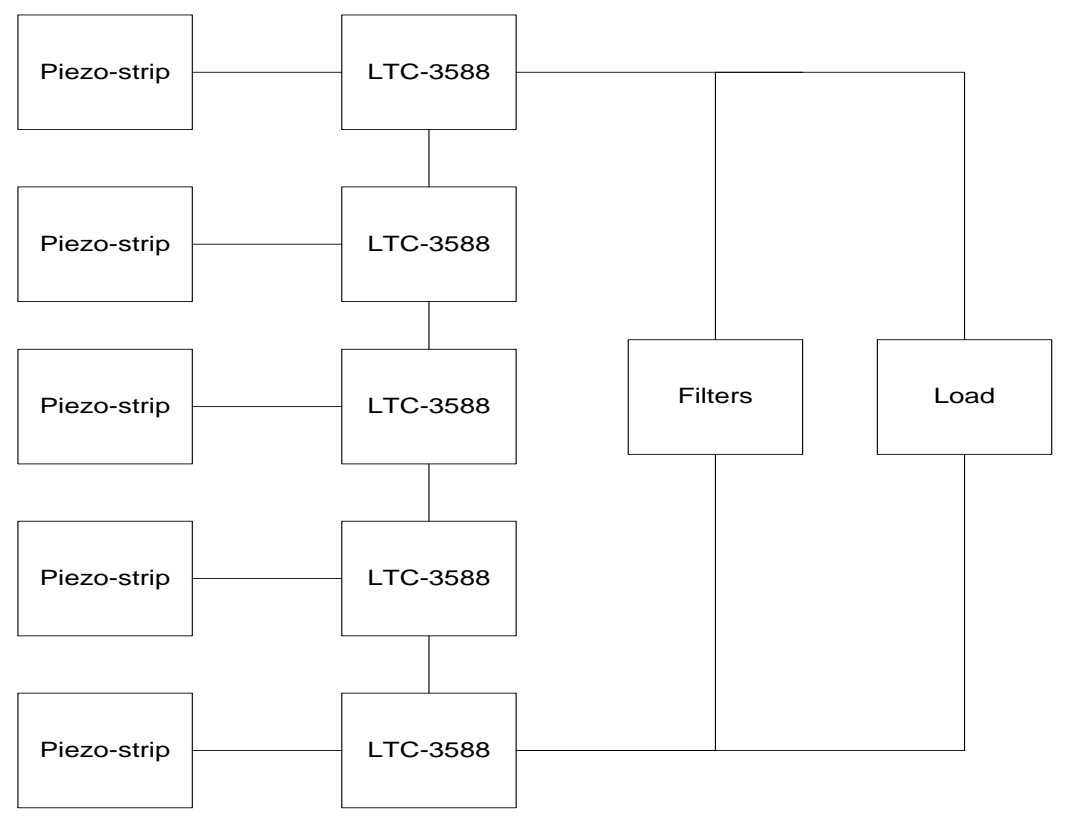

Figure 3-5: System Block Diagram

\subsection{Load}

For initial testing a passive resistor will be used to demonstrate that power can be delivered with this system and will also be used to measure the output power. After initial demonstration of power delivered, this thesis will discuss considerations for future improvements and modifications to this design approach.

Table 3-1 summarizes the design goals for this thesis. 
Table 3-1: Summary of design goals

\begin{tabular}{|l|l|}
\hline Test parameters under concern & Power output \\
\hline Input & 5 LDT0 piezo strips with additional “sails” \\
\hline Converter & LTC 3588-1, 1.8V output \\
\hline Wind speeds & $0.5-30 \mathrm{~m} / \mathrm{s}$ \\
\hline Configuration & 5 tiered - Stacked buck topology \\
\hline Output Voltage & $9 \mathrm{~V}$ (1.8 per chip, 5 chips stacked) \\
\hline Output load & resistor \\
\hline
\end{tabular}




\section{Chapter 4 : Simulation and Component Selection}

\subsection{Simulation Overview}

The LTC3588-1 has an inherent buck design with a maximum voltage output of 3.6V. This may be adequate for powering microcontrollers, but would not suffice for household utility use (120V AC). To remedy this one might wish to use a boost converter, but this would add additional circuitry and might be impractical in the case of stepping up the voltage to $170 \mathrm{~V}$ (AC peak for inverting) with a duty cycle of about $98 \%$. Instead, why not stack the converters up to add their voltages in a series like manner? This thesis will provide a simulation to show that the stacked buck design works in theory. This thesis will also provide a brief derivation of the proposed transfer function for this new topology. For the basic simulation this thesis will focus on using 3 bucks stacked together. A minimum of 2 bucks would be needed to show any relationship but would provide too simplistic of a model. Using 3 begins to show the complexities of the possible relationships between the waveforms in terms of duty cycles, and starting/delay times. More converters allow more complexities, however 3 converters begins to show these complexities well enough that one could extrapolate further, while keeping the derivation and simulation manageable. The proposed topology for the simulation can be seen in Figure 4-1 where $\bar{V}_{o}$ is the average output voltage. 


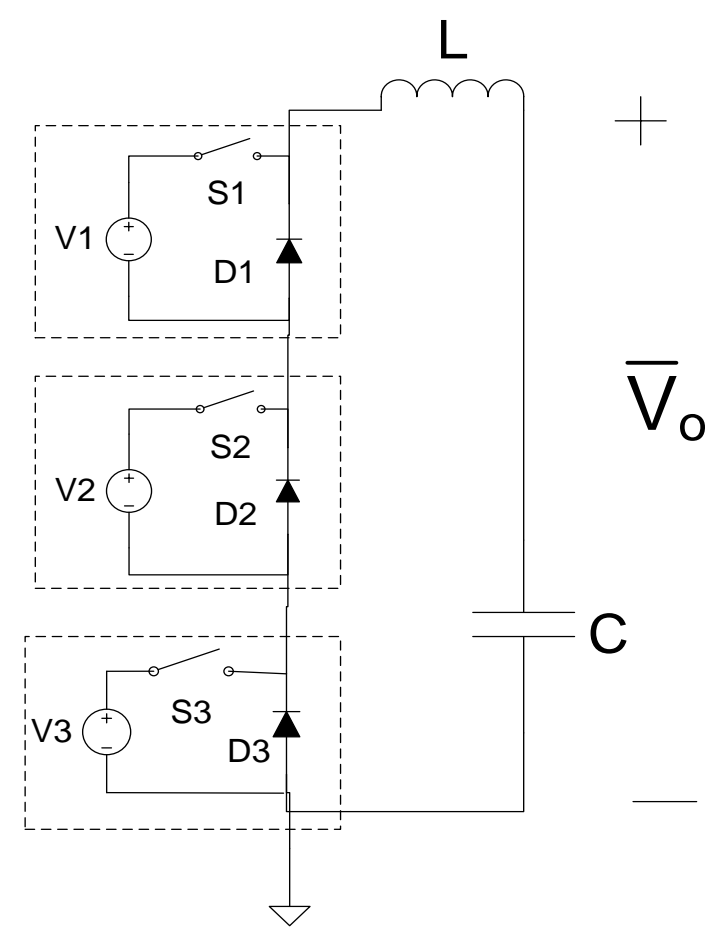

Figure 4-1: Stacked buck topology with 3 tiers

\subsection{Derivation of Transfer Function}

For the purposes of derivation we will assume that all components are ideal and lossless and each buck runs in Continuous Conduction Mode (CCM). For purposes of illustration we will use three sources to simplify the length of the math involved, but this can easily be generalized to $\mathrm{N}$ cases. Figure $4-2$ shows some arbitrary waveforms that might be associated with the signals of the switches. They are distributed to allow for varying duty cycles, and starting delays which might affect the output performance of the system. 


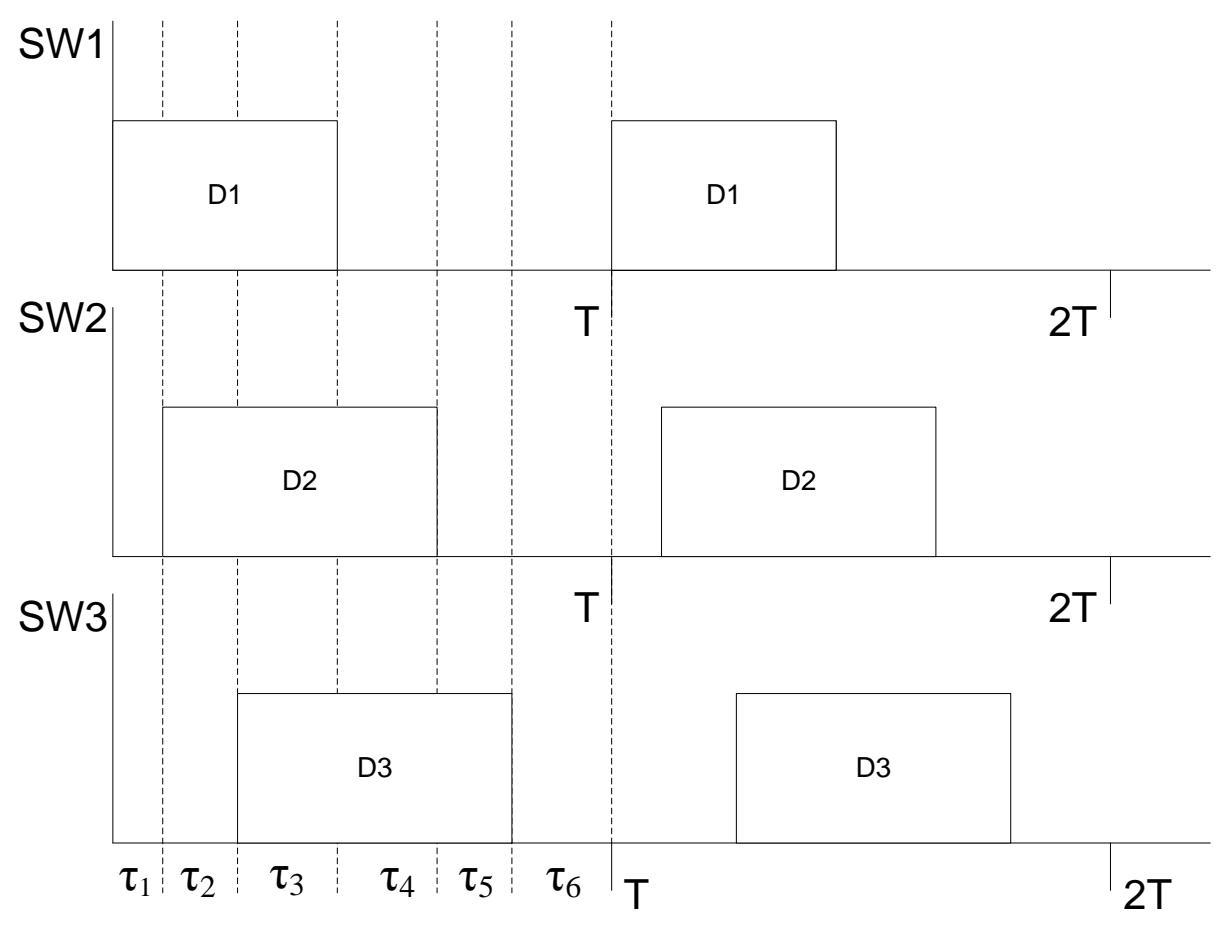

Figure 4-2: Arbitrary wave forms for switching signals

Before we begin the derivation it will be helpful to first define a few of the time delay parameters, $\tau$. A table will be given to summarize these relationships.

Table 4-1: Summary of time delay relationships

\begin{tabular}{|l|l|l|l|l|l|l|}
\hline $\mathrm{t}_{\text {on } 1}$ & $=\mathrm{D}_{1} \mathrm{~T}$ & $=\tau_{1}+\tau_{2}+\tau_{3}$ & & $\mathrm{t}_{\text {off1 }}$ & $=\left(1-\mathrm{D}_{1}\right) \mathrm{T}$ & $=\tau_{4}+\tau_{5}+\tau_{6}$ \\
\hline $\mathrm{t}_{\text {on2 }}$ & $=\mathrm{D}_{2} \mathrm{~T}$ & $=\tau_{2}+\tau_{3}+\tau_{4}$ & & $\mathrm{t}_{\text {off2 }}$ & $=\left(1-\mathrm{D}_{2}\right) \mathrm{T}$ & $=\tau_{1}+\tau_{5}+\tau_{6}$ \\
\hline $\mathrm{t}_{\text {on3 }}$ & $=\mathrm{D}_{3} \mathrm{~T}$ & $=\tau_{3}+\tau_{4}+\tau_{5}$ & & $\mathrm{t}_{\text {off3 }}$ & $=\left(1-\mathrm{D}_{3}\right) \mathrm{T}$ & $=\tau_{1}+\tau_{2}+\tau_{6}$ \\
\hline
\end{tabular}

To find our transfer function we will apply the Volt Second Balance (VSB) rule which states that the average voltage across an inductor over a single period must be 0 , seen in Equation 4-1. 
Equation 4-1

$$
\bar{V}_{L}=\frac{1}{T} \int_{0}^{T} V_{L}(t) d t=0
$$

From our arbitrary switching signals in Figure 4-2 we can derive the volt second balance noticing that the voltage across the inductor at any point is the sum of the source voltages whose switches are on minus the output voltage. We can then multiply this voltage by the time that the voltage is applied across the inductor. This will result in Equation 4-2

Equation 4-2

$$
\begin{gathered}
\int_{0}^{T} V_{L}(t) d t=\left(V_{1}-\bar{V}_{O}\right) \tau_{1}+\left(V_{1}+V_{2}-\bar{V}_{O}\right) \tau_{2}+\left(V_{1}+V_{2}+V_{3}-\bar{V}_{O}\right) \tau_{3} \\
+\left(V_{2}+V_{3}-\bar{V}_{O}\right) \tau_{4}+\left(V_{3}-\bar{V}_{O}\right) \tau_{5}+\left(-\bar{V}_{O}\right) \tau_{6}=0
\end{gathered}
$$

Rearranging and collecting terms with common voltages gives us Equation 4-3 below

Equation 4-3

$$
\begin{gathered}
V_{1}\left(\tau_{1}+\tau_{2}+\tau_{3}\right)+V_{2}\left(\tau_{2}+\tau_{3}+\tau_{4}\right)+V_{3}\left(\tau_{3}+\tau_{4}+\tau_{5}\right)-\bar{V}_{O}\left(\tau_{1}+\tau_{2}+\tau_{3}+\tau_{4}+\tau_{5}\right. \\
\left.+\tau_{6}\right)=0
\end{gathered}
$$

From Equation 4-3 and Table 4-1 we can substitute the $\tau$ terms in parentheses with corresponding duty ratios. We also notice that $\sum_{1}^{6} \tau_{i}=T$ so that we may replace that term with the switching period as well. This results in Equation 4-4 and becomes more familiar. 
Equation 4-4

$$
V_{1} D_{1} T+V_{2} D_{2} T+V_{3} D_{3} T-\bar{V}_{O} T=0
$$

Cancelling out the switching period and rearranging gives our final equation for the transfer function in Equation 4-5.

Equation 4-5

$$
\bar{V}_{O}=V_{1} D_{1}+V_{2} D_{2}+V_{3} D_{3}
$$

And in general we can extend this to $\mathrm{N}$ different voltage inputs with $\mathrm{N}$ duty cycles in Equation 4-6.

Equation 4-6

$$
\bar{V}_{O}=V_{1} D_{1}+V_{2} D_{2}+V_{3} D_{3} \ldots+V_{N} D_{N}=\sum_{i=1}^{N} V_{i} D_{i}
$$

As can be easily seen, this equation is a linear addition of weighted voltage inputs. This makes sense intuitively as neglecting additional voltage sources would result in zero terms for the voltage sources. This would be the same if some switches were never turned on and would result in zero terms for the duty cycles of the associated switch and we might be left with the original transfer function for a simple buck.

\subsection{Circuit Analysis}

The brief explanation on circuit analysis presented here is to provide a few points that may be important to consider when implementing this design. The primary considerations will be on component ratings primarily for the switches and diodes. The 
hope is to show the different cases that the topology may operate in order to gain a better understanding of the demands on the components.

Figure 4-3 shows the current path when all switches are conducting at the same time. It is apparent that the output current for this time frame is shared by all switches conducting. For the case where all switches have the same duty cycle and starting time we can see that the average current for these switches in CCM will be the same as that for a typical buck converter, specifically

$$
\bar{I}_{S W}=\bar{I}_{O}(D)
$$




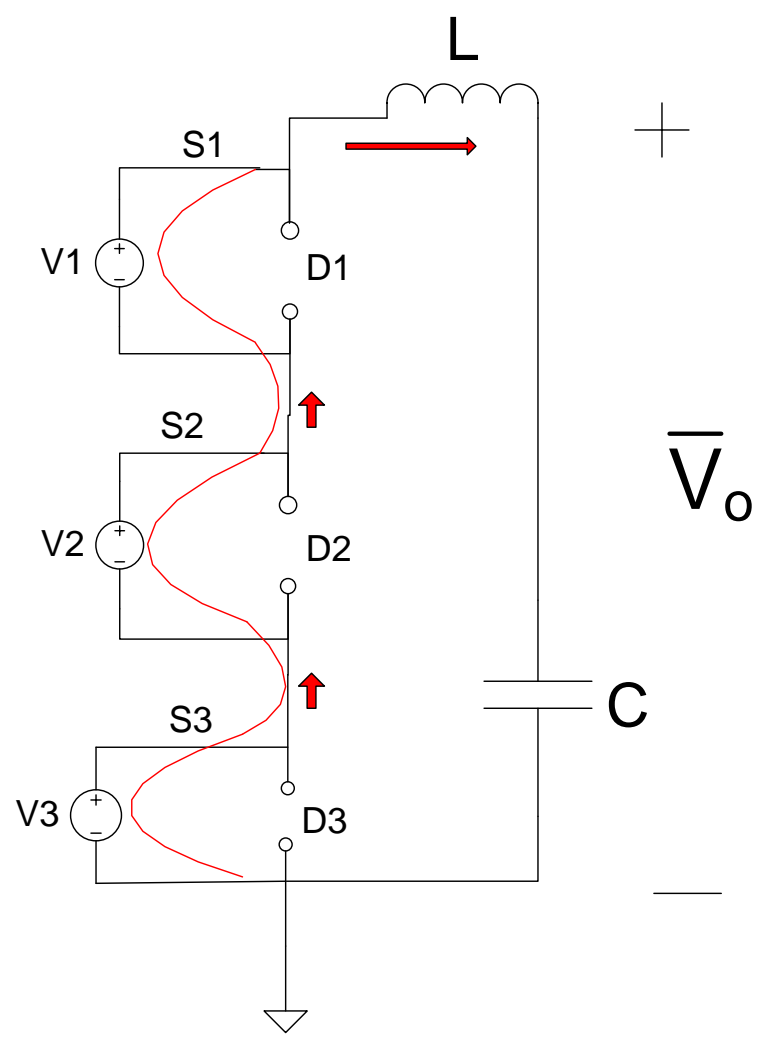

Figure 4-3: Current flow when all switches are conducting

Figure 4-4 shows the case where all switches are off and all diodes are

conducting. In this case all diodes share the same current that is the output current for that moment. If all switches have the same conducting time, and thus all diodes share a conduction time, then the average diode currents will be similar to a standard buck. 


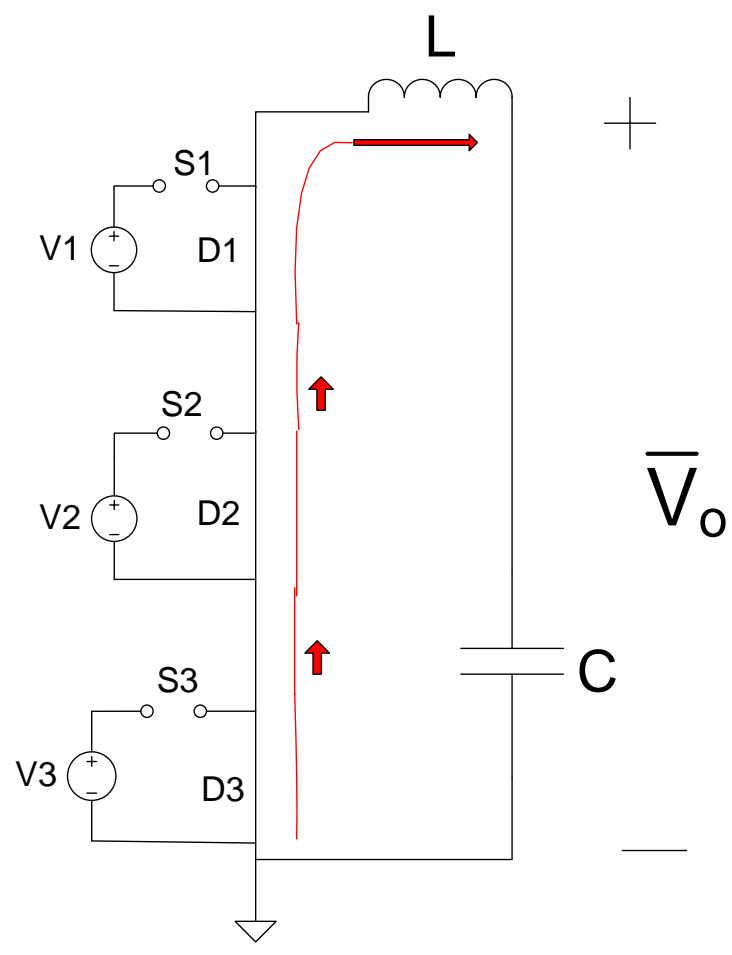

Figure 4-4: current flow when all switches are off

Figure 4-5 illustrates the case where switches are conducting at different times. This allows us to see that at certain times during the period a switch current and a diode current may actually be the same. This begins to show that the average current for a component may no longer be found from a standard buck derivation but will have to be considered further. 


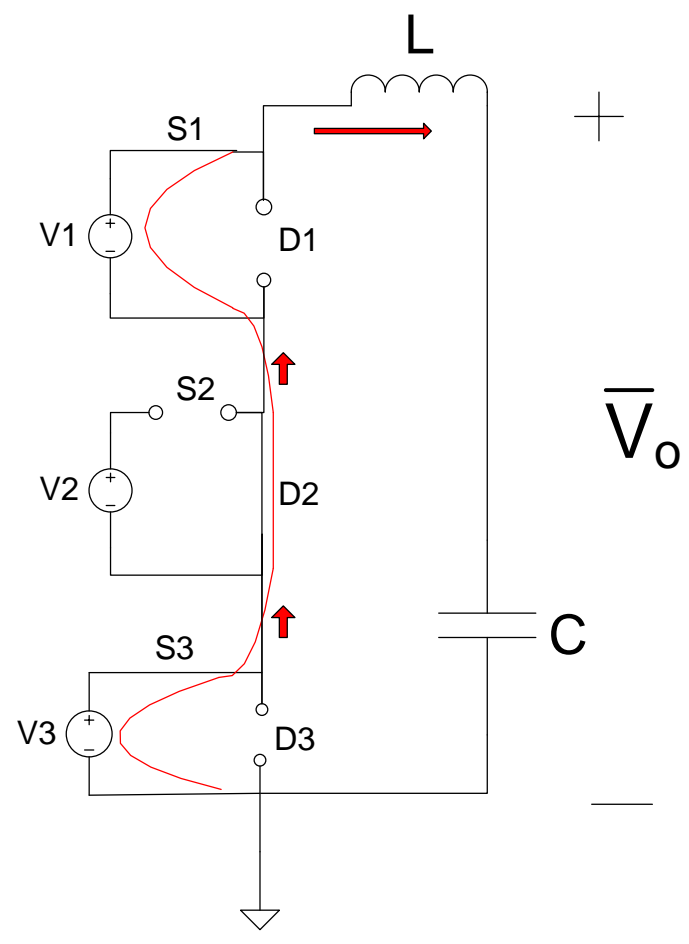

Figure 4-5: current flow when switches 1 and 3 are conducting and switch 2 is off

Figure 4-6 takes this point a bit further to show that because switches may be conducting for different portions of the switching period they may have different current levels, even if they conduct for the same amount of time (i.e. have the same duty cycle). This makes component sizing for average forward currents more complex than for a typical buck. A designer may need to plan for a worst case scenario. A very conservative approach may be to use components whose current ratings are the same as the expected average output current. If the device conducted $100 \%$ of the time it would be the same as the average output current, though we expect each device to turn off for at least some portion of the period so its average current should be less than this. 


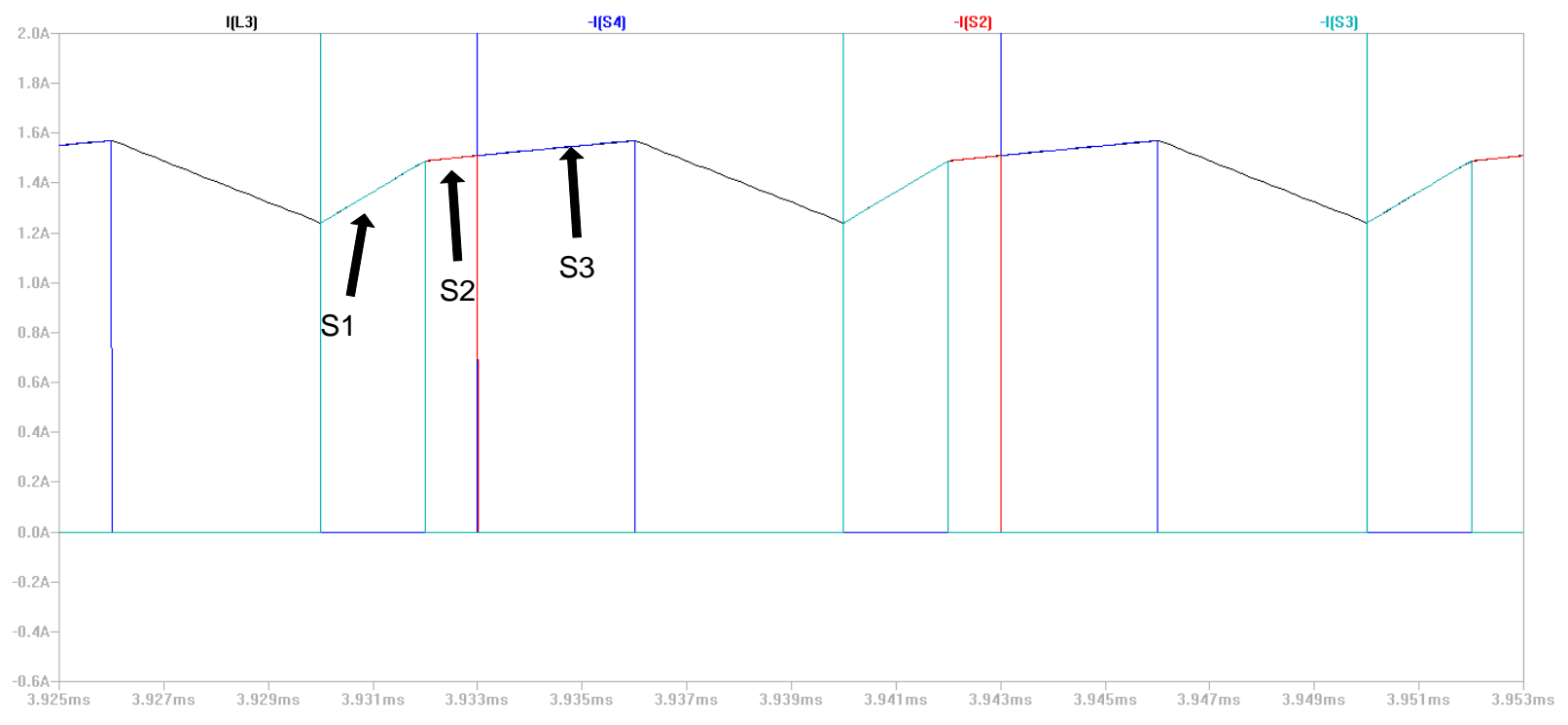

Figure 4-6: Currents in switches compared to inductor current for a switching period

A brief note about the voltage ratings of the switches and diodes is in order. Though it is not explicitly derived here it should be fairly easy to see that for each individual switch the maximum voltage stress that it should see will be its own source voltage. This is apparent when we consider the associated diode to be conducting when the switch is not, thereby effectively allowing the individual source voltage to be across the switch. This is the same as for a standard buck. In general we would expect the same to be true of the diodes; however this is not always the case! Because this topology allows the final output voltage to be larger than a single input source we see that the maximum reverse bias voltage for the diodes is actually

$$
V_{d \max }=\max \left(V_{i}, \frac{V_{O}}{N}\right)
$$


Where the max function indicates the greater of the two quantities and $\mathrm{N}$ is the number of inputs (and therefore diodes). This becomes readily apparent in a scenario where we have larger differences between input voltages. If one input voltage is $10 \mathrm{~V}$, and the other is $2 \mathrm{~V}$ and both have a $50 \%$ duty cycle we expect the output voltage to be $6 \mathrm{~V}$. We will then have $6 \mathrm{~V}$ across two diodes at a time when both switches are conducting. This means that each diode will have 3V across it. This could result in failure of a diode had we only selected a rating of $2 \mathrm{~V}$ !

\subsection{Basic Simulation}

For purposes of this basic simulation three source voltages have been chosen. The reasoning for this is that two sources do not adequately illustrate the complexity of the interactions between sources for more arbitrary duty cycles and delay. The reason for choosing to not simulate more than three sources is because the number of possible combinations increases drastically, and additionally the simulations begin to slow rapidly. However, based on the three source scenario presented here, the reader should be able to extrapolate how additional sources may affect design considerations.

\subsubsection{Specifications of the Simulation}

The simulation program used was LTSpice V4.07e. The desire to use this program comes from its easily used schematic layout and it is free and readily accessible. The voltages are driven with voltage controlled voltage sources with a gain of 1 . The purpose of this is to avoid issues with floating grounds that the simulation has issues with. This also makes 
for a slightly more realistic model of the rectified floating piezoelectric sources as they are inherently differential voltages.

Voltage sources may be any value, but as a matter of simplicity and convenience all three sources are $10 \mathrm{~V}$. The load is chosen to be a $5 \mathrm{ohm}$ static load resistor. This is to allow for currents in the low amps range, primarily for easy viewing. The output inductor and capacitor are chosen to be $100 \mu \mathrm{H}$ and $100 \mu \mathrm{F}$ respectively. This is to allow for significant smoothing of the output waveforms. The diodes are Diodes inc. model DFLS220L with $I_{S}=25 \mu A$ and $R_{S}=47 m \Omega$. This diode was chosen for its low $R_{S}$ value among the available options in the simulation program. The switches are a custom model with $R_{o n}=1 n \Omega$ and $R_{\text {off }}=100 M \Omega$. A very low value of $R_{o n}$ is chosen to mitigate loses in the switch. The switching period is set to be which corresponds to a frequency of 100 $\mathrm{kHz}$. This was chosen to represent a typical switching period of a commercial buck converter. Generalized cases can then be easily drawn from the results presented below. This model attempts to minimize any resistances to best simulate an ideal converter. However there are some limitations to this as, mathematically, the simulation program has trouble with near zero resistances.

\subsubsection{Same duty cycle, no delays}

Figure 4-7 shows waveforms for the case where all input voltages are the same and equal to $10 \mathrm{~V}$, the switches all start at the same time and all have the same duty cycle of 0.5 . This is the simplest case and is almost like having a single buck converter with a source of $30 \mathrm{~V}$. The important difference is that the unfiltered output voltage is actually series combination of multiple inputs. The switching waveform is blue and is labeled as 
V(n003). We can see that the waveform has a 50\% duty cycle and switches between approximately 0 volts and 30 volts. The red waveform is the inductor current, labeled I(L3). We can see that is takes on the very familiar triangular shape that is typical of a regular buck converter. The blue line through the center is the output voltage and is approximately 14.3V. From the derived ideal transfer function we see that the output voltage should be 15 volts. This slight difference is reasonable if we consider the slight drops across the switches and diodes since they are not ideal in the simulation. The results here are nearly identical to what we would expect from a single buck converter whose input voltage was 30V (which is the sum of the three input voltages) with a duty cycle of 50\%. For this simple case the converter behaves as we expect.

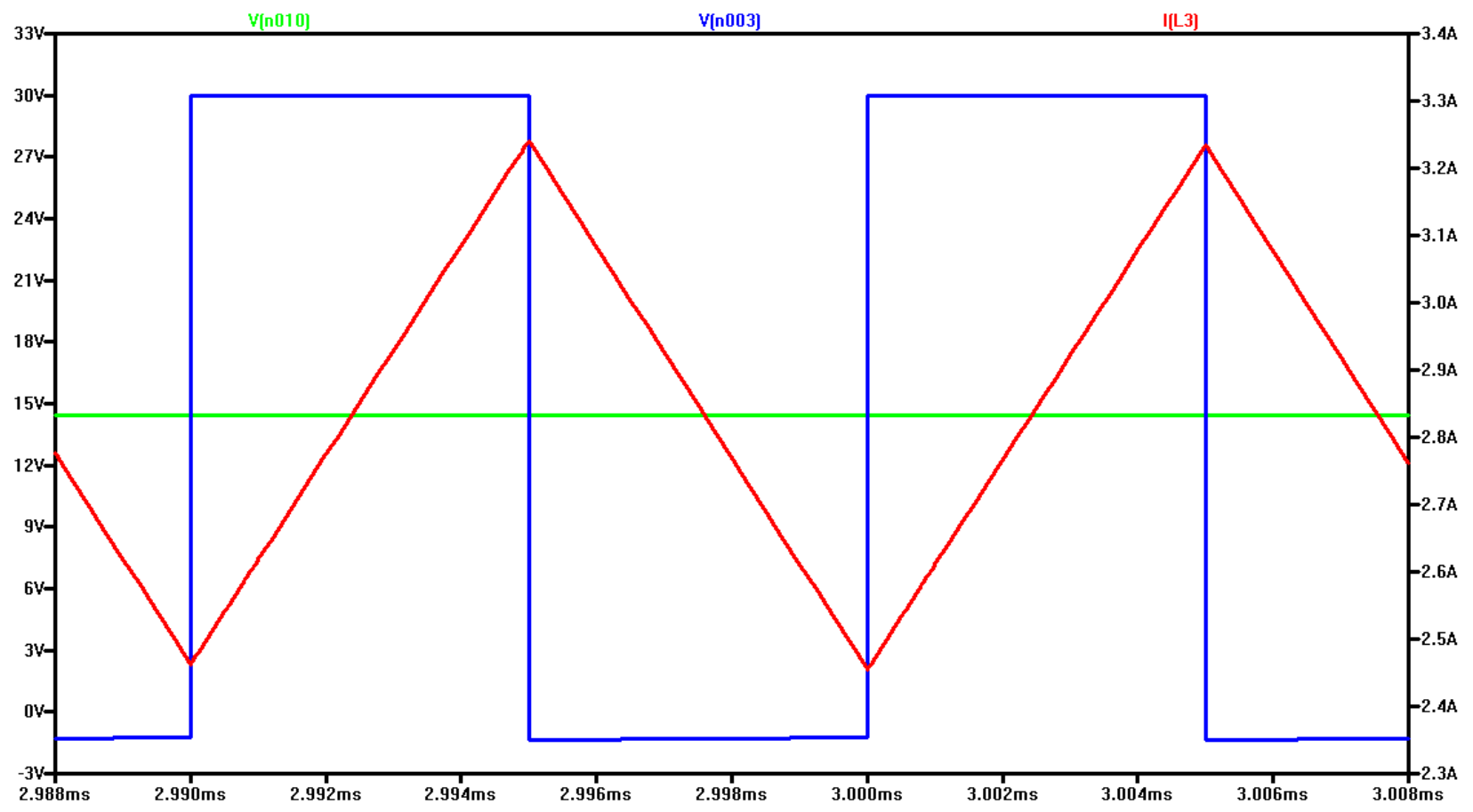

Figure 4-7: $V_{1}=V_{2}=V_{3}=10 \mathrm{~V}, D_{1}=D_{2}=D_{3}=0.5, \tau_{1}=\tau_{2}=0$ 


\subsubsection{Different duty cycles, no delays}

Figure 4-8 shows results for our stacked buck with all input voltages at 10V, with all switches having the same turn on time, but different turn off times. The duty cycles are $40 \%, 30 \%$, and $10 \%$. With these duty cycles we expect the output voltage to be $8 \mathrm{~V}$, the simulated output voltage is $7.2 \mathrm{~V}$.

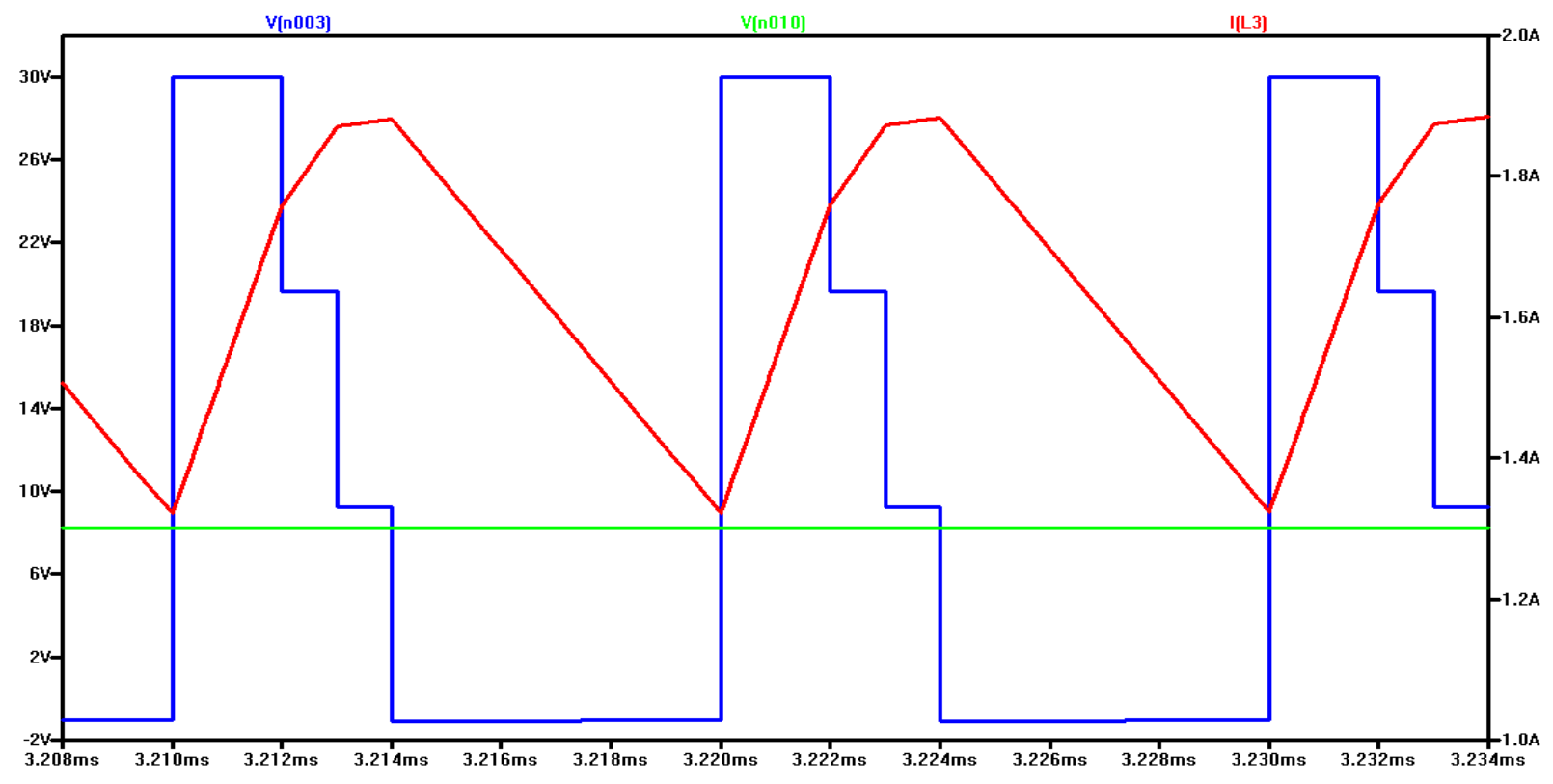

Figure 4-8: $\mathrm{V}_{1}=\mathrm{V}_{2}=\mathrm{V}_{3}=10 \mathrm{~V}, \mathrm{D}_{1}=0.4 \mathrm{D}_{2}=0.3 \mathrm{D}_{3}=0.2, \tau_{1}=\tau_{2}=0$

Again this result is not far off and the discrepancy can be attributed to lossy components. We can see that the unfiltered node voltage, labeled V(n003), has a descending step type of shape. The steps are at $30 \mathrm{~V}, 20 \mathrm{~V}, 10 \mathrm{~V}$, and $0 \mathrm{~V}$. This corresponds to the addition of the input voltages with $30 \mathrm{~V}$ being the sum of the three, $20 \mathrm{~V}$ for two, $10 \mathrm{~V}$ for a single, and $0 \mathrm{~V}$ when all switches are off. The interesting event occurring at this stage is that the inductor current waveform is becoming significantly different from the 
typical triangular shape of a standard buck converter. The slope is of course predictable

according to $\frac{d i}{d t}=\frac{V_{L}}{L}$. When all three switches are conducting the inductor current has the steepest slope with the voltage across the inductor being the sum of the inputs minus the average output voltage. Thus we see that for the case where all switches begin to conduct at the same time with different duty cycles that as each switch turns off the slope of the inductor current gradually decreases. When all the switches are off the inductor current has only $-V_{O}$ across it so that it begins to discharge.

Because the waveform is not typical of a standard buck converter this may cause difficulties when choosing component sizing. Such component sizing as critical inductance to maintain continuous conduction mode, or the approximate average output current or ripple voltage which may depend on this inductance value as well. The detailed analysis of this waveform are not discussed in this thesis, but are briefly introduced with some discussion.

\subsubsection{Different duty cycles, arbitrary delays}

Figure 4-9 shows a more arbitrary case of duty cycles with the three source voltages still the same $10 \mathrm{~V}$ but with duty cycles of $80 \%, 60 \%$, and $30 \%$. These switching cycles have the following respective delays; 0 , 2us, and 3us. The theoretical output voltage, which as we recall should not depend on any delays, is $16 \mathrm{~V}$. The simulated output voltage is approximately $15.3 \mathrm{~V}$. Again because of lossy components we can accept a small discrepancy. 


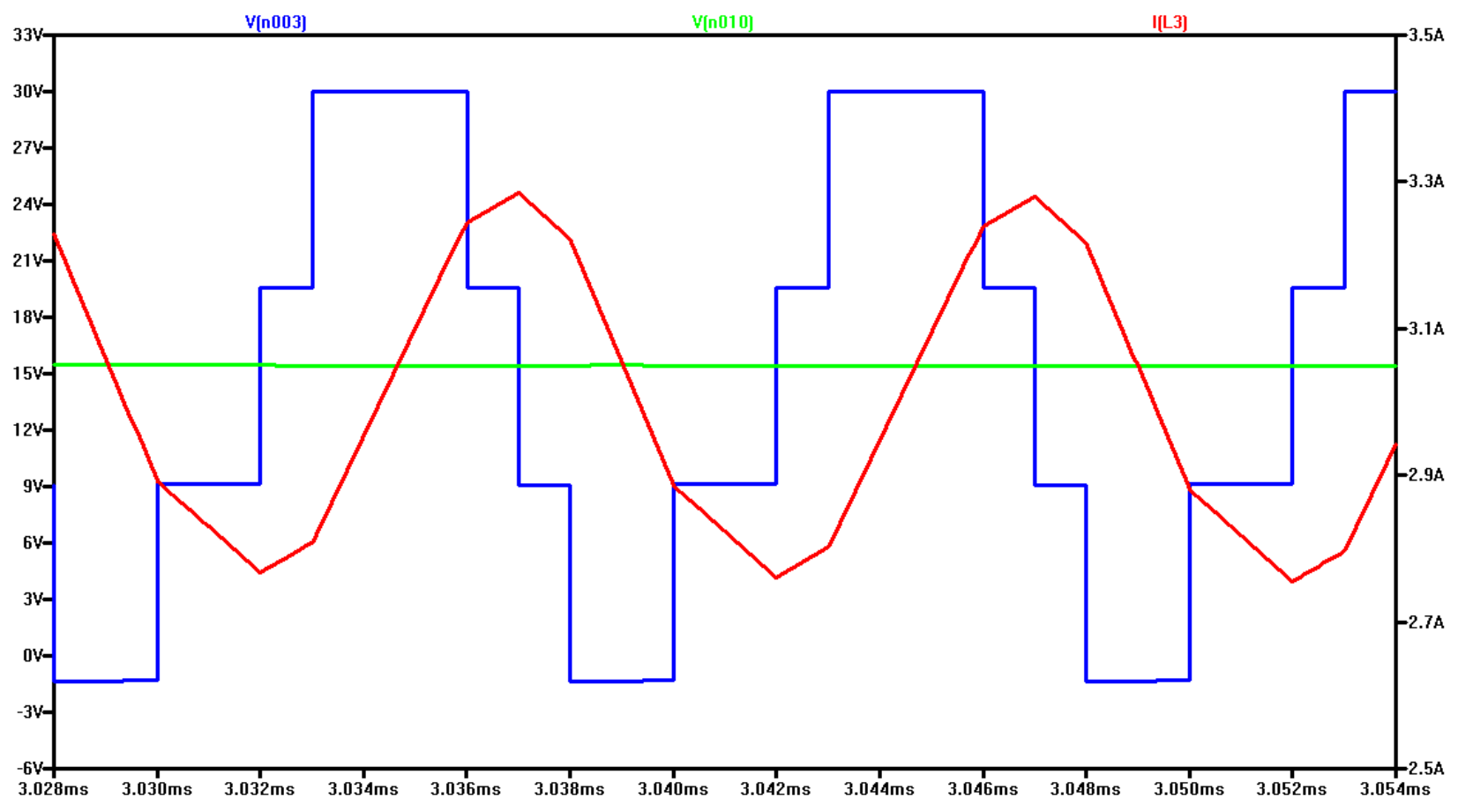

Figure 4-9: $V_{1}=V_{2}=V_{3}=10 \mathrm{~V}, D_{1}=0.8 D_{2}=0.6 \quad D_{3}=0.3, \tau_{1}=0 \quad \tau_{2}=2 \mu \mathrm{s} \quad \tau_{3}=3 \mu \mathrm{s}$

Figure 4-9 shows a similar step pattern as the previous case, but we note an important distinction here; the inductor current is actually declining with a single switch conducting! In a regular buck converter this would never happen because the source voltage is always higher than the output voltage. However, because we are stacking the output voltages there is the desired potential to have the resulting voltage higher than a single input. This allows for a case where the average output voltage is actually higher than a single input. In this particular case we have an output of $15.3 \mathrm{~V}$ with an input of $10 \mathrm{~V}$. This results in a declining inductor current in two places during the switching period. This has even more curious implications for inductor sizing than the previous example. This will be discussed in further detail in the following section. 


\subsection{Inductor Current Discussion.}

Because the inductor currents for this stacked-buck converter are not typical this section has been included to discuss some points to consider. In some cases the multiple input bucks may not have any synchronization between switches and may have separate controllers for each (such as the LTC3588-1 used for this thesis). Because of this we may not be able to predict exactly how the switches will behave, nor what kind of delays they will have and what associated waveform will result. It may be desirable to plan for a worst case scenario whose points of consideration will be briefly discussed.

\subsubsection{Same duty cycle, no delays}

We recall from Figure 4-7 that this case is essentially identical to a typical buck converter. Therefore we may treat this case as such and no special attention, beyond the standard, is needed for inductor sizing.

\subsubsection{Different duty cycles, no delays}

With different duty cycles and the same starting times we can reasonably assume that the inductor current will increase fastest at the beginning of the period and begin to decrease more rapidly until the end of the switching period where (assuming all duty cycles under 100\%) the output voltage will be discharging the inductor most rapidly. It may be reasonable to size critical inductance from a modified version of the normal buck equation for critical inductance from

Equation 4-7 found in [29]. 
Equation 4-7

$$
L_{C r}=\frac{-V_{O}(1-D)}{2 f I_{O}}
$$

Replacing the term (1-D) with the fraction of switching period where no switches are conducting, would effectively make $\mathrm{D}=\max \left(\mathrm{D}_{1}, \mathrm{D}_{2} \ldots\right)$. An even more conservative approach may be to assume that the inductor discharges over an entire period. We should note however that the average output current may no longer be $1 / 2$ of the current ripple as is typical of a regular buck. This is due to the irregular nature of the waveform and will become more pronounced in the case where switch delays occur.

\subsubsection{Different duty cycles, arbitrary delays}

This case is an attempt to illustrate what some of the more erratic behavior may look like, and what it may mean for design considerations. Figure 4-10 shows the unfiltered output voltage as well as the inductor current. We see that the unfiltered voltage is a series of pulses that are either $10 \mathrm{~V}$ or $0 \mathrm{~V}$. 


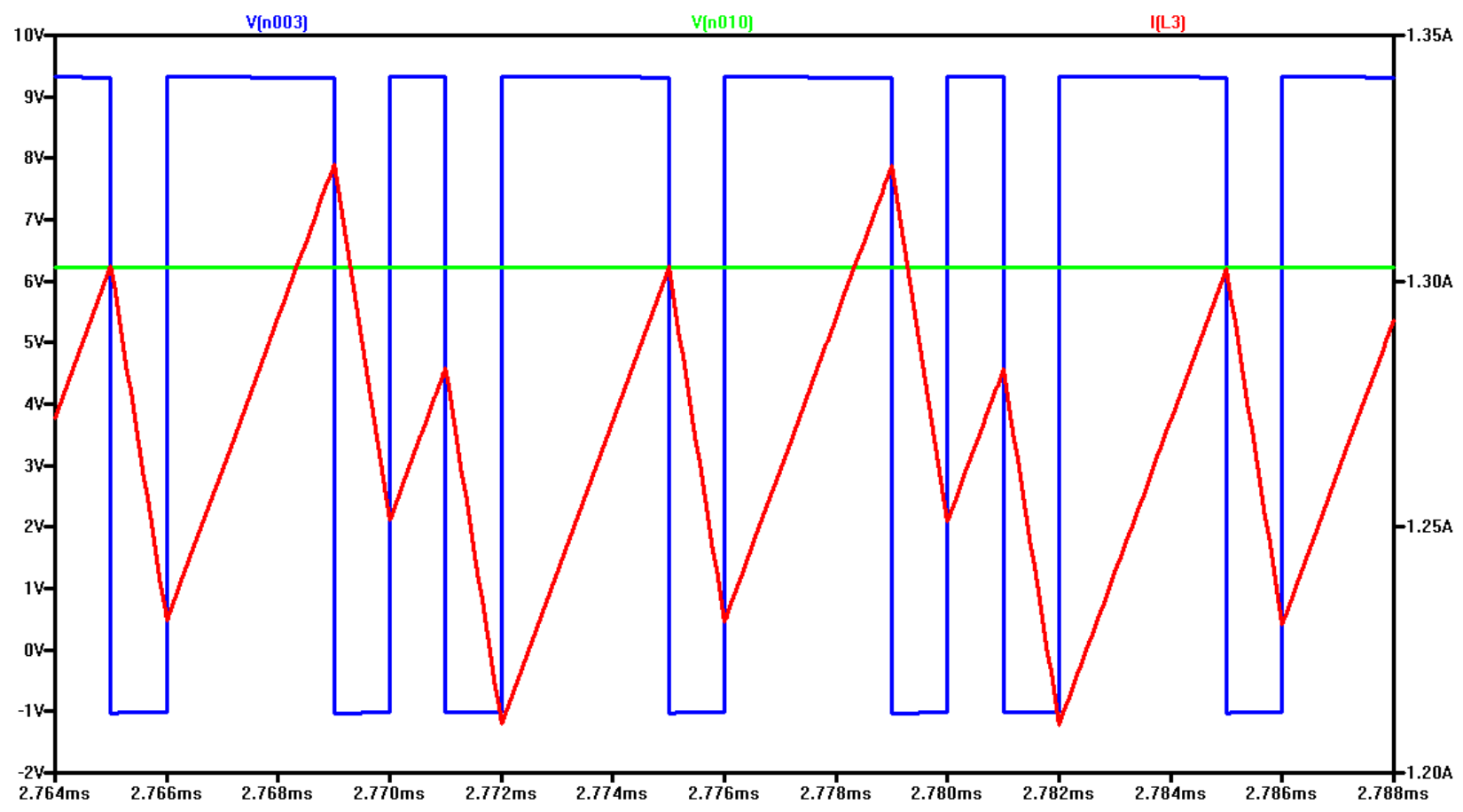

Figure 4-10: $V_{1}=V_{2}=V_{3}=10 \mathrm{~V}, D_{1}=0.1 \quad D_{2}=0.3 \quad D_{3}=0.3, \tau_{1}=0 \quad \tau_{2}=2 \mu s \quad \tau_{3}=6 \mu \mathrm{s}$

These correspond to the inductor either charging or discharging at a maximum rate for this specific scenario. We see in the figure that the waveform is anything but typical. There are many rapid changes in inductor current slope occurring which makes inductor sizing very difficult. The current ripple for this case may actually be smaller than for a case where all switches conduct simultaneously, as is the difference between a simple parallel buck converter and a buck which uses an interleaved control design. However it is impossible to know for certain what sort of waveform will result if the control method is discrete for each input. For this reason the designer may want to consider a worst case scenario when determining sizing for the inductor. 


\subsection{Component Justification}

Figure 4-11 shows a single stage converter for the purposes of clarification while discussing component sizing justifications. The final project will have 5 stages with identical components as it is assumed each input will be experiencing the same energy input. It should be noted that the individual stages will each have an LC filter for the output stage. The reason for this is due to the feedback of the chip. Without proper feedback, we cannot hope to obtain the proper output voltage level, but we cannot use the unfiltered square wave type output for the feedback as it will not give an accurate depiction of the output voltage level (over voltage, ground). The simulation model in section 4.5 shows that the concept of a stacked buck will work. However due to the design limitations of the already commercially available LTC3588-1 (stacking was not anticipated when designing this chip) it is necessary to add these additional filters to smooth out the voltage waveform so that the internal regulation of the buck will behave as we anticipate. The output of one buck will still be fed into the ground/reference of the next allowing us to stack the overall voltage output of the system. 


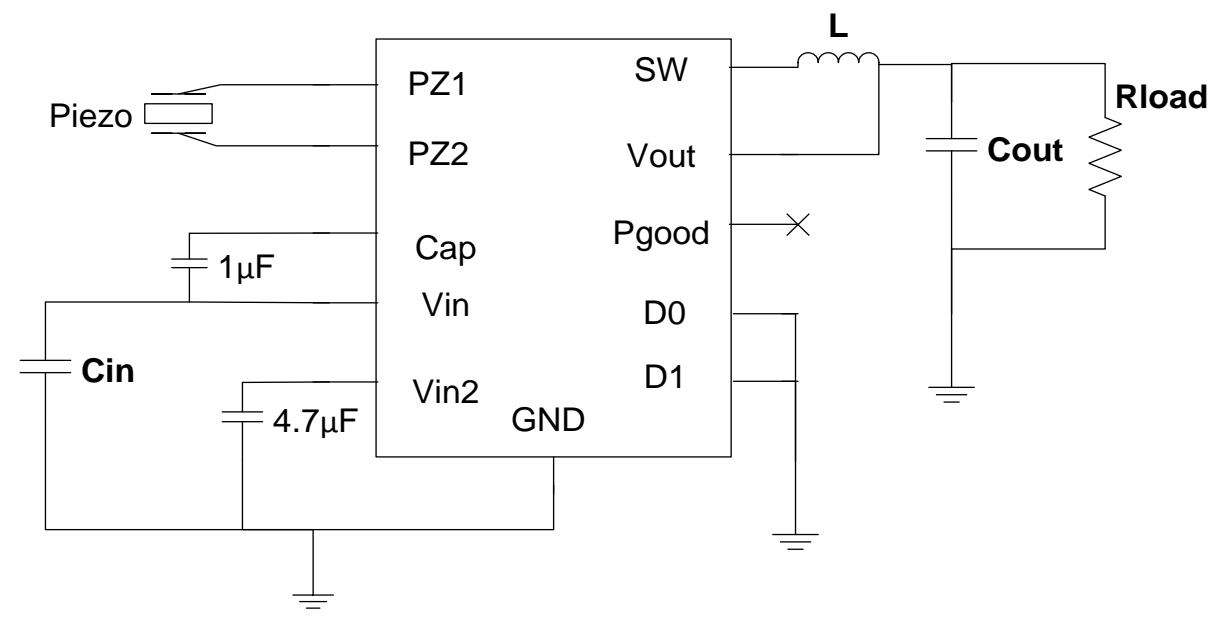

Figure 4-11: Single stage converter

The primary focus here will be on the sizing of input and output capacitors. Although normally the inductor is a major focus for any DC-DC converter it will briefly be shown here that the exact sizing is not crucial, but rather an approximated size range. The Capacitors are the primary concern because they are the main storage elements and should be sized based on the energy necessary to deliver to the load, and based on the rate of energy that is harvested (the input power). The load, in this case, is chosen to demonstrate that energy is being harvested from the sources and delivered through the new topology. Because the power of this system is anticipated to be quite low, we will need a large resistor for a lower power output.

\subsubsection{Load Resistor}

The size of the load resistor is fairly straight forward and depends only on the output voltage and the expected power produced. Too large a resistor may not show us the full power potential of the system. A resistor that demands slightly more power than is being generated would be ideal. This would allow measurements to be made from the 
energy delivered in a pulse and comparing it to the total period between pulses. This is effectively finding the average power from a periodic energy waveform. However, if too small of a resistor (in terms of ohms) is used it will make it difficult to measure the pulse length as the energy will be dissipated very quickly. Equation 4-8 shows how a pulsed output power can be calculated from a static load resistor and fixed voltage. In a later section the period timing will be discussed as it relates to capacitor sizing.

$$
\begin{gathered}
\text { Equation 4-8 } \\
P_{\text {o avg }}=\frac{V_{o}^{2}}{R}\left(\frac{t_{\text {pulse }}}{T_{\text {period }}}\right)
\end{gathered}
$$

It is estimated that piezoelectric input might produce around $20 \mu \mathrm{W}$ for higher wind velocities producing a maximum around $100 \mu \mathrm{W}$. At 9V output (1.8V x 5 tiers) using a $1 \mathrm{M} \Omega$ resistor results in a power demand of $81 \mu \mathrm{W}$. As this will not occur at the lower wind speeds, this should be adequate for the lower wind speeds. For higher wind speeds, if the piezoelectric sources produce more power than this, a simple decrease in the resistance should solve this problem (using a variable resistor box).

\subsubsection{Inductor Size}

The recommended size of inductor as presented in the application section for the LTC3588-1 is $10 \mu \mathrm{H}$. When the critical inductance is calculated for this application based on the normal critical inductance equation for a buck converter, seen in Equation 4-9, we obtain roughly $1 \mathrm{H}$ ! 


$$
\begin{gathered}
\text { Equation 4-9 } \\
L_{c}=\frac{(1-D)}{2 f} \frac{\bar{V}_{o}}{\bar{I}_{o \text { min }}}
\end{gathered}
$$

This is obtained assuming an input for a single stage of $4 \mathrm{~V}$, an output of $1.8 \mathrm{~V}$, and an output current of $1 \mu \mathrm{A}$. The data sheet for the LTC3588-1 does not refer to the switching frequency, and is estimated to be $400 \mathrm{kHz}$ based on the Operating waveforms found on page 6 of [27]. The approximate period of the inductor current waveforms is about $2.5 \mu$ s which translates to $400 \mathrm{kHz}$. While there are several approximations made here, the idea is to point out that the inductor current is not going to be in continuous conduction mode for any reasonable values of inductance, nor is it necessarily desirable for this experiment. The approximate energy storage in the inductor at $1 \mu \mathrm{H}$ and $10 \mu \mathrm{H}$ is on the order of $10^{-8}$ or $10^{-7}$ Joules (from Equation $4-10$ with $250 \mathrm{~mA}$ as the peak inductor current).

$$
\begin{aligned}
& \text { Equation 4-10 } \\
& E=\frac{1}{2} \cdot L \cdot i^{2}
\end{aligned}
$$

So the choice of inductance here is far from critical. For this reason $1 \mu \mathrm{H}$ is chosen as it is a very easily available value, small in physical size, and cheap. 


\subsubsection{Capacitor Sizing}

A brief note about the capacitors between Vin-Cap, and Vin2-GND; these capacitors are used for internal rail generation, and are the suggested values as found in [27]. Because this thesis is interested in power output available from our piezoelectric sources, these capacitors are not of much interest. The capacitors labeled Cin and Cout found in Figure 4-11 are of significant interest. The primary purpose of Cin is to be a storage device where the energy provided at the input can be accumulated. This allows for a buildup of energy that can be supplied to the load in a burst, as the energy source is likely to have a much lower power output than is demanded by the load. The output capacitor, Cout, acts similarly as another storage device but is also used as a typical output filter. The primary concern for the sizing of these capacitors is the timing periods for the output pulses. The average output power will be fixed for a static resistor and a set output voltage. Following Equation 4-8, the ratio of the pulse length and the pulse period must be fixed also. This means that a choice is allowed between more frequent pulses that are short, or longer pulses at occur less often. For purposes of measurement it is convenient to have more frequent pulses so that they may be easier to encounter. A pulse period of one second is chosen for this.

For the purposes of modeling, the piezoelectric device will be treated like a sinusoidal current source. The reason for this is similar to photovoltaic cells, being that they are really energy sources rather than voltage sources. A current source seems to better approximate this as a voltage source would very quickly "fill” a capacitor while a current source builds up the energy stored over time. This is much closer to what will 
actually occur during the experiment. Equation 4-11 shows the relationship between current and voltage in a capacitor as a function of time.

$$
\begin{gathered}
\text { Equation 4-11 } \\
V=\frac{1}{C} \int_{0}^{T} i(t) d t
\end{gathered}
$$

This is important as the accumulation of energy will take time to build in the capacitors. Since it is desirable to determine the value of capacitor that will reach a specified voltage in a given amount of time, the equation is easily rearranged to give a suitable value. Using a time of one second, a voltage of $4 \mathrm{~V}$, and a current of $1 \mu \mathrm{A}$, a capacitance of about $0.3 \mu \mathrm{F}$ is obtained. Since this result is merely a target guideline it may be more convenient to choose a more plentiful or convenient value of either $1 \mu \mathrm{F}$ or $0.1 \mu \mathrm{F}$. This may result in a pulse period other than one second, but this is acceptable as the one second window was also a target guideline. The next question becomes, should the input and output capacitors be the same size, or sized in a particular manner?

To better understand the relationship of energy exchange between the input and output capacitor a simulation may be helpful to illustrate. Figure 4-12 shows a plot of output voltage (bottom) and input capacitor voltage (top) for the case of a single stage converter with $1 \mu \mathrm{A}$ sinusoidal current source input, Cin of $0.1 \mu \mathrm{F}$, and Cout of $0.1 \mu \mathrm{F}$. 


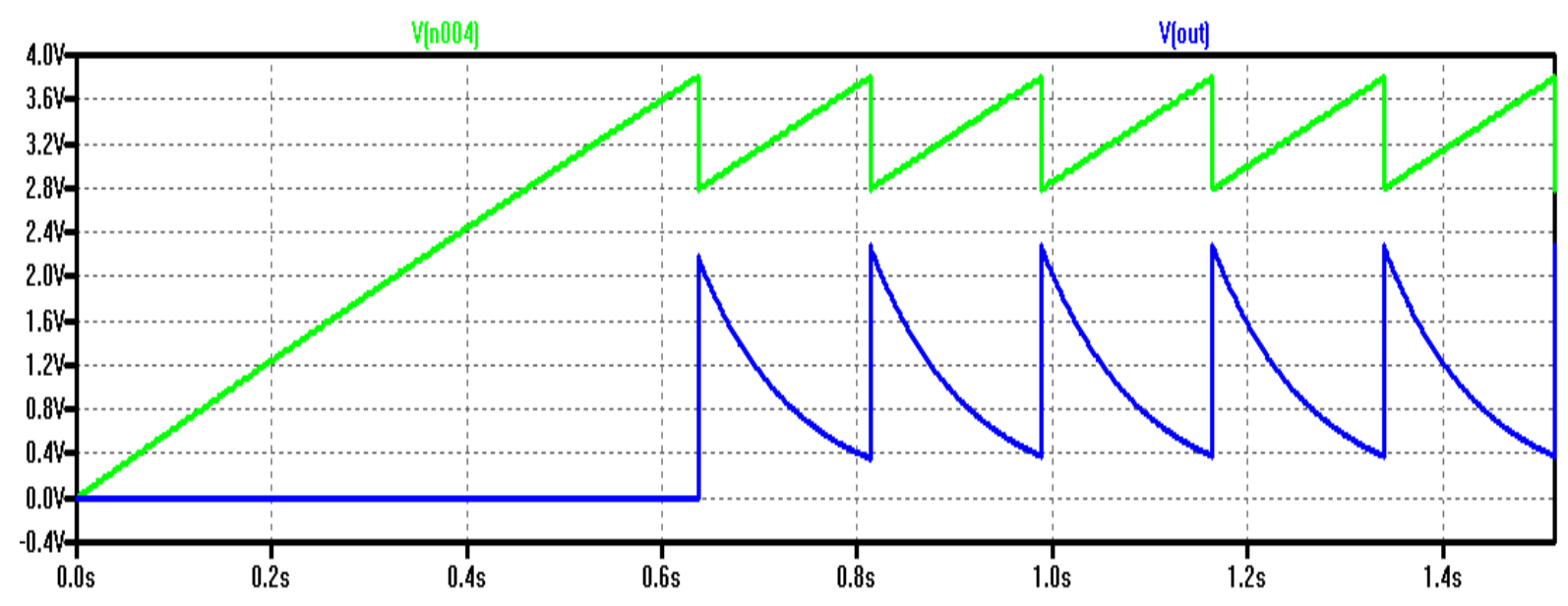

Figure 4-12: Vin and Vout with $\mathrm{Cin}=\mathrm{Cout}=0.1 \mu \mathrm{F}$

A quick examination of the plot shows that the output has a period of about 0.2 seconds, which is acceptable for measurement. However the output waveform is not a simple square output as is desirable for calculation purposes (integration of a waveform by visually gathering data points from an oscilloscope, is neither accurate nor easy). While this set up is technically acceptable, another selection of capacitor ratio may be easier for calculation purposes.

Figure 4-13 shows the scenario where Cin is $0.1 \mu \mathrm{F}$ and Cout is $1 \mu \mathrm{F}$. 


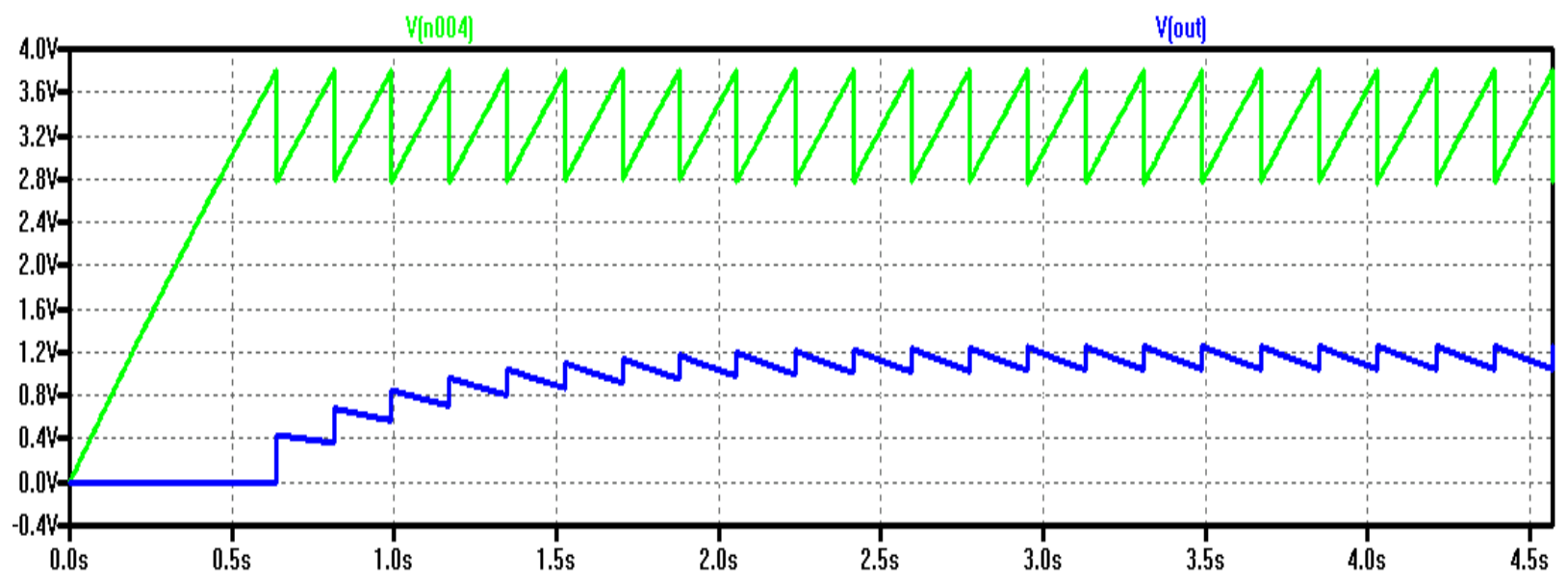

Figure 4-13: Vin and Vout with $\mathrm{Cin}=0.1 \mu \mathrm{F}$ and $\mathrm{Cout}=1 \mu \mathrm{F}$

This case is perhaps worse than the first. Because there is no periodicity in the output voltage waveform it is difficult to know if the power being delivered to the load is comparable to the load. Another point to note is that the output voltage never makes it to the nominal output of $1.8 \mathrm{~V}$ (though it may be possible after a very long time, it is undesirable for measuring purposes). Certainly the case of a much larger output capacitor is not desirable for measurement of power harnessed and delivered to a static load resistor.

Figure 4-14 shows the case where Cin is $0.1 \mu \mathrm{F}$ and Cout is $0.01 \mu \mathrm{F}$. 


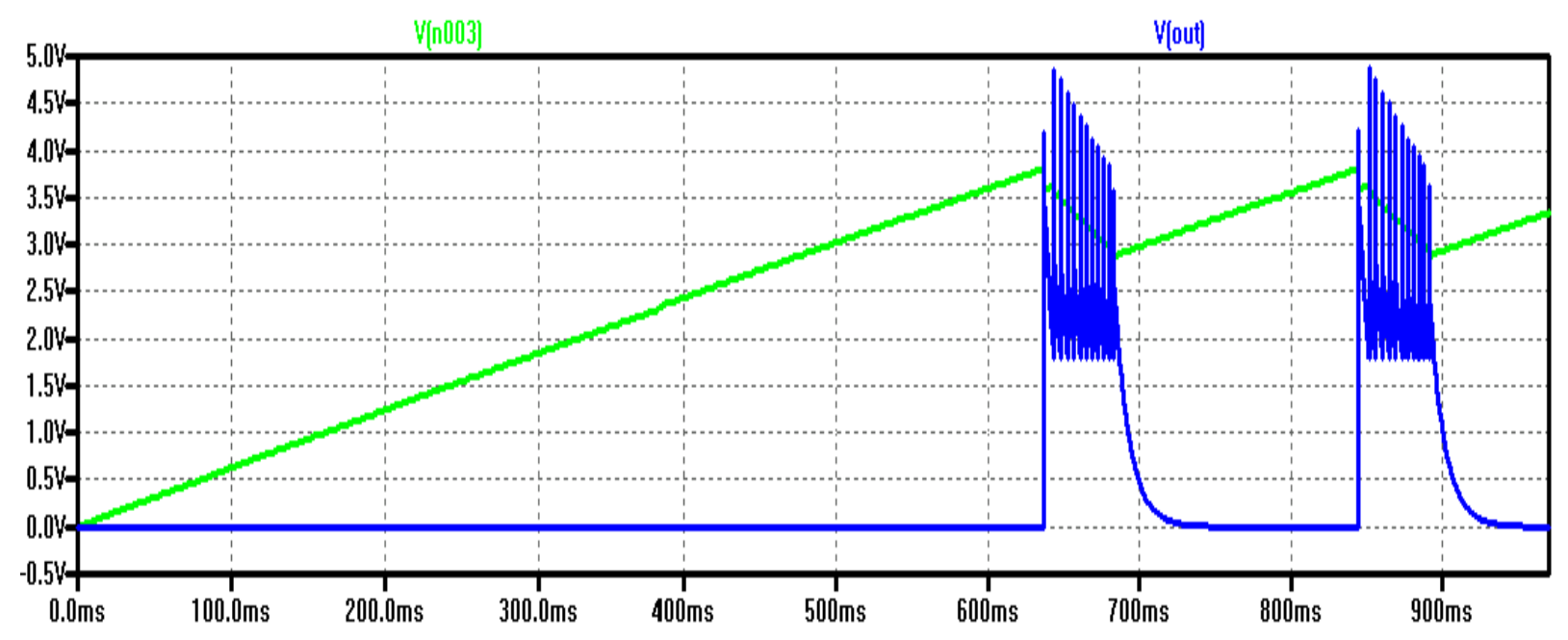

Figure 4-14: Vin and Vout with $\mathrm{Cin}=0.1 \mu \mathrm{F}$ and $\mathrm{Cout}=0.01 \mu \mathrm{F}$

This case much better approximates a pulsed output with a much larger input than output capacitor. This case results in a pulse period of about 0.6 seconds which is perhaps even better than a one second window.

Table 4-2 contains the component values to be used for the experiment.

Table 4-2: Summary of component values to be used

\begin{tabular}{|c|c|}
\hline Component & Value \\
\hline Inductor & $1 \mu \mathrm{H}$ \\
\hline Cin & $0.1 \mu \mathrm{F}$ \\
\hline Cout & $0.01 \mu \mathrm{F}$ \\
\hline Load Resistor & $\sim 1 \mathrm{M} \Omega$ \\
& $\begin{array}{c}\text { (may be adjusted depending on } \\
\text { power output and pulse duration) }\end{array}$ \\
\hline
\end{tabular}




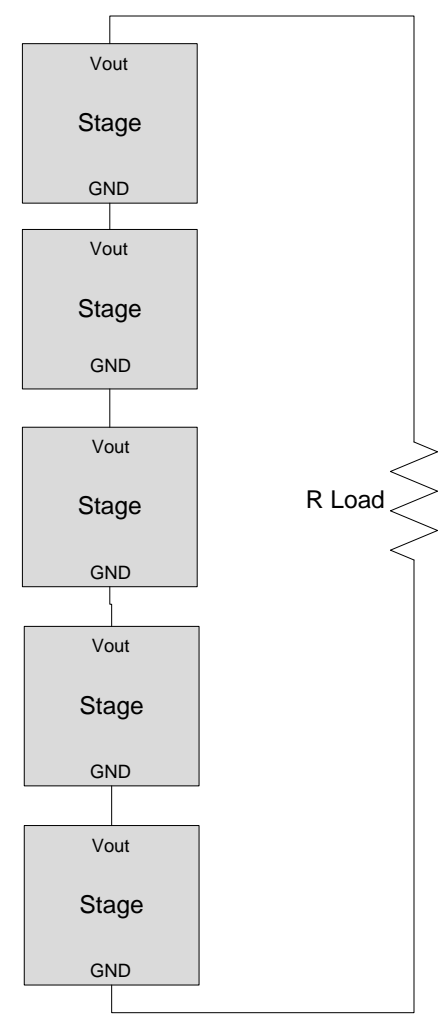

Figure 4-15: System Level Design

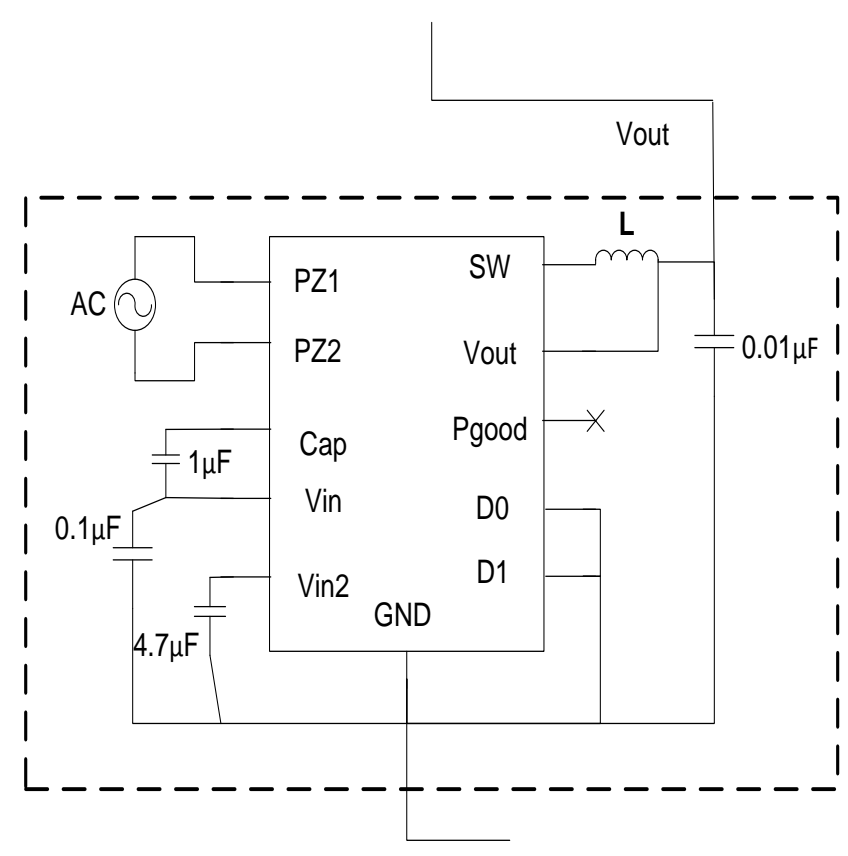

Figure 4-16: Individual stage detail

Figure 4-15 shows the system level design for this thesis with Figure 4-16 showing the details of each individual stage.

Figure 4-17 shows the output voltage for the completed 5 tiered stack buck assembly. Each stage has the same input and component values as listed in Table 4-2. The exception, of course, is that there is only one load resistor that is between the reference of the bottom converter, and the output of the top converter. This gives us an approximate average output voltage around 9V. 


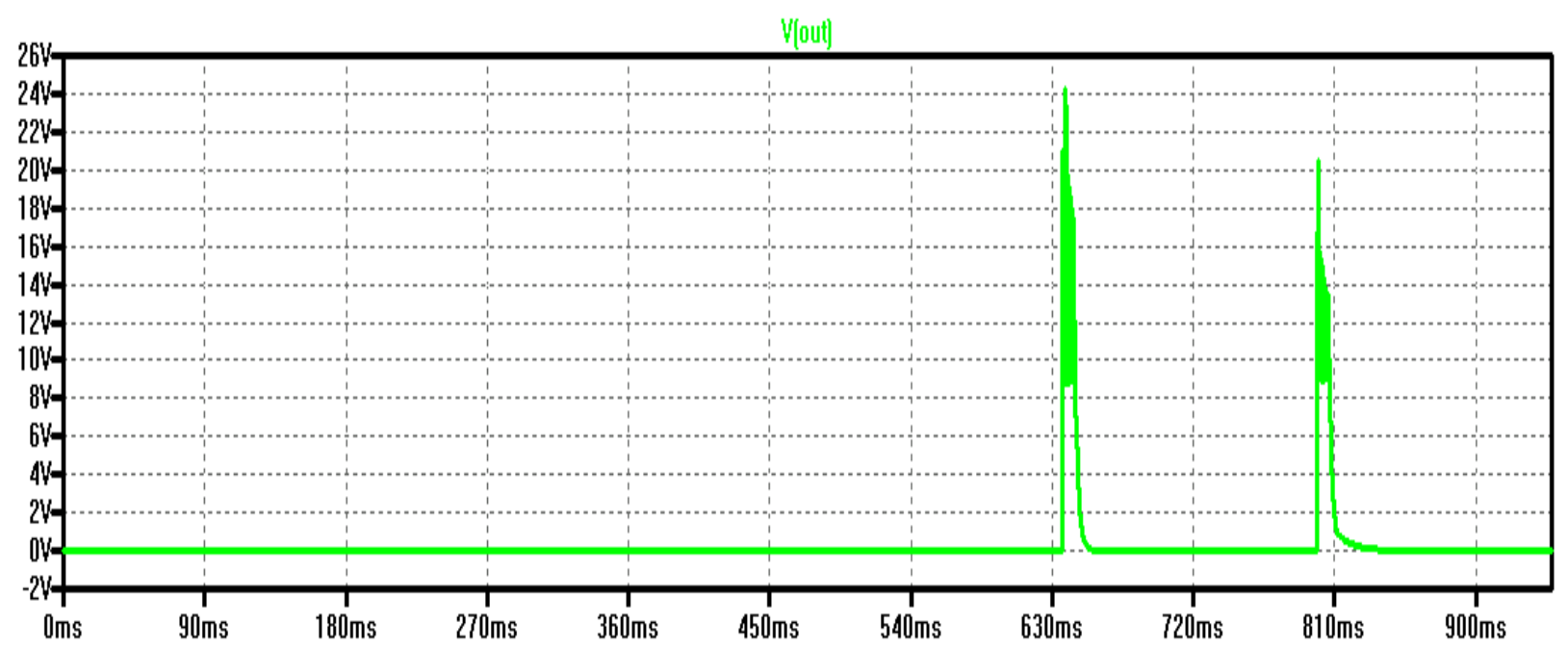

Figure 4-17: Output, 5 tiers. $C i n=0.1 \mu F$, Cout $=0.01 \mu F, L=1 \mu H$ per stage. $R_{L}=1 M \Omega$

Figure 4-18 shows a closer view of the pulsed output. It is easy to see that there are voltage spike transients. These are due to the quick flow of energy from input to output via the fast current ramping of the inductor (up to 250mA). While this may be factored into voltage rating of capacitors, it is not of major concern as the output will be approximated as a square pulse for output power calculations.

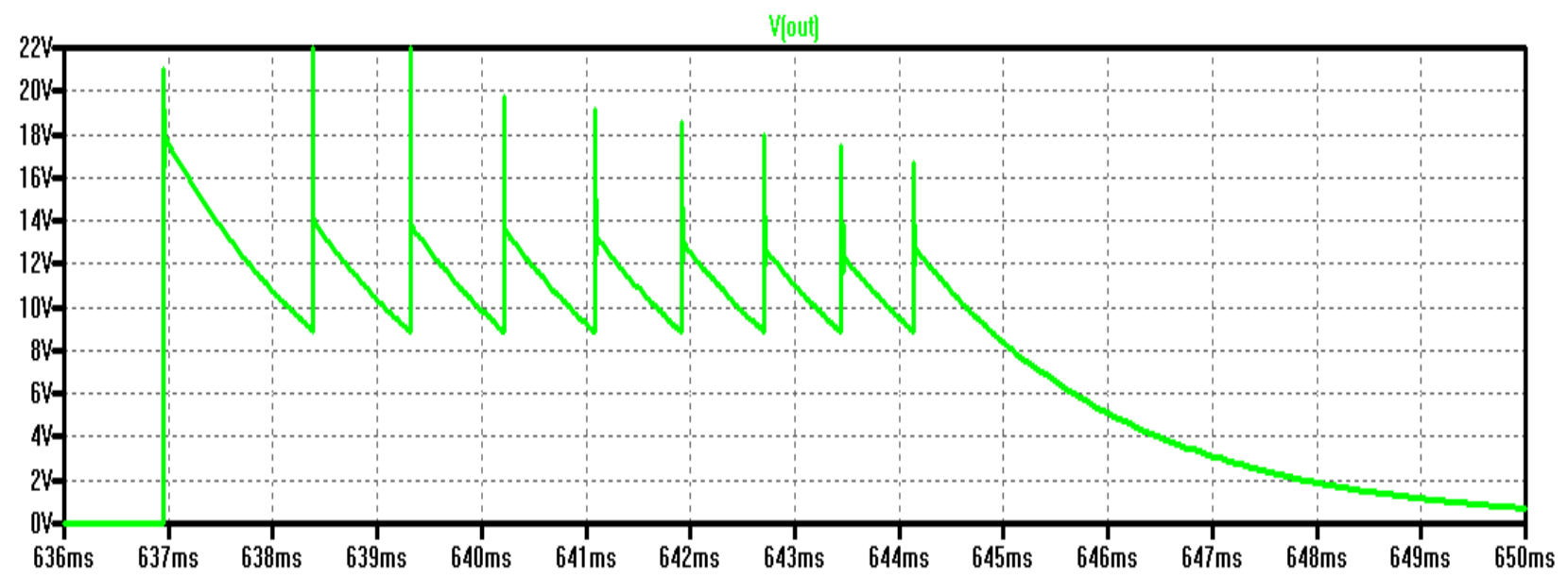

Figure 4-18: Close up view of the pulse output. 


\section{Chapter 5 : Hardware Design, Setup and Testing}

\subsection{Hardware Design}

Figure 5-1 shows the top copper layer for the board design and was created using Express PCB software. Since the design is taking in five inputs into five discrete stages they have been split accordingly into nearly identical layouts. Each stage has its own ground plane (the bottom copper layer simply has a matching ground plane for each stage). The reference of each stage is the output of the preceding stage (with the exception of stage $\mathrm{E}$ whose reference is designated as terminal $\mathrm{Y}$ and considered the base stage here). The total output voltage of the stack is measured from $\mathrm{X}$ to $\mathrm{Y}$, with $\mathrm{X}$ being the positive terminal, and Y the reference. 


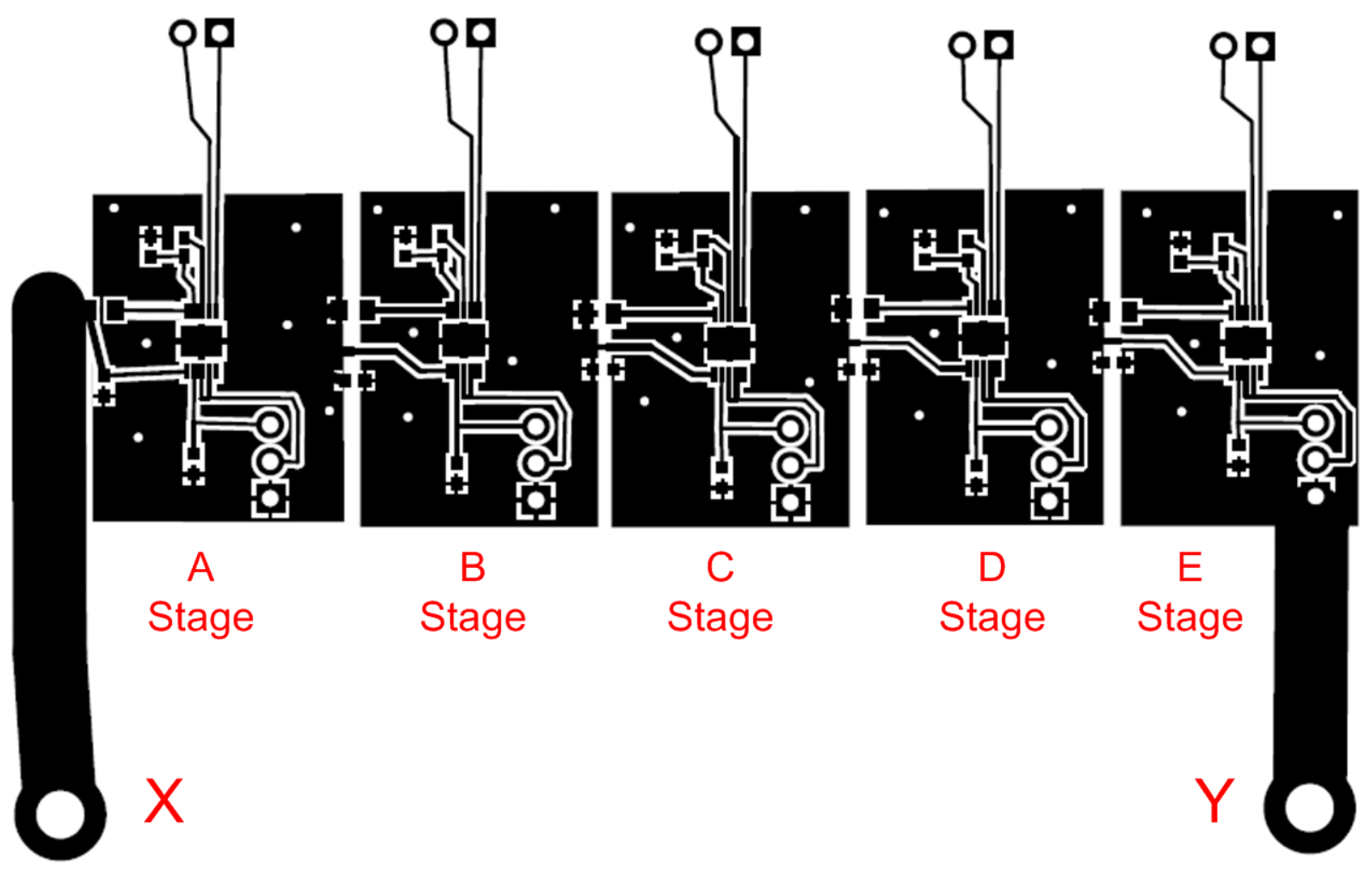

Figure 5-1: Top Copper Layer of Board Design

\subsection{Hardware Verification Setup}

Figure 5-2 is a picture of the completed assembly for hardware verification purposes. The major differences are that the values of the input and output capacitors have changed from the values discussed in Chapter 4 . The values for this purpose are Cin of $10 \mu \mathrm{F}$ and Cout of $4.7 \mu \mathrm{F}$. the reason for the increase is to lessen the ripple so that the feedback sensing loop will have a more stable output voltage to read. This will help to ensure proper operation of each stage. 


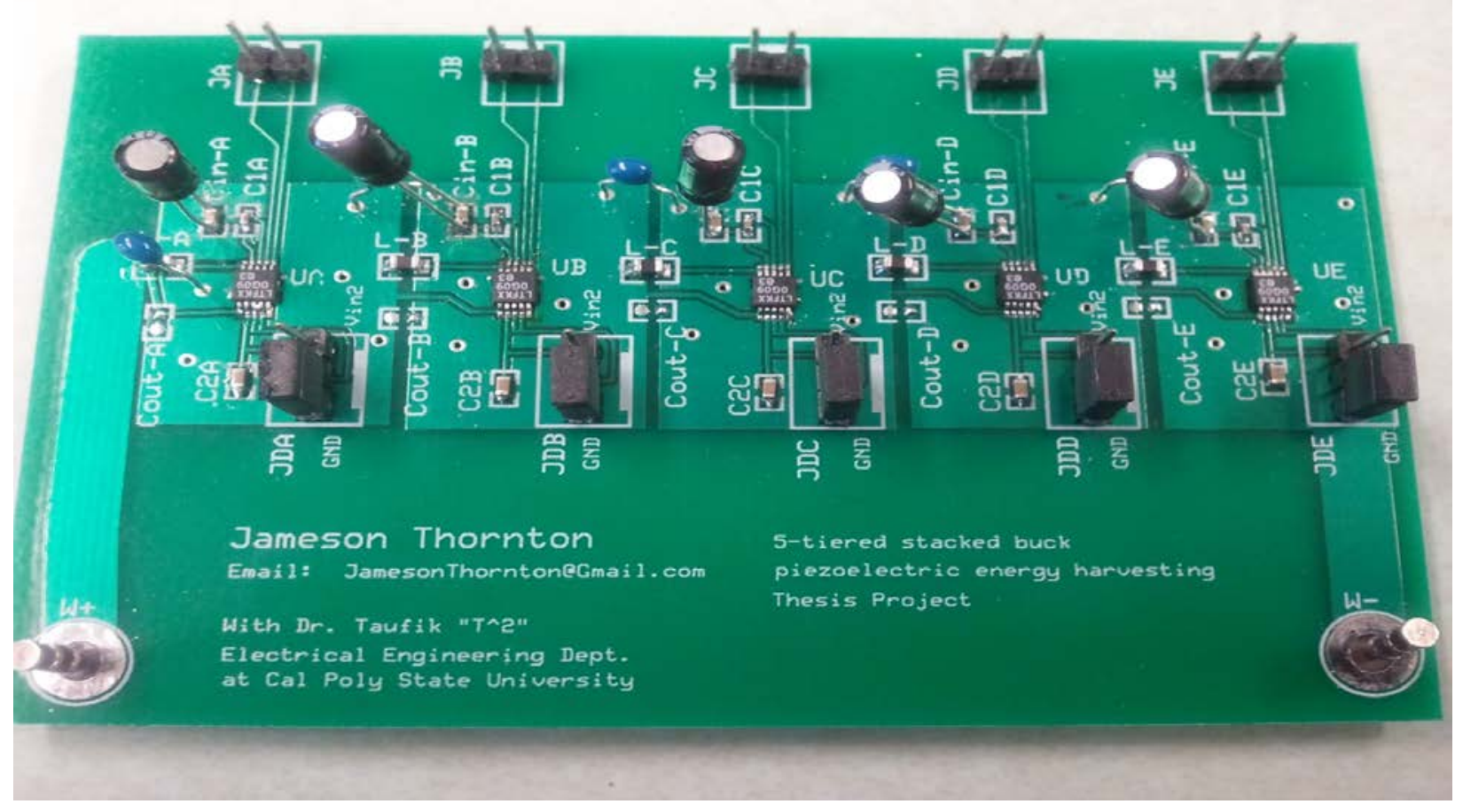

Figure 5-2: Hardware Verification Assembly

The hardware verification is to demonstrate that the stacked buck works in practice as predicted in theory and simulation. To show this, each stage will be provided with various voltages from different sources and the output will be measured and analyzed.

Table 5-1 contains equipment used for this portion of the testing.

Table 5-1: Equipment used

\begin{tabular}{|l|l|l|}
\hline Device & Manufacturer & Model \\
\hline DC Source & MPJA & $9313-P S$ \\
\hline DC Source & Topward Electric instruments & TPS - 4000 \\
\hline DC Source & Jameson Thornton (Custom) & IME-156 Power Supply \\
\hline Oscilloscope & Gw Instek & GDS - 2204 \\
\hline Multimeter & Gw Instek & GDM - 8245 \\
\hline
\end{tabular}

Figure 5-3 shows the lab setup for the hardware verification. Each input is given its own source to verify that the topology still works with different inputs. Also, using a source 
with a shared common reference would not simulate well the true independence of different piezoelectric sources.

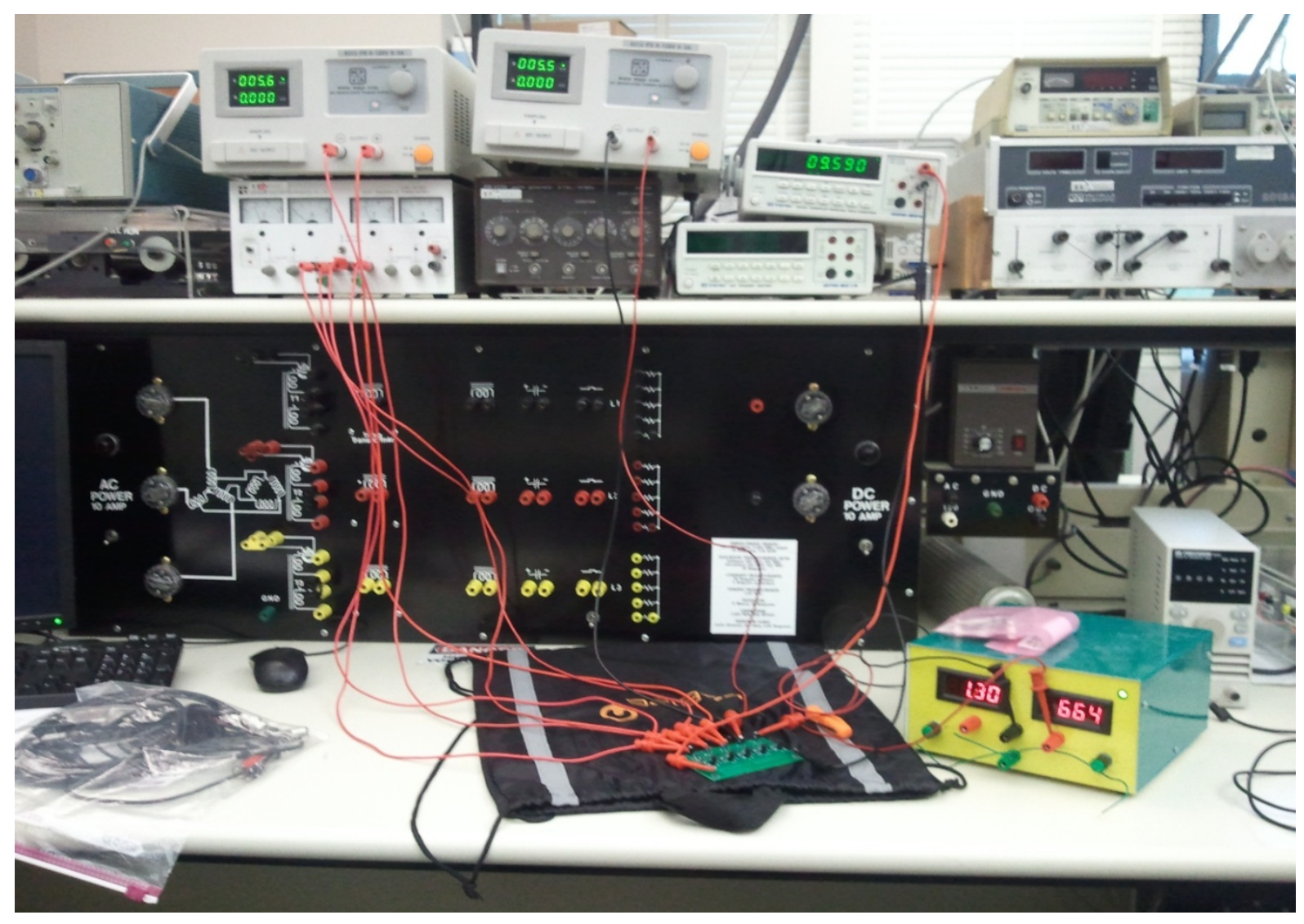

Figure 5-3: Lab Setup for Hardware Verification

\subsection{Hardware Verification Test and Results}

Using the hardware listed in Table 5-1 and the setup as pictured in Figure 5-3, tests were performed to verify the capabilities of the stacked buck topology. First, to show that the voltages do in fact stack a single input was used with the stage voltage and total system voltage measured with no load. Then additional voltage sources were added to show that with each additional input, the output voltage increased proportionally.

Figure 5-4 and Figure 5-5 show the output across stage $\mathrm{E}$ and across terminals $\mathrm{X}$ and $\mathrm{Y}$ (the entire stack) respectively. Both measurements have a single input of $10 \mathrm{~V}$ into stage 
E. The difference is a drop in voltage when measuring across the entire stack. This is likely due to the conduction across the body diodes of the inactive stages. Similar patterns are noticeable with multiple inputs and the drops across inactive stages can be approximated for each inactive stage. The associated figures for 2, 3, 4 and 5 inputs can be seen in Figure 5-6 through Figure 5-12. Table 5-2 has a summary of the results and shows that for each unused stage a drop of $0.2 \mathrm{~V}$ can be expected per stage.

Table 5-2: Voltages measured across active stages and across the entire stack

\begin{tabular}{|l|r|r|r|r|r|}
\hline \# of Inputs & 1 & 2 & 3 & 4 & 5 \\
\hline Voltage Across Stage(s) (V) & 1.96 & 3.92 & 5.83 & 7.7 & 9.69 \\
\hline Voltage Across Whole Stack (V) & 1.26 & 3.39 & 5.55 & 7.51 & 9.69 \\
\hline Voltage Loss (V) & 0.69 & 0.53 & 0.28 & 0.19 & 9.69 \\
\hline Loss per Stage (V) & 0.17 & 0.18 & 0.14 & 0.19 & 0 \\
\hline
\end{tabular}

Due to the hysteretic nature of the converter, the output voltage waveform for a single stage is close to a decaying sawtooth wave, as seen in Figure 5-4 and Figure 5-5. If the converter utilized a PMW feedback control, the output would likely be smoother. However, because of the energy accumulation and storage nature associated with most applications for this chip it is necessary to use a hysteretic control method. This transfers energy from input to output when the output voltage decreases to its specified threshold (1.8V for this case) and turns off when the output reaches an upper threshold (or when the input reaches an under voltage condition). This helps to prevent the chip from short cycling the system. 
Figure 5-6 and Figure 5-7 show the output across the two active stages (B \& C) and across the whole stack ( $\mathrm{X} \& \mathrm{Y}$ ). A major difference that is immediately noticeable is that the waveform is no longer sawtooth-like. This is because each converter acts independently and regulates its own output voltage and not the total output voltage. For example Stage B may hit its lower threshold of $1.8 \mathrm{~V}$ and transfer charge from input to output to increase the output voltage to about $2 \mathrm{~V}$ while Stage C may be around $1.9 \mathrm{~V}$ with not transfer from input to output. This is why a sudden jump in voltage may occur, causing the output to have a kind of double step sawtooth. Keeping in mind that each stage has little to no correlation with the other stages we can think of each stage as having a statistically random voltage between $1.8 \mathrm{~V}$ and $2 \mathrm{~V}$. In some cases the voltages may be in sync and reach a peak and valley at the same time, or they may occur more chaotically. In either case a guaranteed minimum would be the chosen output voltage multiplied by the number of stages. In this case $1.8 \mathrm{~V}$ multiplied by 2 would be $3.6 \mathrm{~V}$ at minimum. In many cases this minimum won't even be reached as the converters would have to be in sync and this is more statistically rare than all of the other possibilities (like rolling 2 dice and having them show exactly 2). This also corresponds heavily to the average output voltage.

Figure 5-7 through Figure 5-12 show similar behavior, but with increasingly chaotic interrelations. 


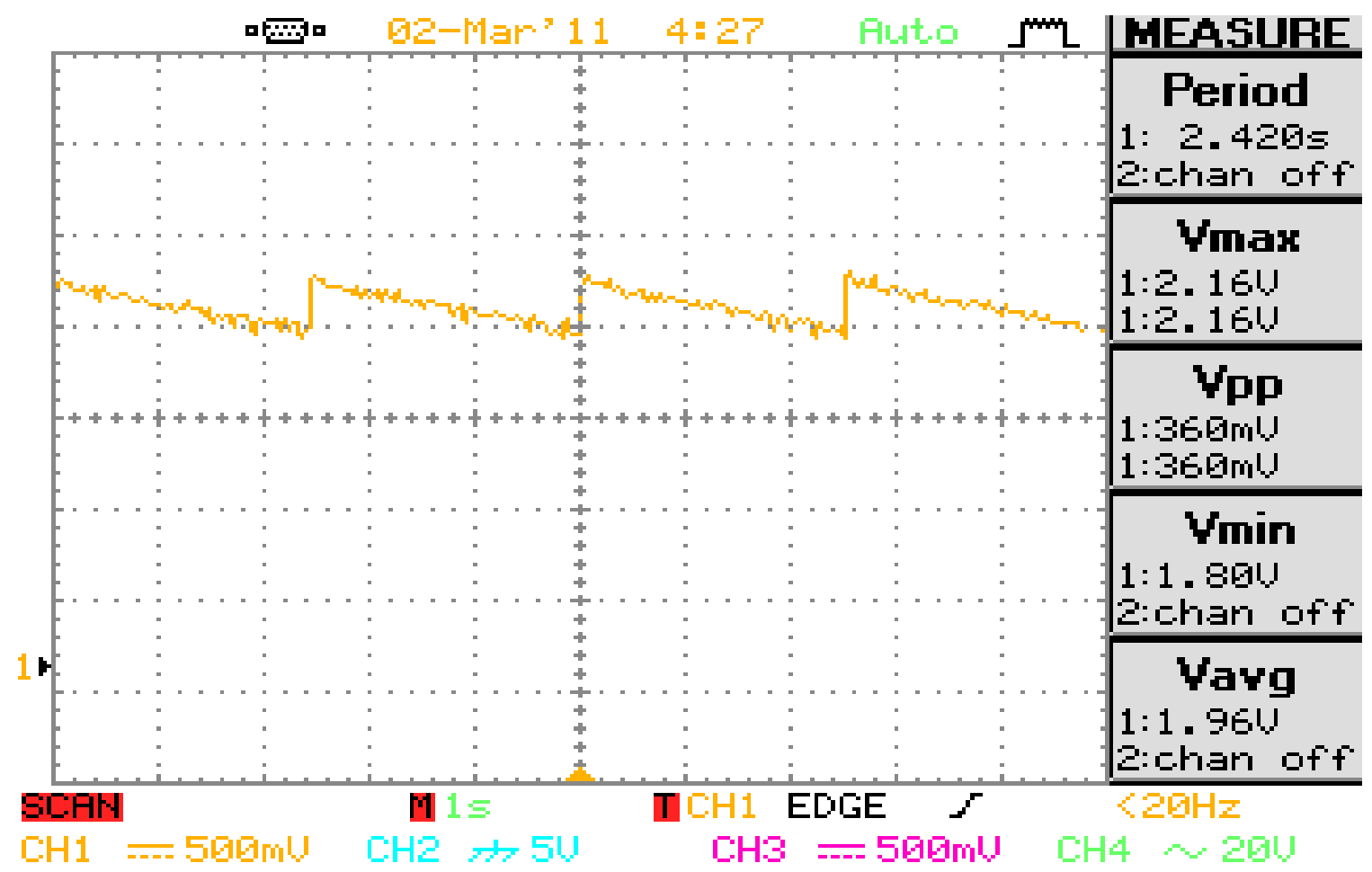

Figure 5-4: Measured Across Stage E. Inputs $[A, B, C, D, E]=[0,0,0,0,10]$

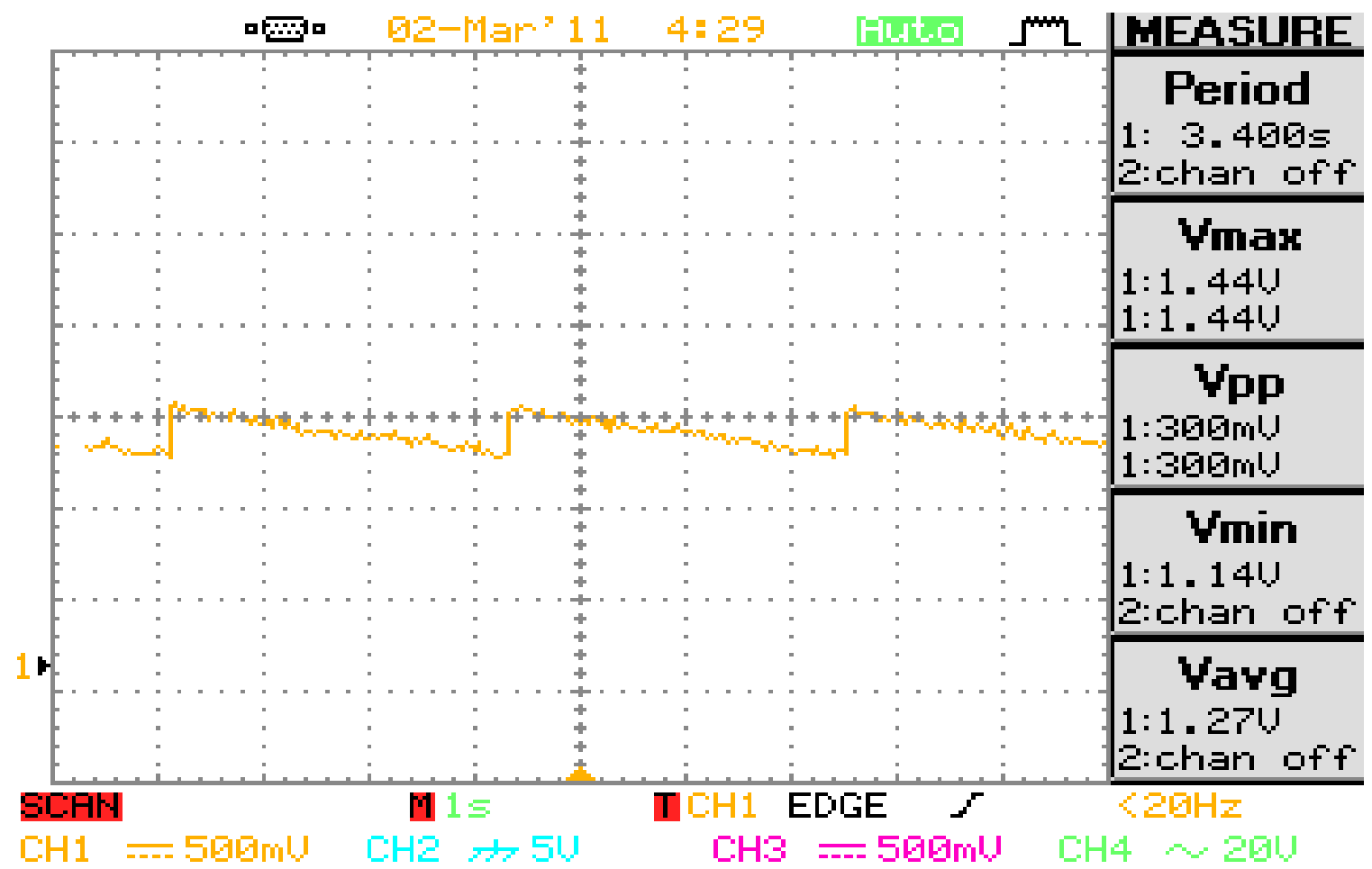

Figure 5-5: Measured Across Whole Stack. Inputs $[A, B, C, D, E]=[0,0,0,0,10]$ 


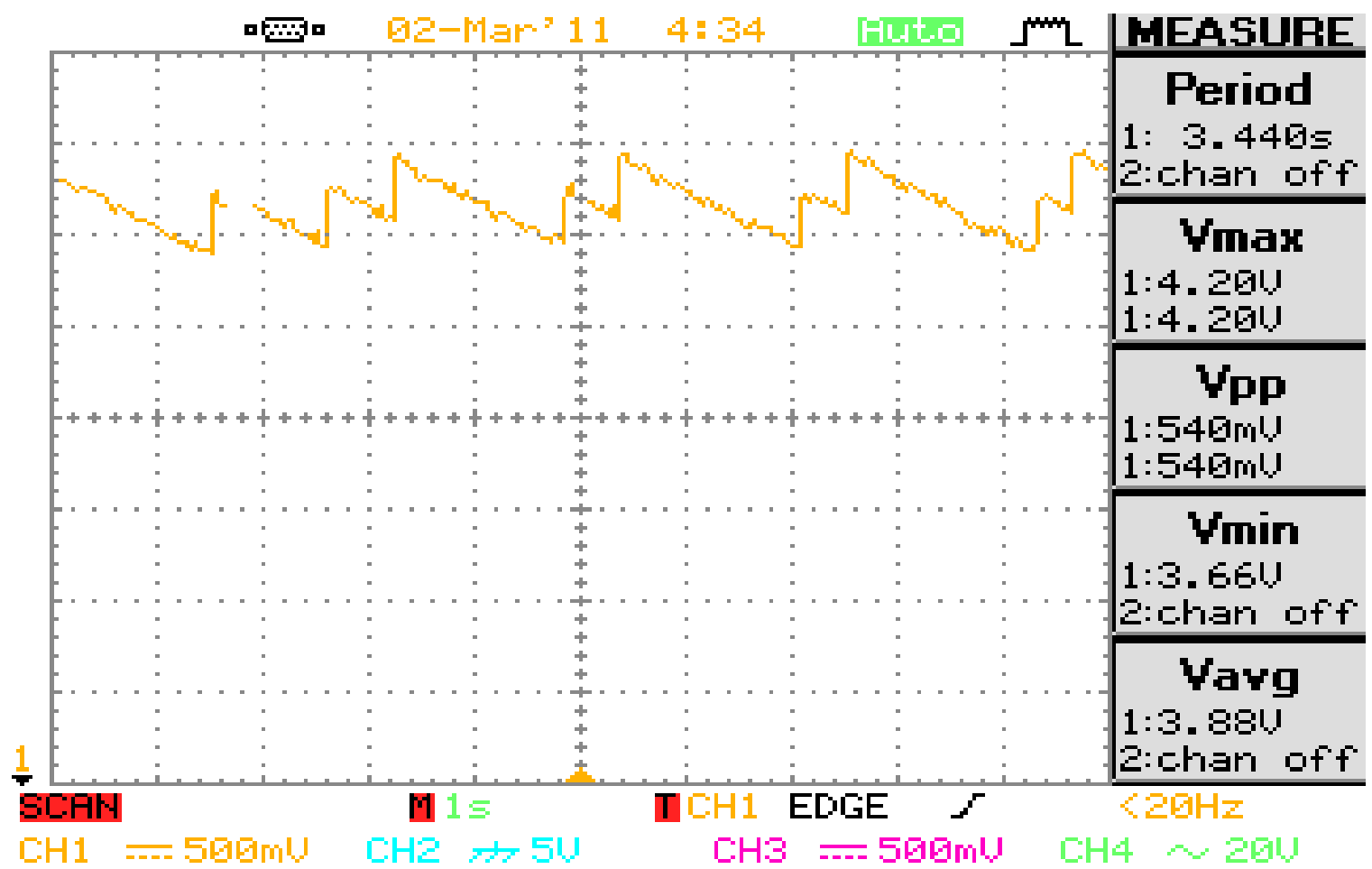

Figure 5-6: Measured Across Stages B \& C. Inputs $[A, B, C, D, E]=[0,10,10,0,0]$

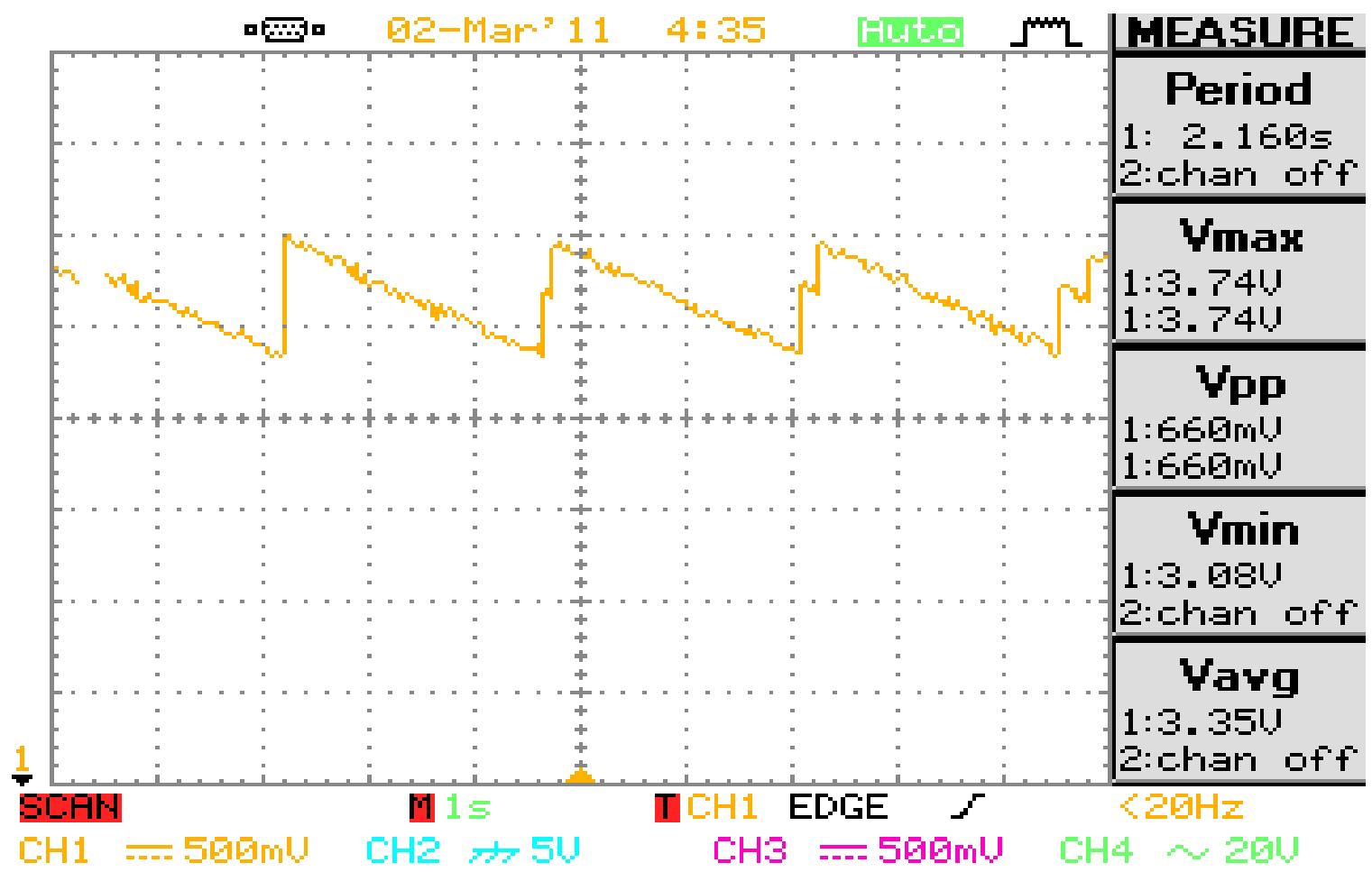

Figure 5-7: Measured Across Entire Stack. Inputs $[A, B, C, D, E]=[0,10,10,0,0]$ 


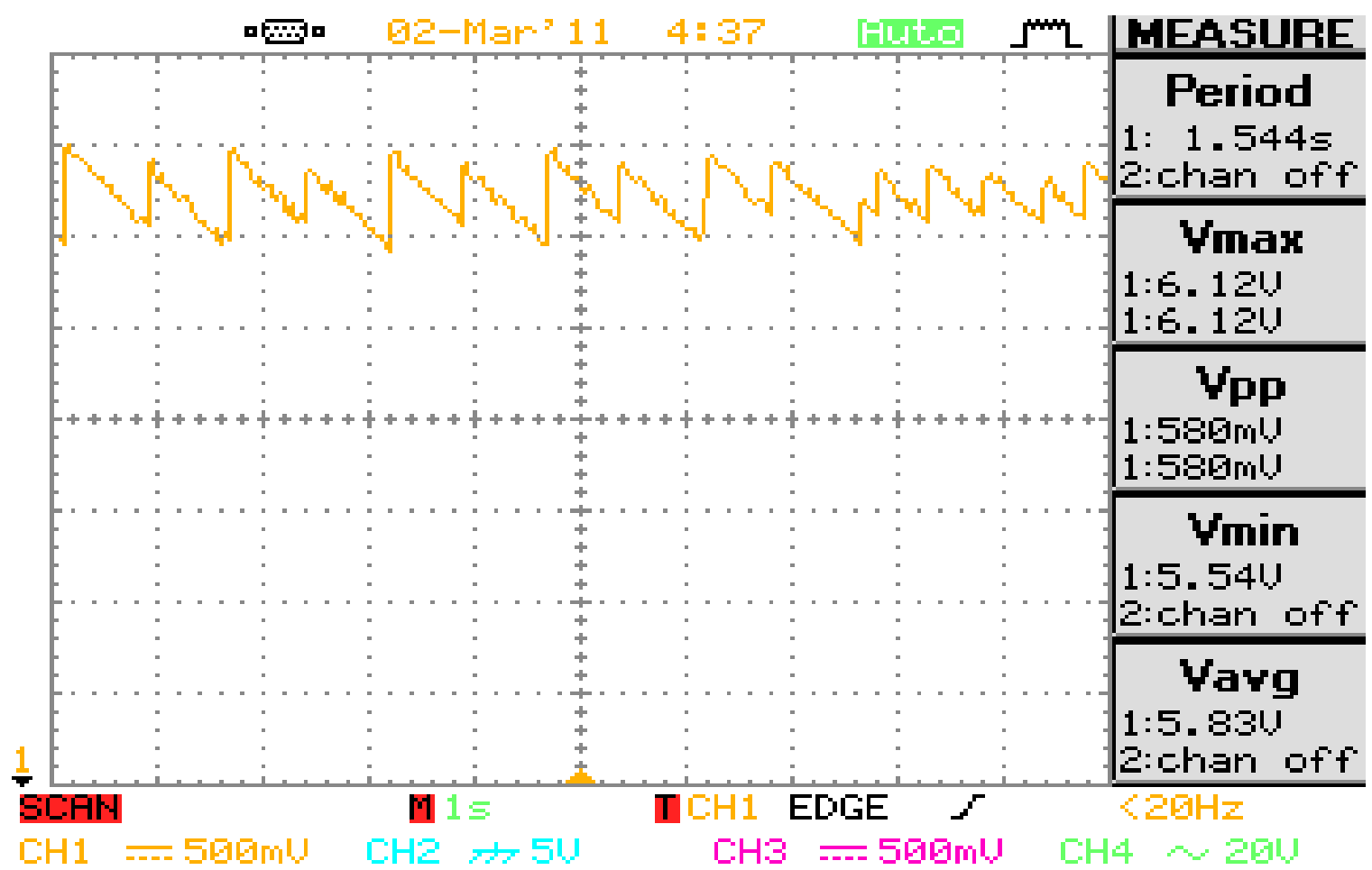

Figure 5-8: Measured Across Stages A-C. Inputs $[A, B, C, D, E]=[10,10,10,0,0]$

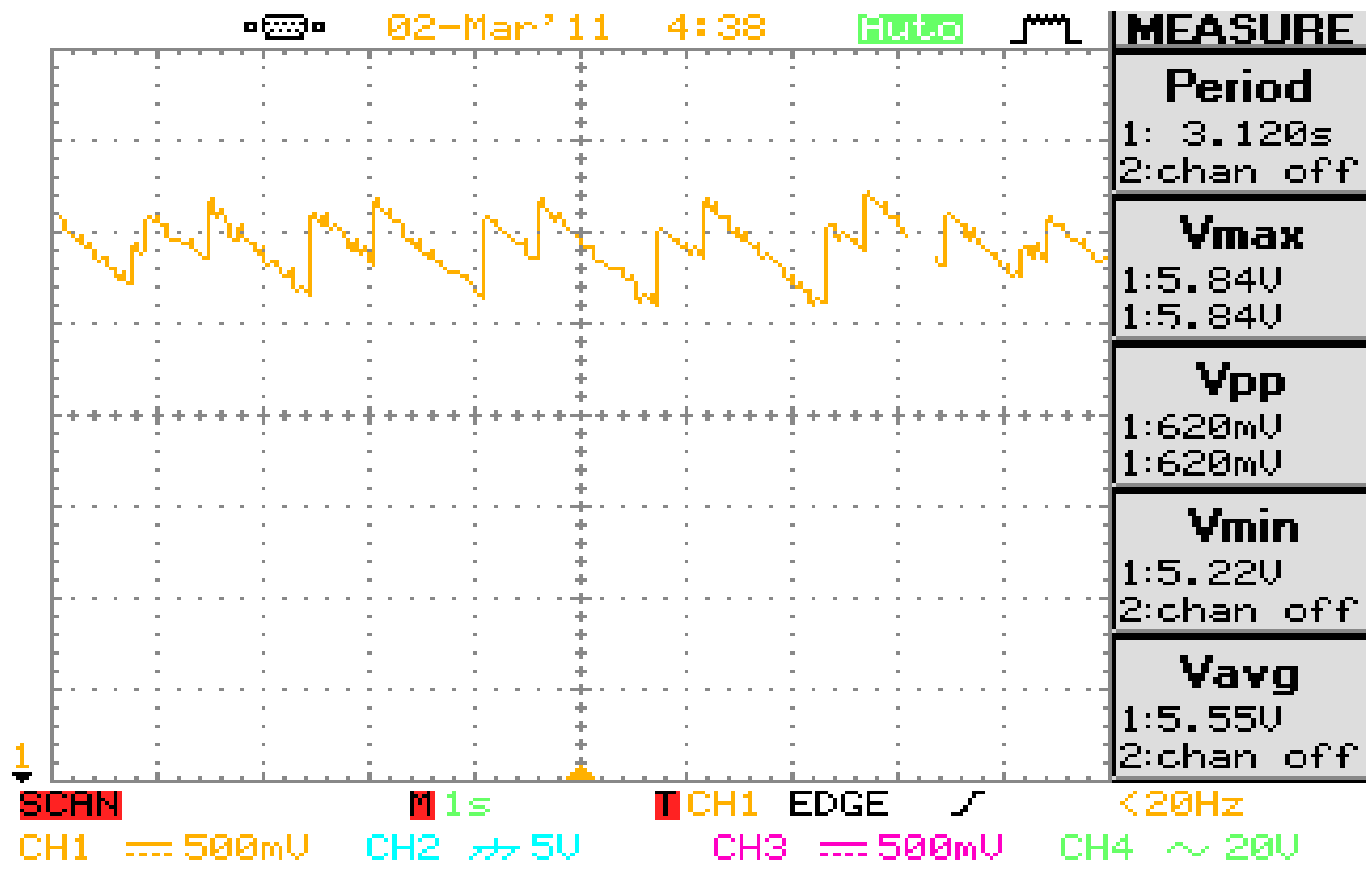

Figure 5-9: Measured Across Entire Stack. Inputs $[A, B, C, D, E]=[10,10,10,0,0]$ 


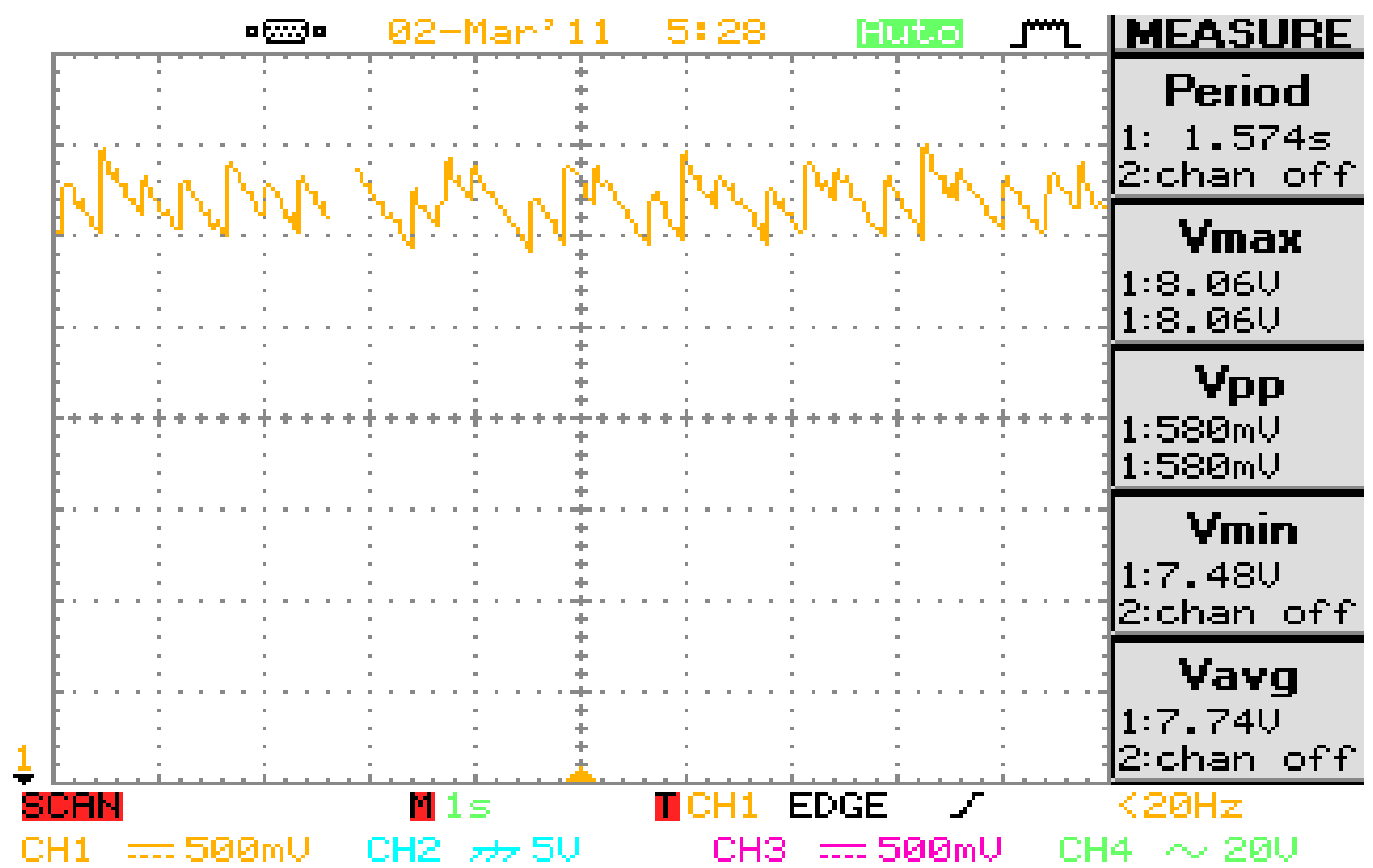

Figure 5-10: Measued Across A-D. Inputs $[A, B, C, D, E]=[10,10,10,10,0]$

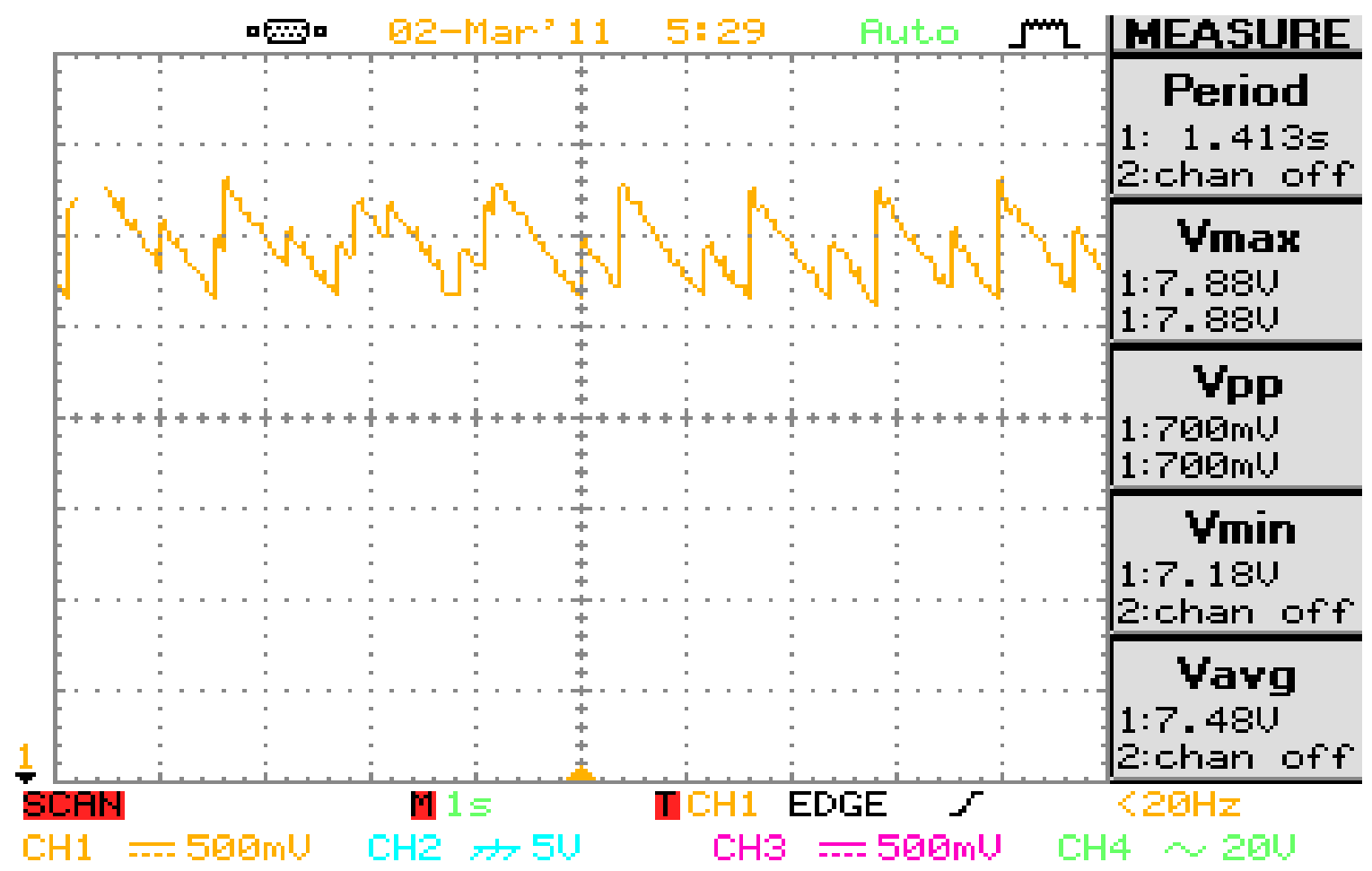

Figure 5-11: Measured Across Whole Stack. Inputs $[A, B, C, D, E]=[10,10,10,10,0]$ 


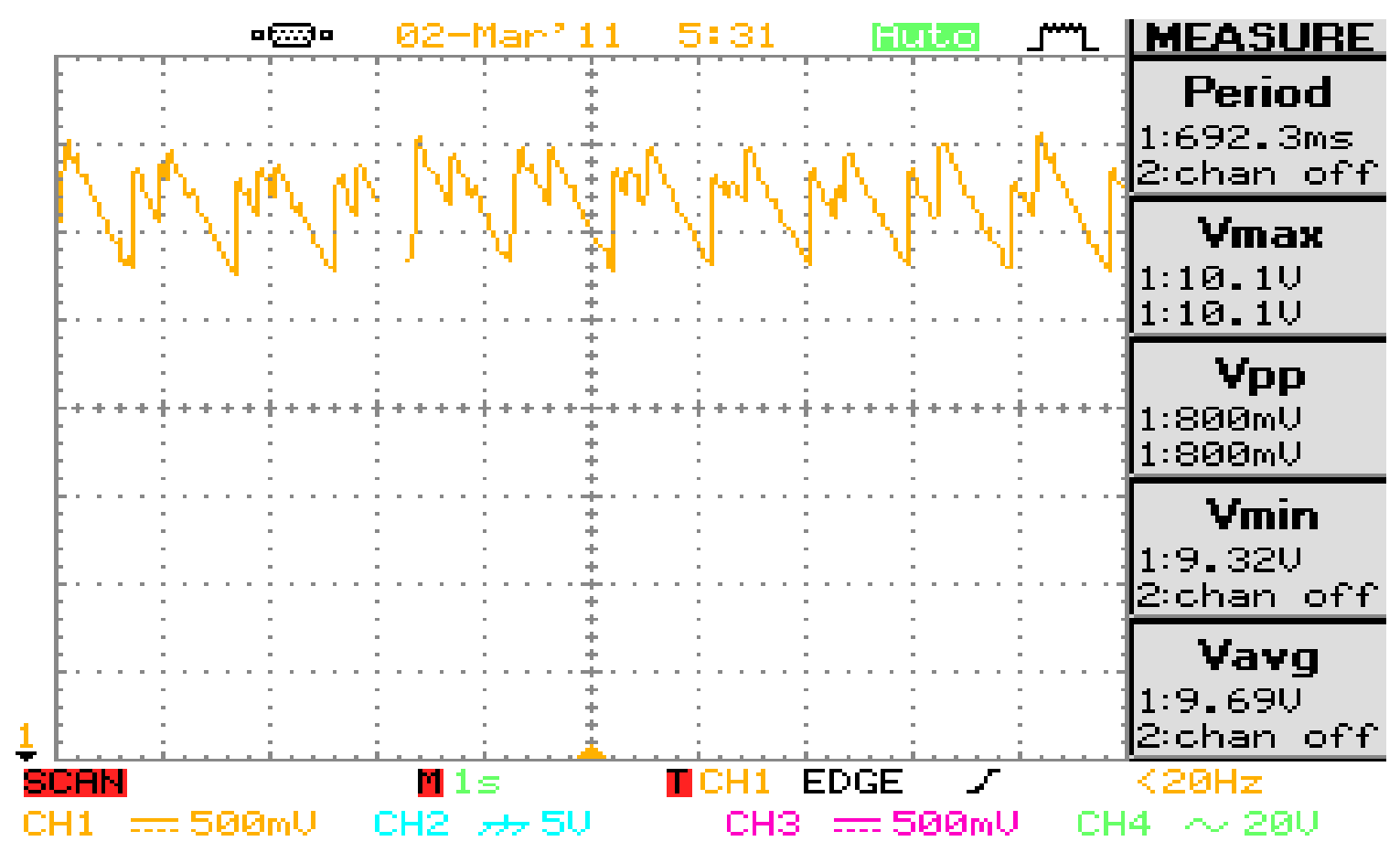

Figure 5-12: Measured Across Whole Stack. Inputs [A,B,C,D,E] $=[10,10,10,10,10]$

Next to test the capabilities of the system, voltages ranging from $6 \mathrm{~V}$ to $15 \mathrm{~V}$ were applied to the system at no load. For simplicity 3 voltage levels were supplied with all sources being the same for the initial no load test $(6 \mathrm{~V}, 10 \mathrm{~V}$, and $15 \mathrm{~V})$ as well as a single case where each input voltage is different from the others to illustrate working operation with different inputs. After the no load tests, several tests were run to see the performance of the converter for increasing loads. Loads of $400 \Omega, 200 \Omega, 120 \Omega, 100 \Omega$, and $1 \mathrm{M} \Omega$, Assuming a maximum load of 100mA these represent, approximately, 25\% load, 50\% load, 75\% load, $100 \%$ load, and light loads that may represent a system connected, but not fully utilizing the energy available.

A summary of results can be found in Table 5-3 with a listing of figures for the associated oscilloscope captured waveforms. Figure 5-13 and Figure 5-14 are provided as a visual indication of the converter's performance in terms of average output voltage and 
output ripple voltage each as a function of output current. A few general trends are noticeable with the data obtained. The two unsurprising trends are that a higher input voltage produces a slightly higher output voltage, and that higher load currents decrease output voltage. This is especially apparent with a load above $50 \mathrm{~mA}$ where the converter has problems properly regulating. While each converter is rated up to $100 \mathrm{~mA}$ output, it may be an issue with the selected components as they were initially chosen for loads under $10 \mathrm{~mA}$. The results that are perhaps a little less obvious are that higher input voltage produces higher output voltage ripple, and that higher loads tend to produce lower output voltage ripple.

As discussed above the output voltage is not likely to be exactly 9V due to the independent nature of the design and hysteretic control of each converter. Instead, a more statistically likely value is somewhere between $9 \mathrm{~V}$ and $10 \mathrm{~V}(5 \times 1.8$ and $5 \mathrm{x} 2)$.

Table 5-3: Summary of Results

\begin{tabular}{|c|c|c|c|c|c|c|c|c|}
\hline \multirow[b]{2}{*}{ Load Conditions } & \multicolumn{5}{|c|}{ Input Voltages } & \multirow[b]{2}{*}{ Average $\mathrm{V}_{\mathrm{o}}(\mathrm{V})$} & \multirow{2}{*}{$\begin{array}{c}\text { Voltage } \\
\text { Ripple (V) } \\
\end{array}$} & \multirow[b]{2}{*}{ Figure } \\
\hline & A & B & $\mathrm{C}$ & D & $\mathbf{E}$ & & & \\
\hline \multirow{4}{*}{$\begin{array}{c}\text { No Load (scope } \\
\text { only 10M) }\end{array}$} & 6 & 6 & 6 & 6 & 6 & 9.5 & 0.72 & Figure 5-15 \\
\hline & 10 & 10 & 10 & 10 & 10 & 9.8 & 1.1 & Figure 5-16 \\
\hline & 15 & 15 & 15 & 15 & 15 & 10.4 & 1.6 & Figure 5-17 \\
\hline & 5 & 7.5 & 10 & 12 & 15 & 9.8 & 1.3 & Figure 5-18 \\
\hline \multirow{2}{*}{$400 \mathrm{Ohm}$} & 6 & 6 & 6 & 6 & 6 & 9.37 & 0.9 & Figure 5-19 \\
\hline & 10 & 10 & 10 & 10 & 10 & 9.7 & 1 & Figure 5-20 \\
\hline \multirow{2}{*}{$200 \mathrm{Ohm}$} & 6 & 6 & 6 & 6 & 6 & 9.2 & 0.5 & Figure 5-21 \\
\hline & 10 & 10 & 10 & 10 & 10 & 9.6 & 1 & Figure 5-22 \\
\hline \multirow{2}{*}{120 Ohm } & 6 & 6 & 6 & 6 & 6 & 6.67 & 0.5 & Figure 5-23 \\
\hline & 10 & 10 & 10 & 10 & 10 & 6.87 & 0.8 & Figure 5-24 \\
\hline \multirow{2}{*}{$100 \mathrm{Ohm}$} & 6 & 6 & 6 & 6 & 6 & 6.5 & 0.5 & Figure 5-25 \\
\hline & 10 & 10 & 10 & 10 & 10 & 6.9 & 0.8 & Figure 5-26 \\
\hline \multirow{2}{*}{$1 \mathrm{M} \mathrm{ohm}$} & 6 & 6 & 6 & 6 & 6 & 9.5 & 0.74 & Figure 5-27 \\
\hline & 10 & 10 & 10 & 10 & 10 & 9.7 & 1.3 & Figure 5-28 \\
\hline
\end{tabular}


A note about Figure 5-16 is in order. Note that on the left side the waveform has a very small ripple with many sawtooth forms intermixed. This is in contrast to the right side of the waveform where the individual outputs seem to coordinate and give much larger ripple and a more characteristic waveform. This is due to the independent nature of the design. Each converter accumulates and conditions energy without regard to the other converters. While additional filtering may reduce this issue, it may still pose some problems if the output voltage needs to fit within tight specifications. For the loaded cases of Figure 5-19 through Figure 5-28 it is readily seen that the output waveforms no longer appear to be the same sawtooth like waveforms as before. This is due to the more rapid drain of energy. The previous waveforms all had a load current of less than 1mA, whereas the following waveforms have much higher currents comparatively. The following waveforms are simply more chaotic versions of the preceding ones because the energy drains much faster and therefore each converter has a jump in the output voltage at faster intervals. 


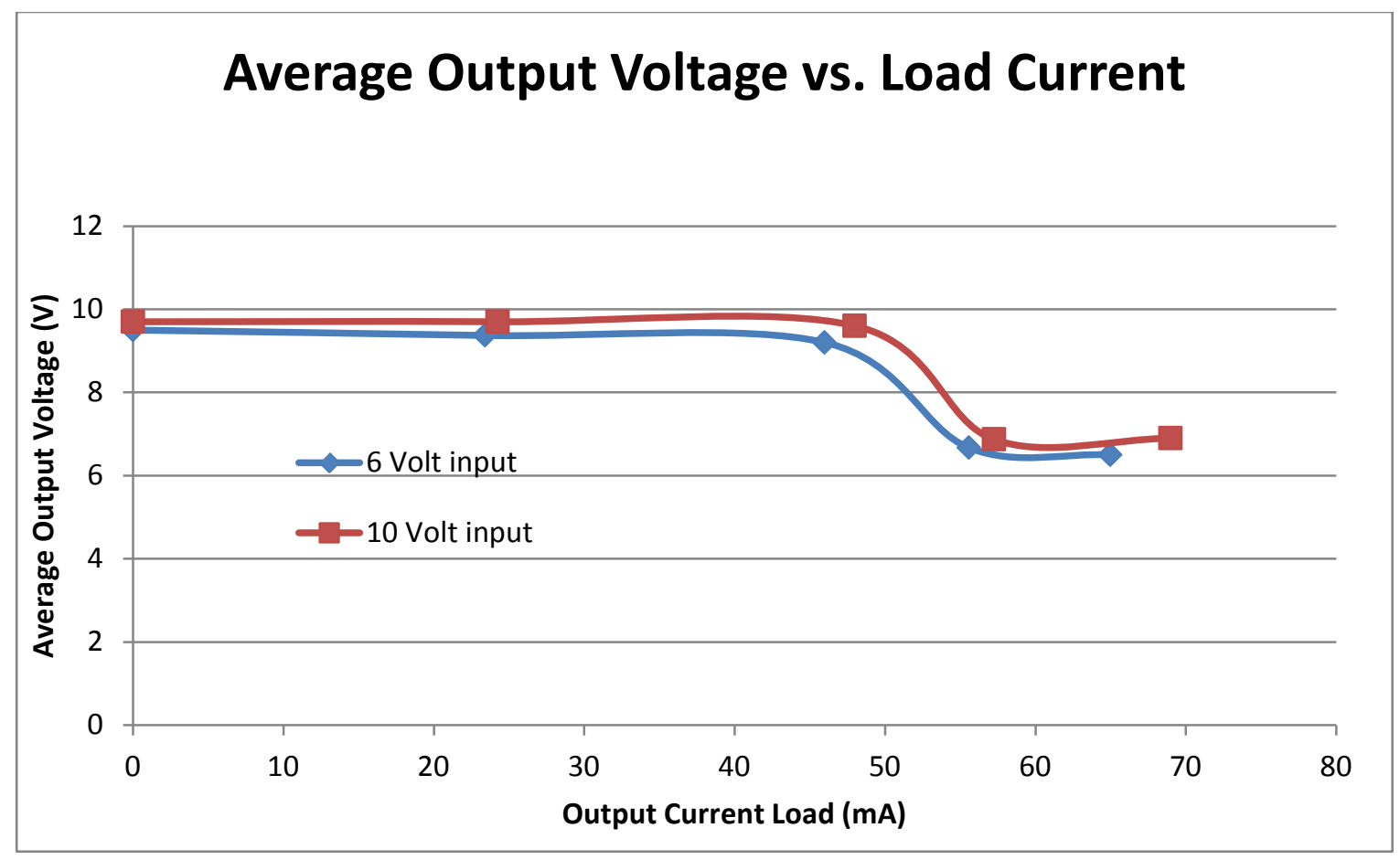

Figure 5-13: Load Regulation Profile

\section{Output Voltage Ripple as a Function of Output Current}

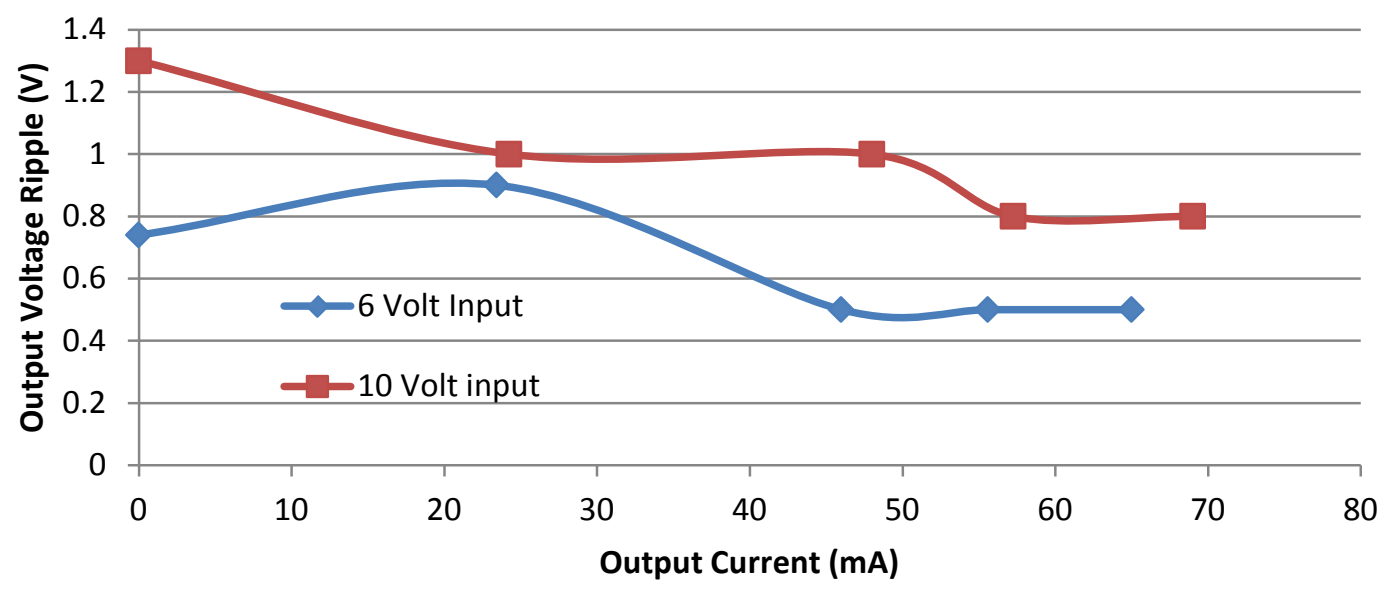

Figure 5-14: output voltage ripple profile as a function of output current 


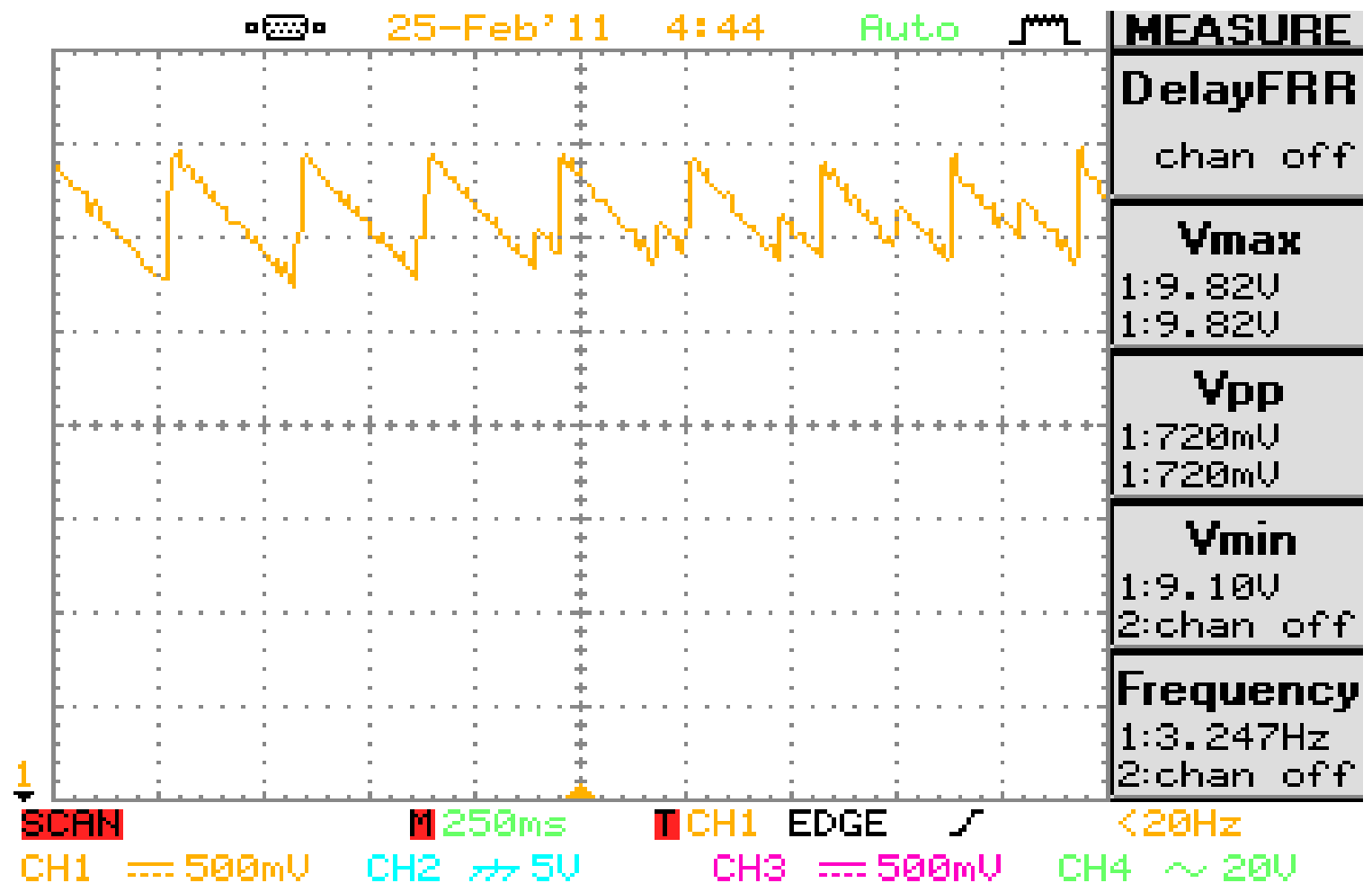

Figure 5-15: No Load, inputs $[A, B, C, D, E]=[6,6,6,6,6]$, Vo $=9.5 \mathrm{~V}$

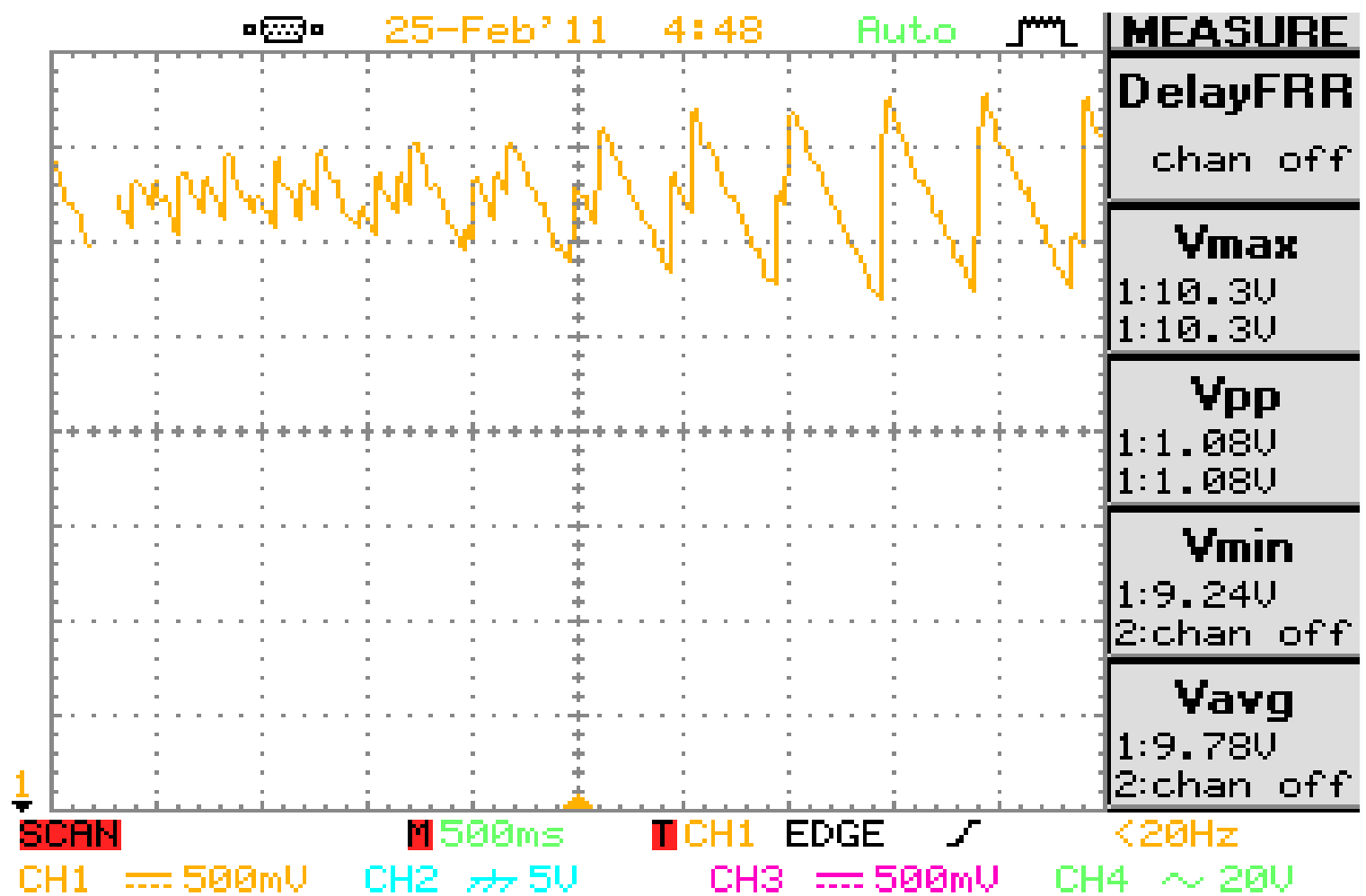

Figure 5-16: No Load, inputs $[A, B, C, D, E]=[10,10,10,10,10]$, Vo $=9.78 \mathrm{~V}$ 

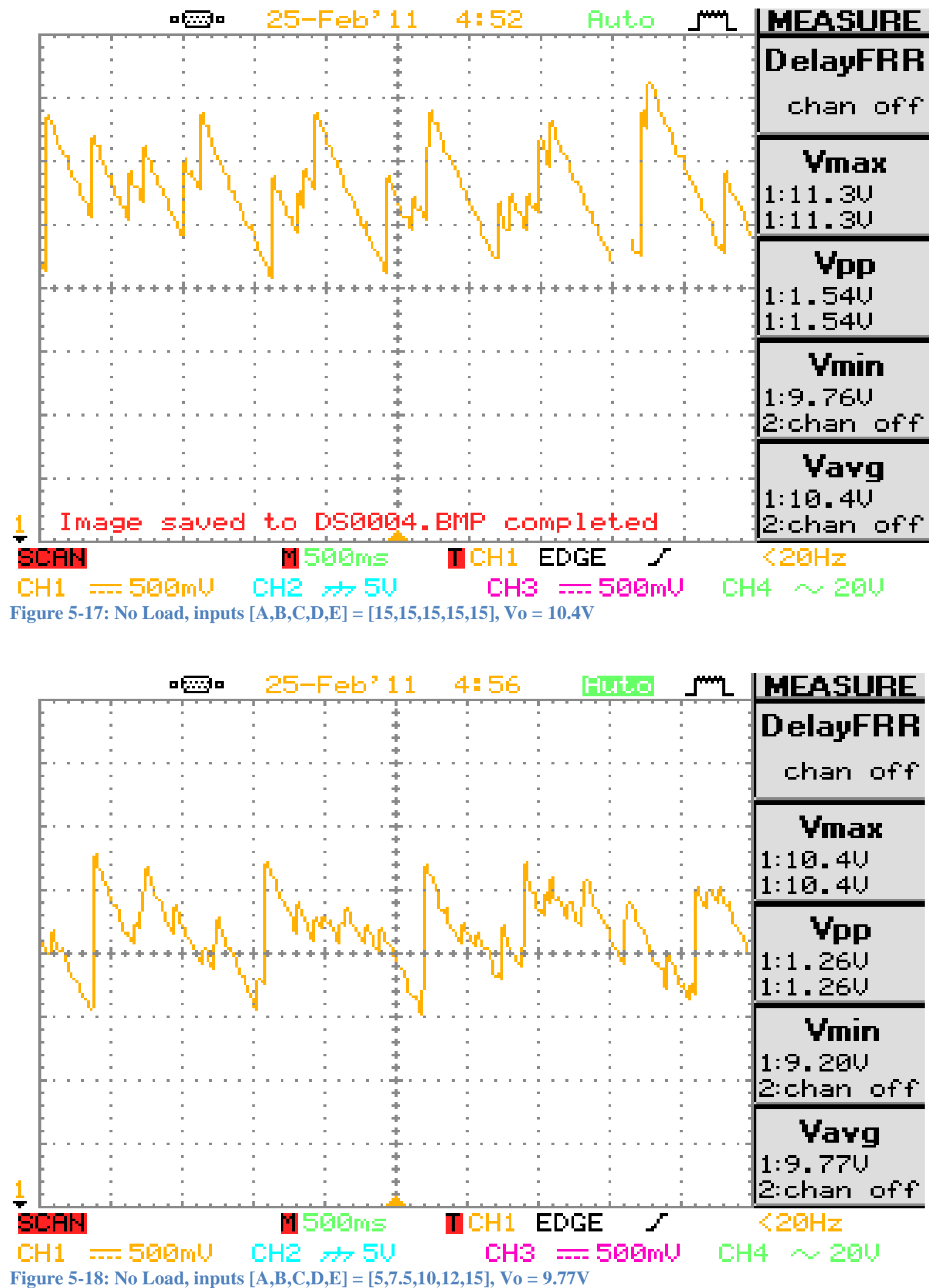


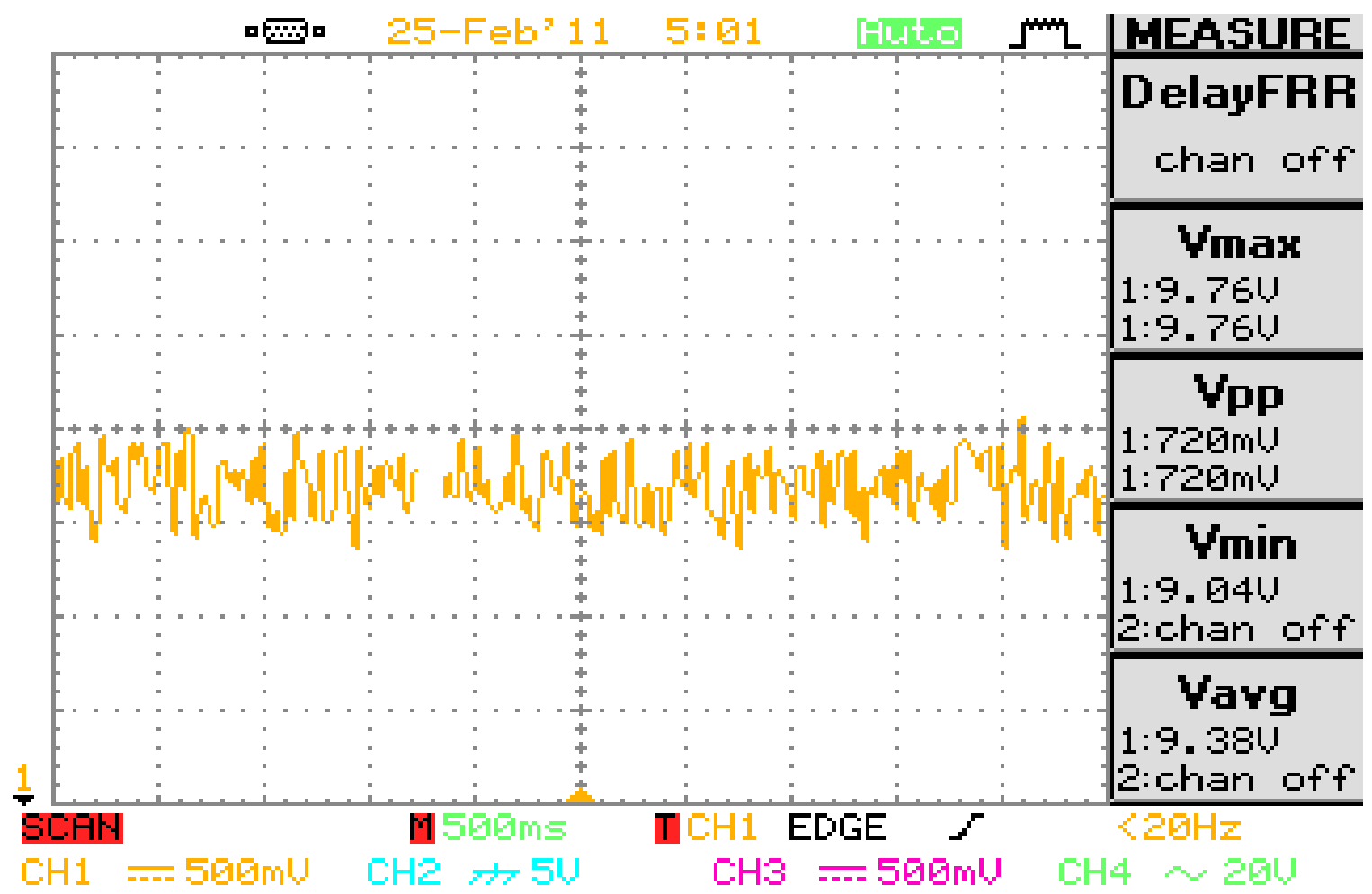

Figure 5-19: $\mathrm{Load}=400 \mathrm{ohm}$, inputs $[\mathrm{A}, \mathrm{B}, \mathrm{C}, \mathrm{D}, \mathrm{E}]=[6,6,6,6,6], \mathrm{Vo}=9.4 \mathrm{~V}$

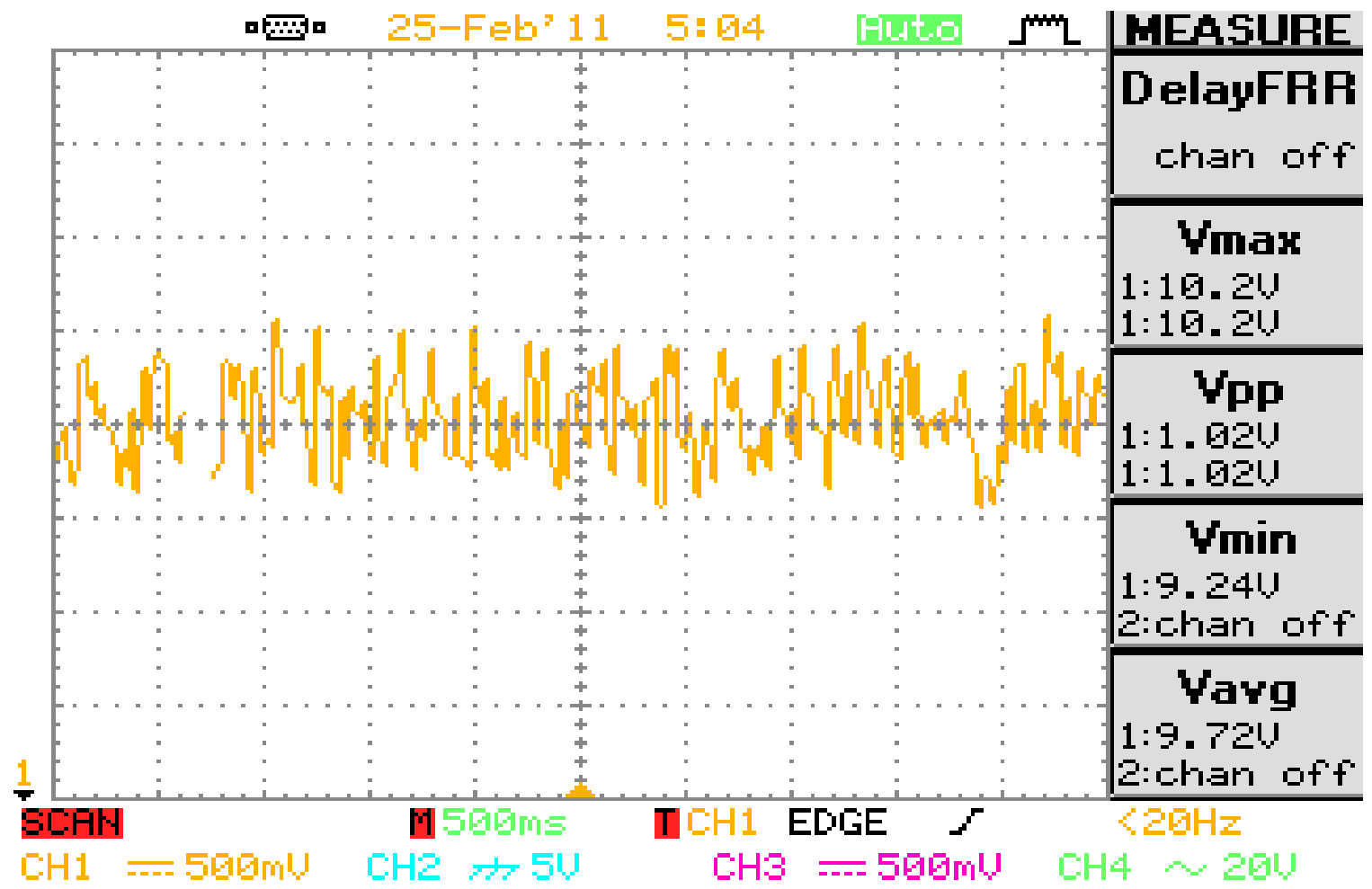

Figure 5-20: Load $=400 \mathrm{ohm}$, inputs $[A, B, C, D, E]=[10,10,10,10,10]$, Vo $=9.7 \mathrm{~V}$ 


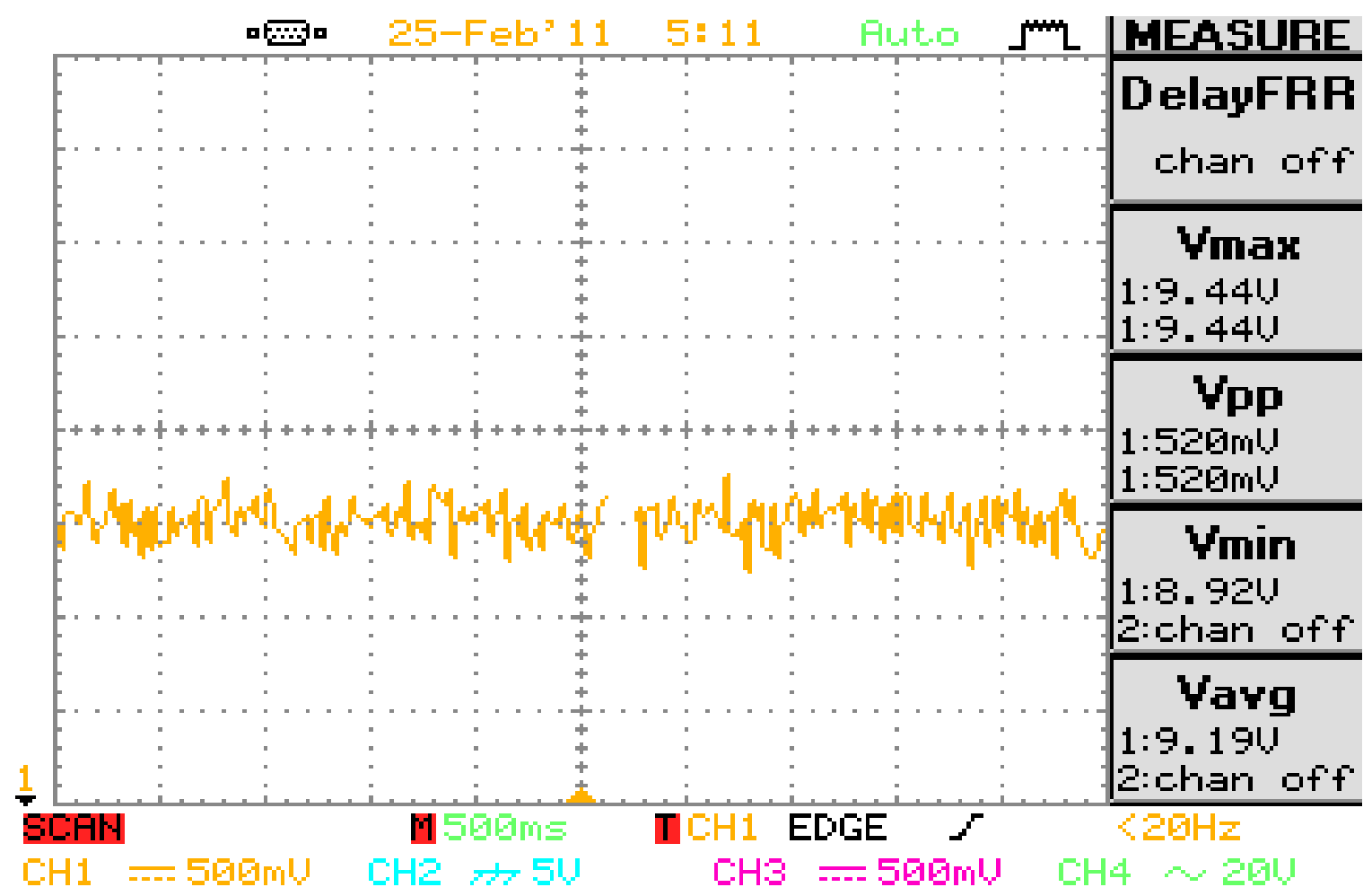

Figure 5-21: Load $=200 \mathrm{ohm}$, inputs $[\mathrm{A}, \mathrm{B}, \mathrm{C}, \mathrm{D}, \mathrm{E}]=[6,6,6,6,6], \mathrm{Vo}=9.2 \mathrm{~V}$

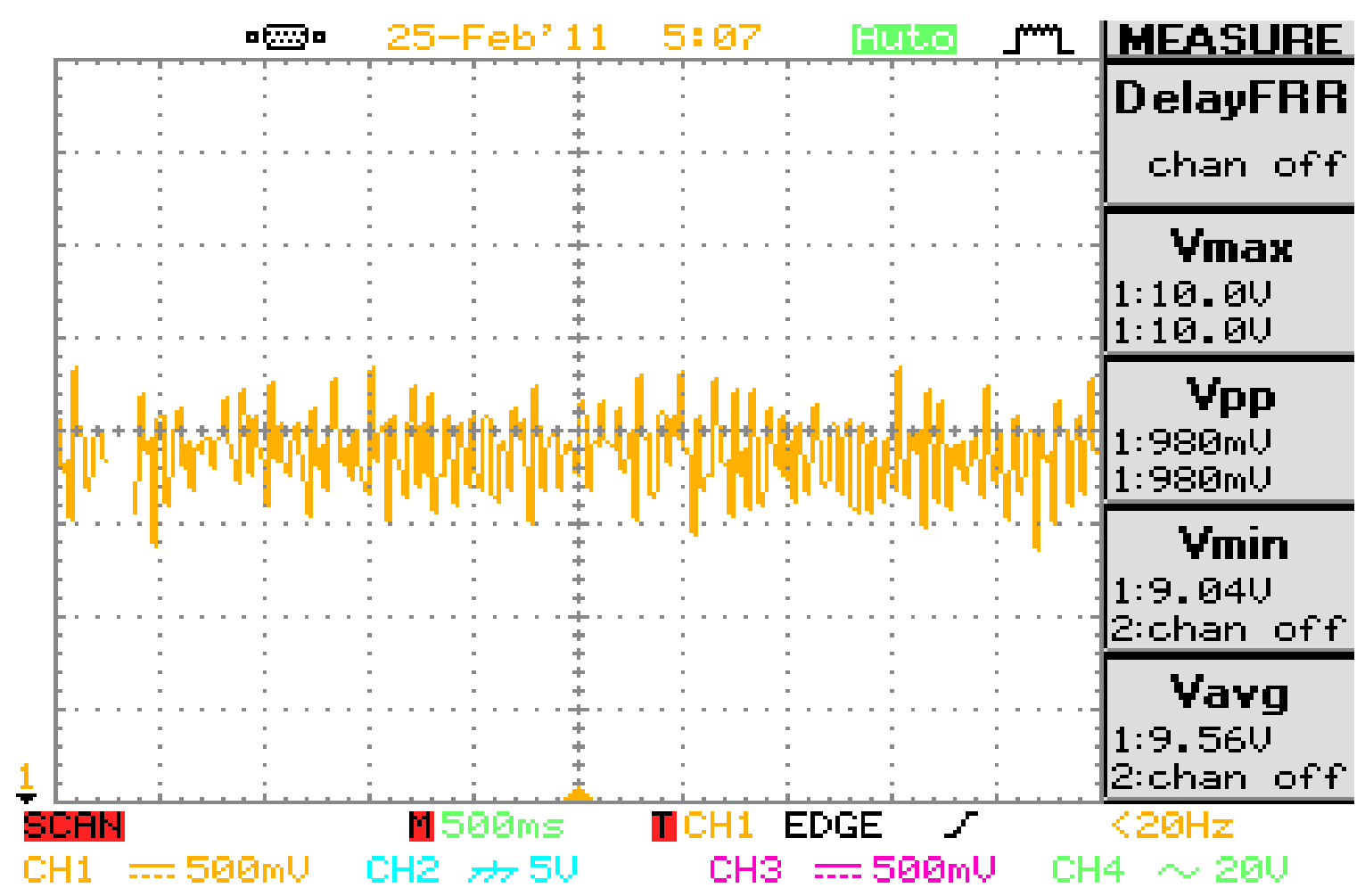

Figure 5-22: Load $=200 \mathrm{ohm}$, inputs $[\mathrm{A}, \mathrm{B}, \mathrm{C}, \mathrm{D}, \mathrm{E}]=[10,10,10,10,10], \mathrm{Vo}=9.56$ 


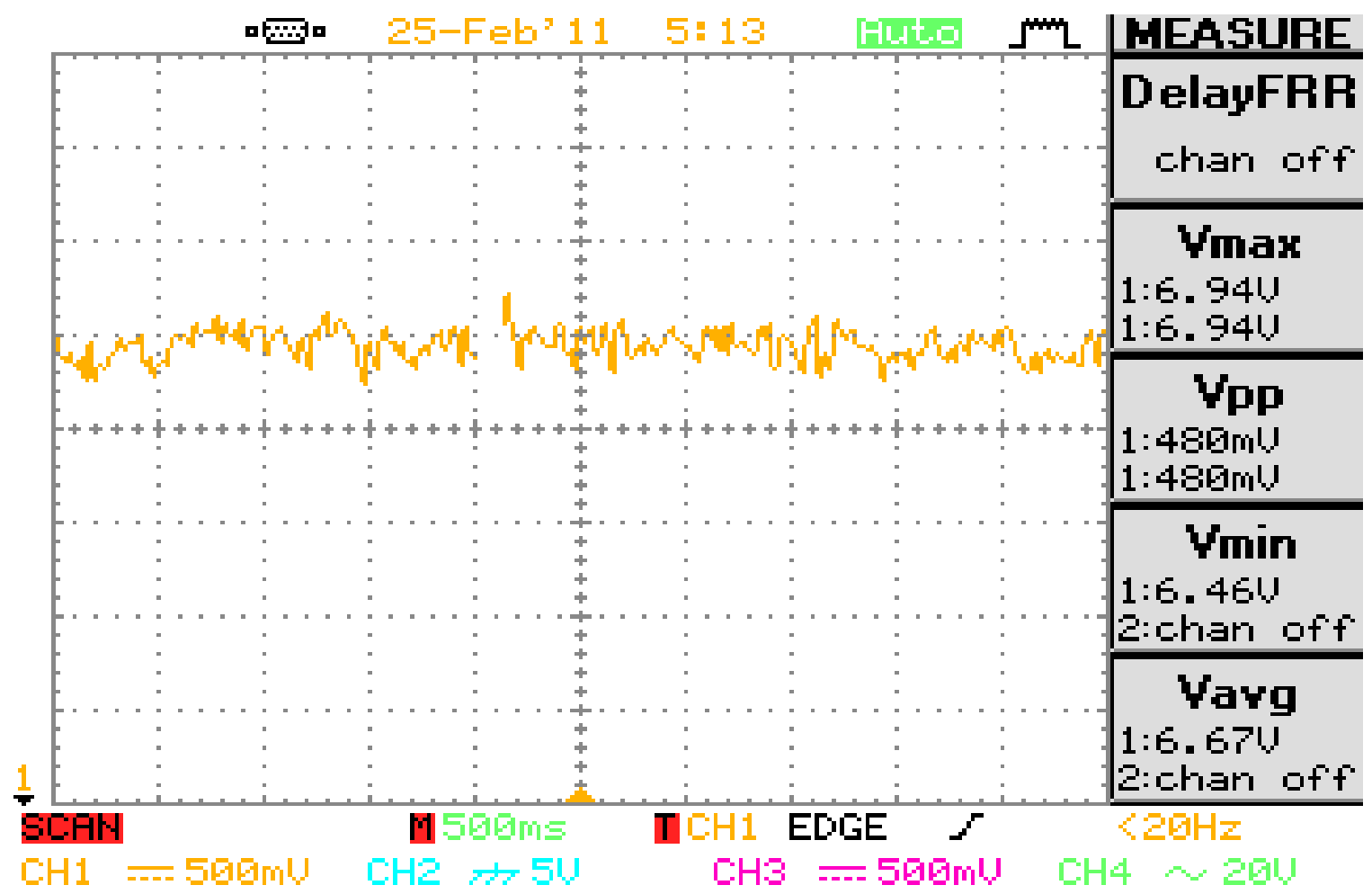

Figure 5-23: Load $=120 \mathrm{ohm}$, inputs $[\mathrm{A}, \mathrm{B}, \mathrm{C}, \mathrm{D}, \mathrm{E}]=[6,6,6,6,6], \mathrm{Vo}=6.67 \mathrm{~V}$

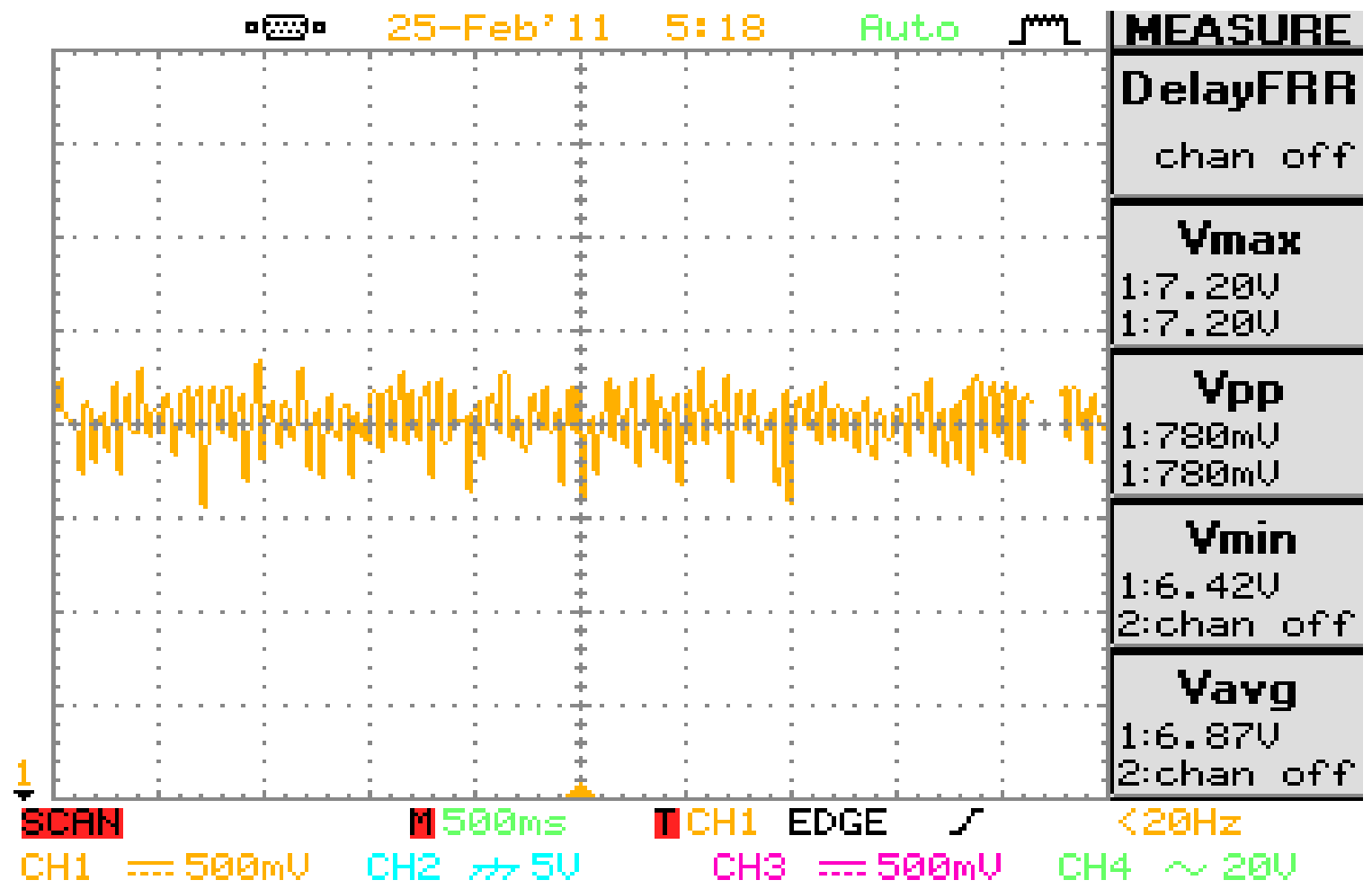

Figure 5-24: Load $=120 \mathrm{ohm}$, inputs $[A, B, C, D, E]=[10,10,10,10,10]$, Vo $=6.87 \mathrm{~V}$ 


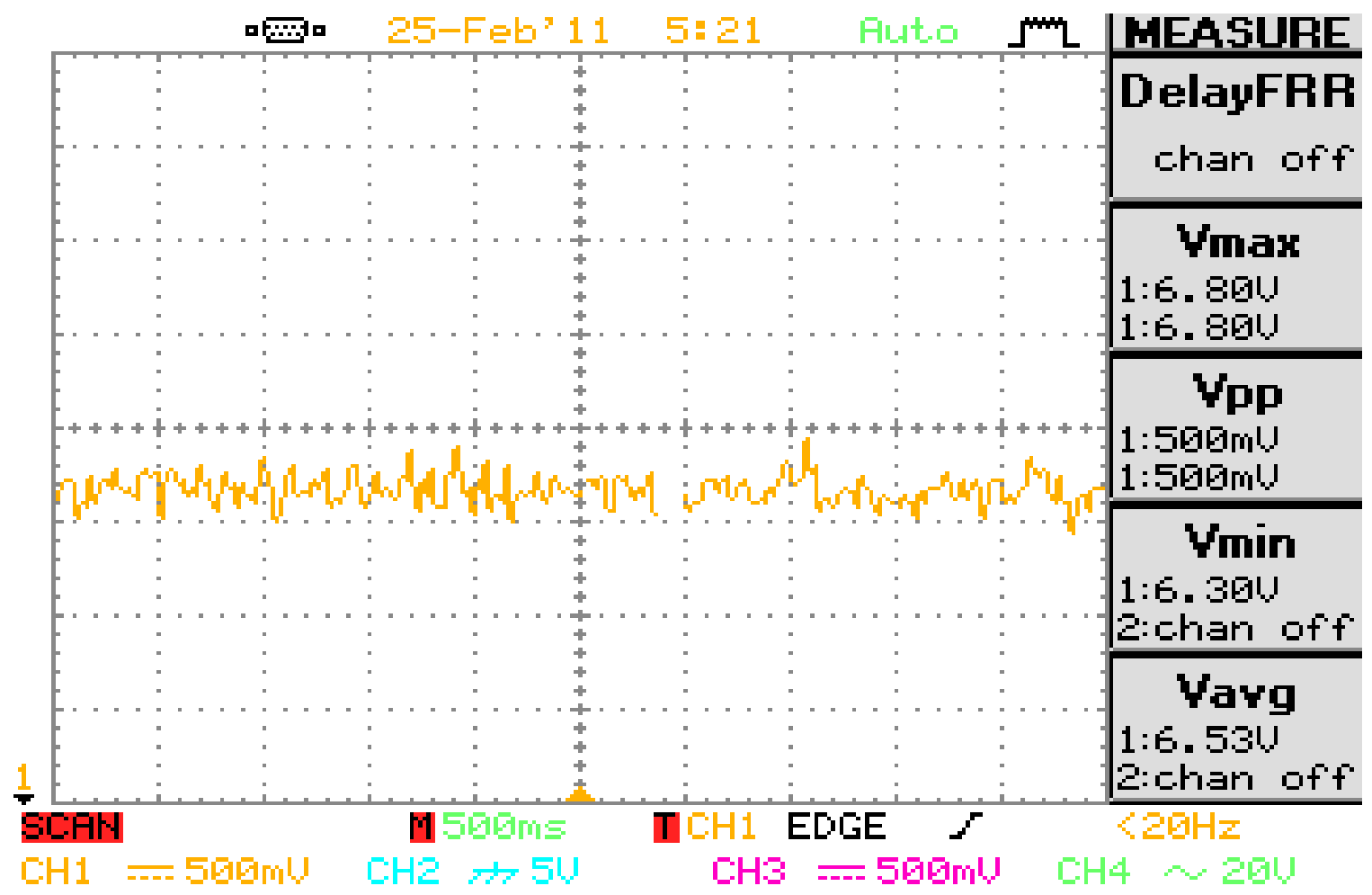

Figure 5-25: Load $=100 \mathrm{ohm}$, inputs $[\mathrm{A}, \mathrm{B}, \mathrm{C}, \mathrm{D}, \mathrm{E}]=[6,6,6,6,6], \mathrm{Vo}=6.53 \mathrm{~V}$

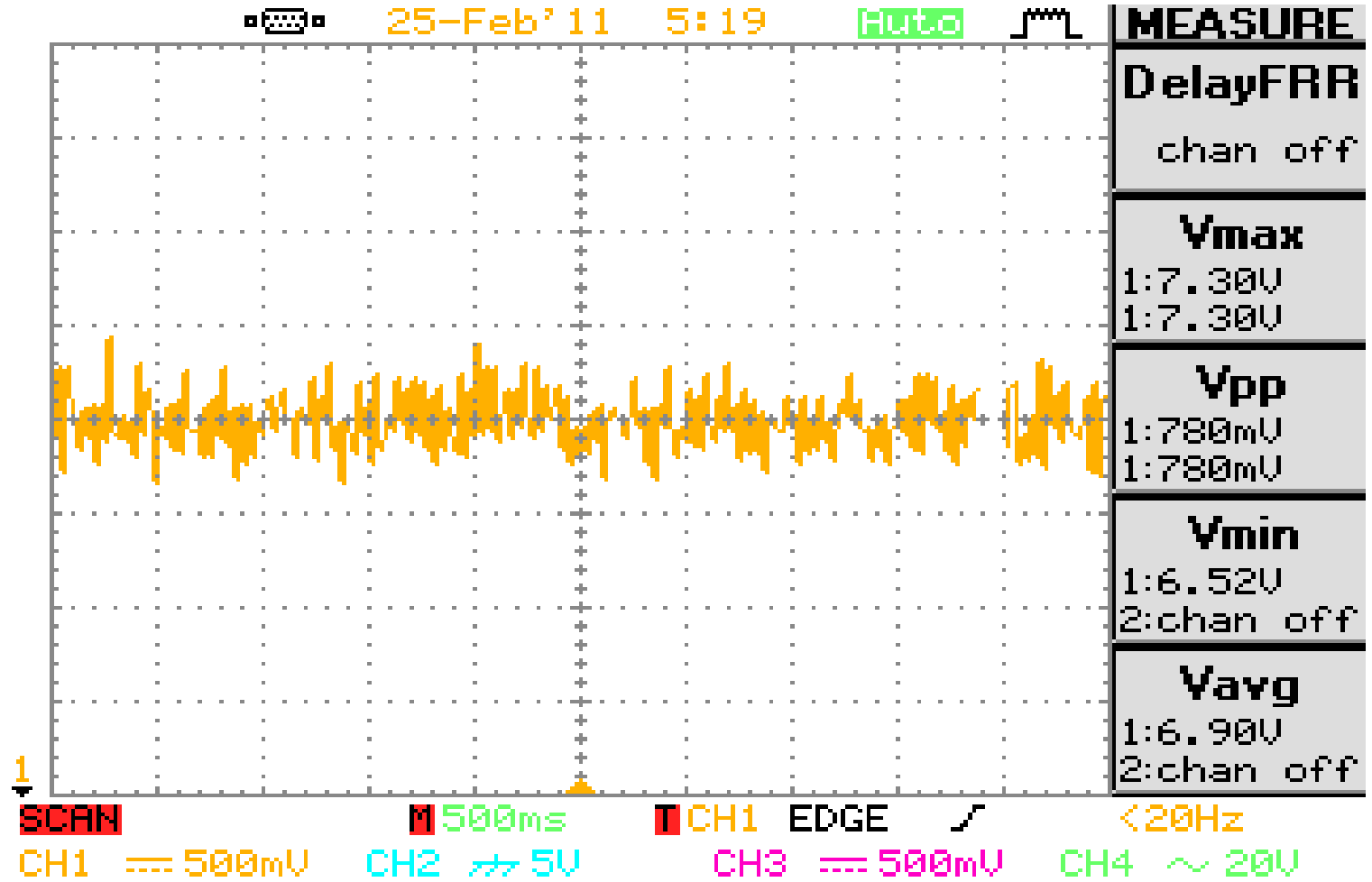

Figure 5-26: Load $=100 \mathrm{ohm}$, inputs $[\mathrm{A}, \mathrm{B}, \mathrm{C}, \mathrm{D}, \mathrm{E}]=[10,10,10,10,10], \mathrm{Vo}=6.9 \mathrm{~V}$ 


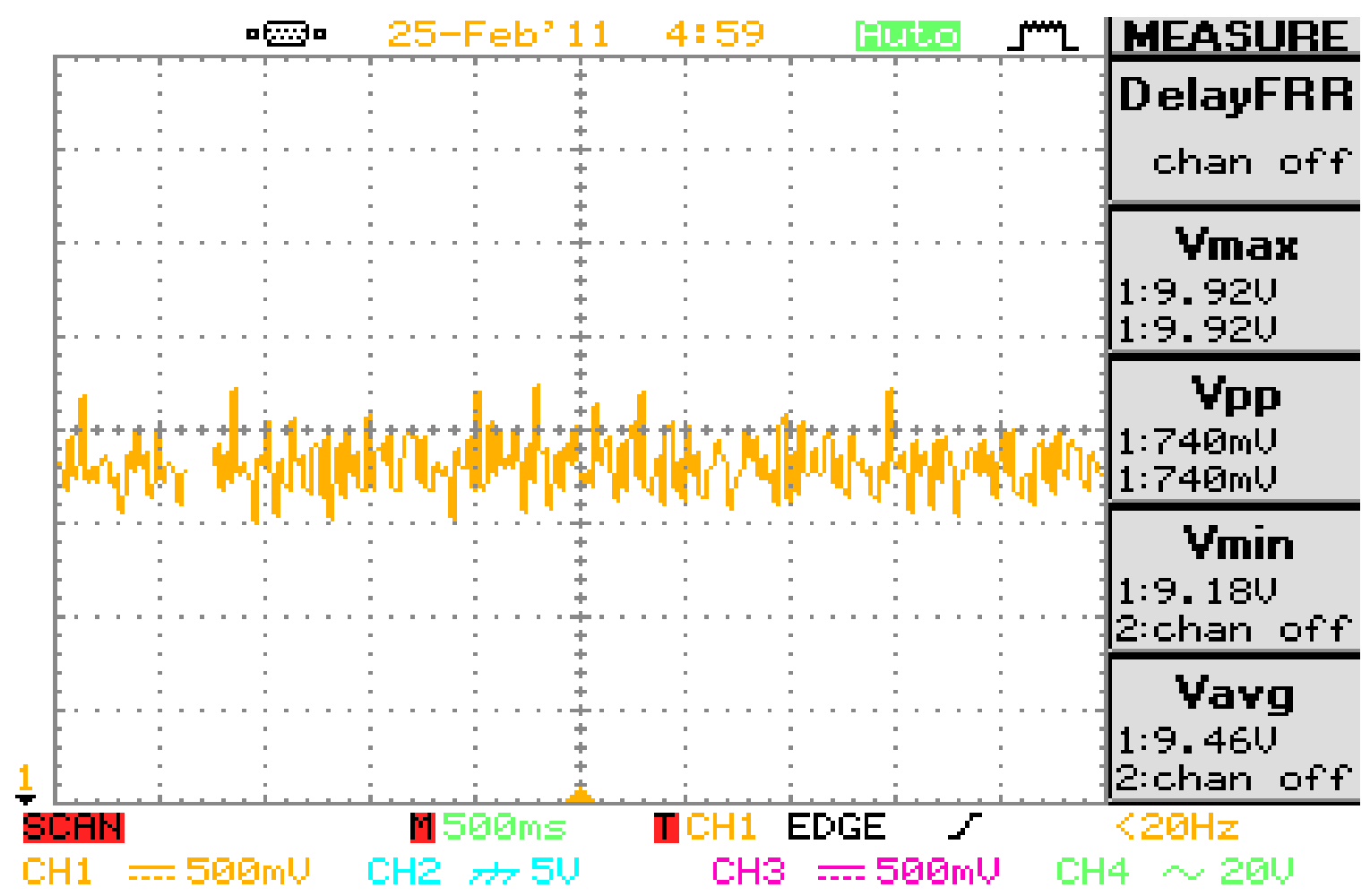

Figure 5-27: Load $=1 \mathrm{Mohm}$, inputs $[\mathrm{A}, \mathrm{B}, \mathrm{C}, \mathrm{D}, \mathrm{E}]=[6,6,6,6,6], \mathrm{Vo}=9.46 \mathrm{~V}$

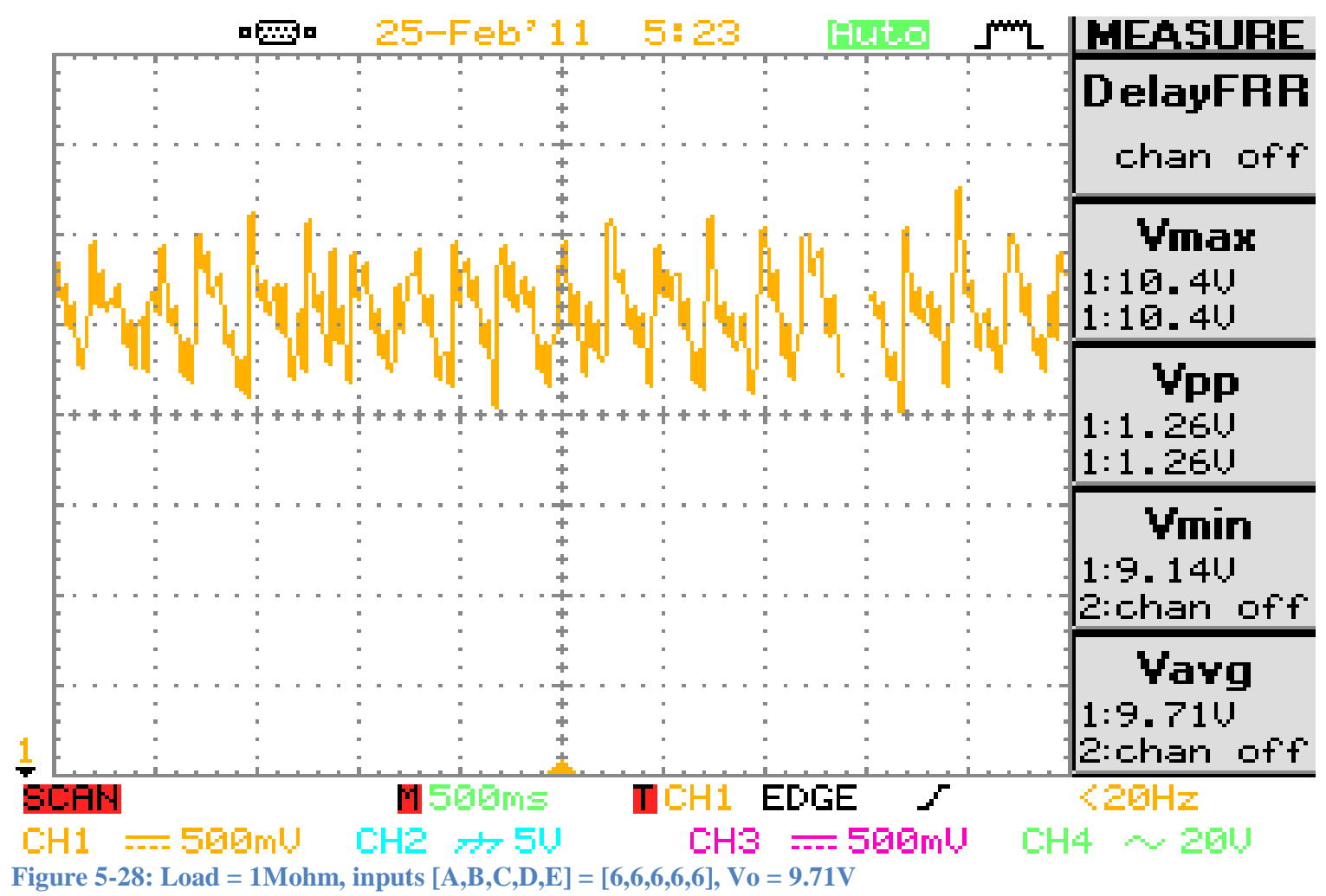




\subsection{Piezoelectric Energy Harvesting Test and Results}

This portion of the experiment was performed using the same board layout as before with the capacitor values discussed in Chapter 4 (Cin of $0.1 \mu \mathrm{F}$ and Cout of $0.01 \mu \mathrm{F})$. The piezoelectric strips used were model LDT0 manufactured by Measurement Specialties. Additional "sails" were added to enhance the effective area of the strip to magnify the deflections of vibration for any given wind speed. Figure 5-29 is a picture of a piezoelectric strip with added "sail". The "sail" is simply a piece of plastic cut out from an overhead projector slide. Bare 22 gauge wire is soldered onto the leads so that this device may be inserted into readily available sockets to allow the device to be swapped out for repair, or for other modified sails if desired.

Five of these constructed energy harvesting inputs are then inserted into a perforated proto-board as shown in Figure 5-30. This completed assembly is then put inside the wind tunnel for testing as shown in Figure 5-31. The wind tunnel used for this experiment is manufactured by TecQuipment, model AF10 “Modular Flow Bench". 


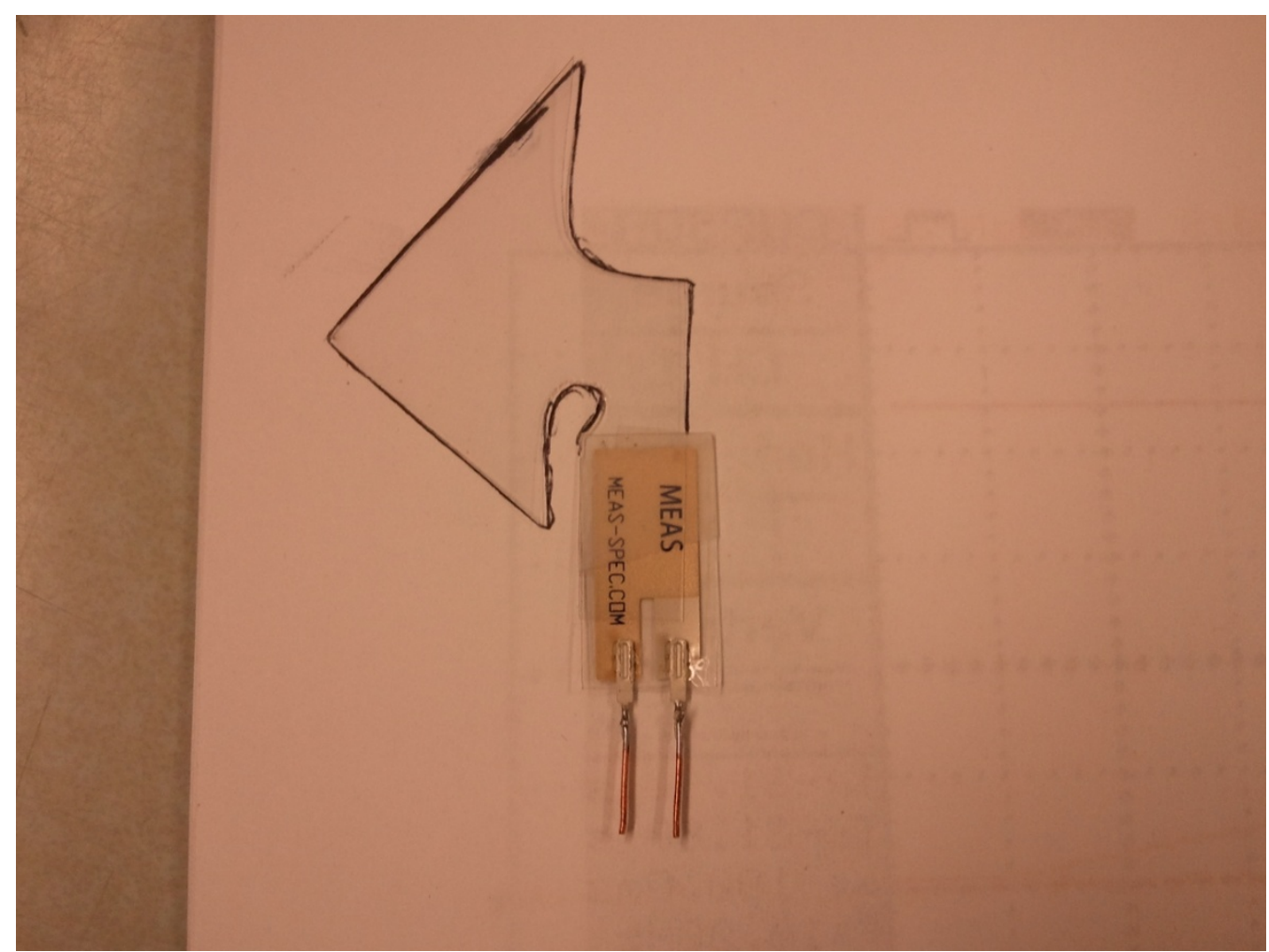

Figure 5-29: Piezoelectric Strip with Added "sail"

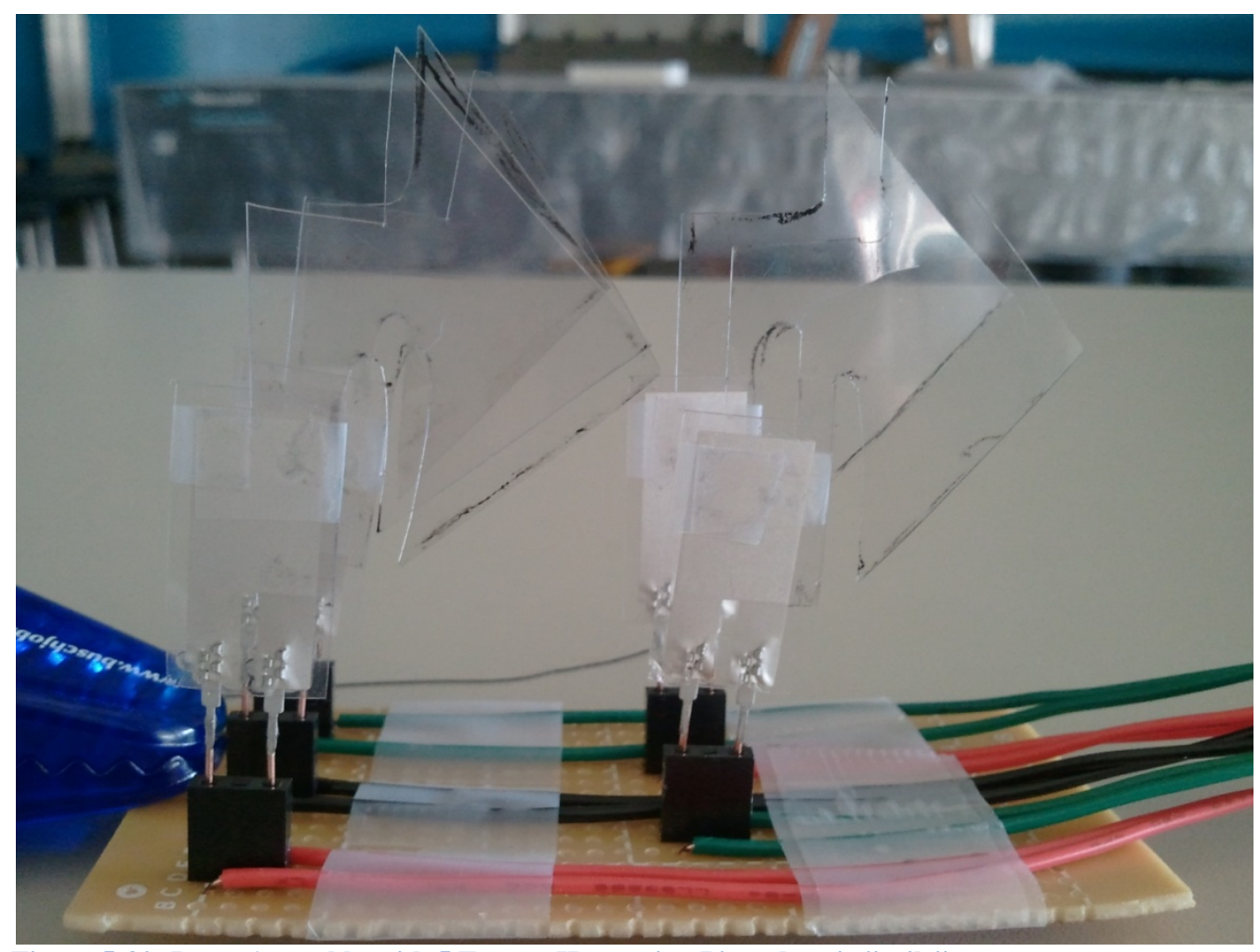

Figure 5-30: Input Assembly with 5 Energy Harvesting Piezoelectric "sails" 


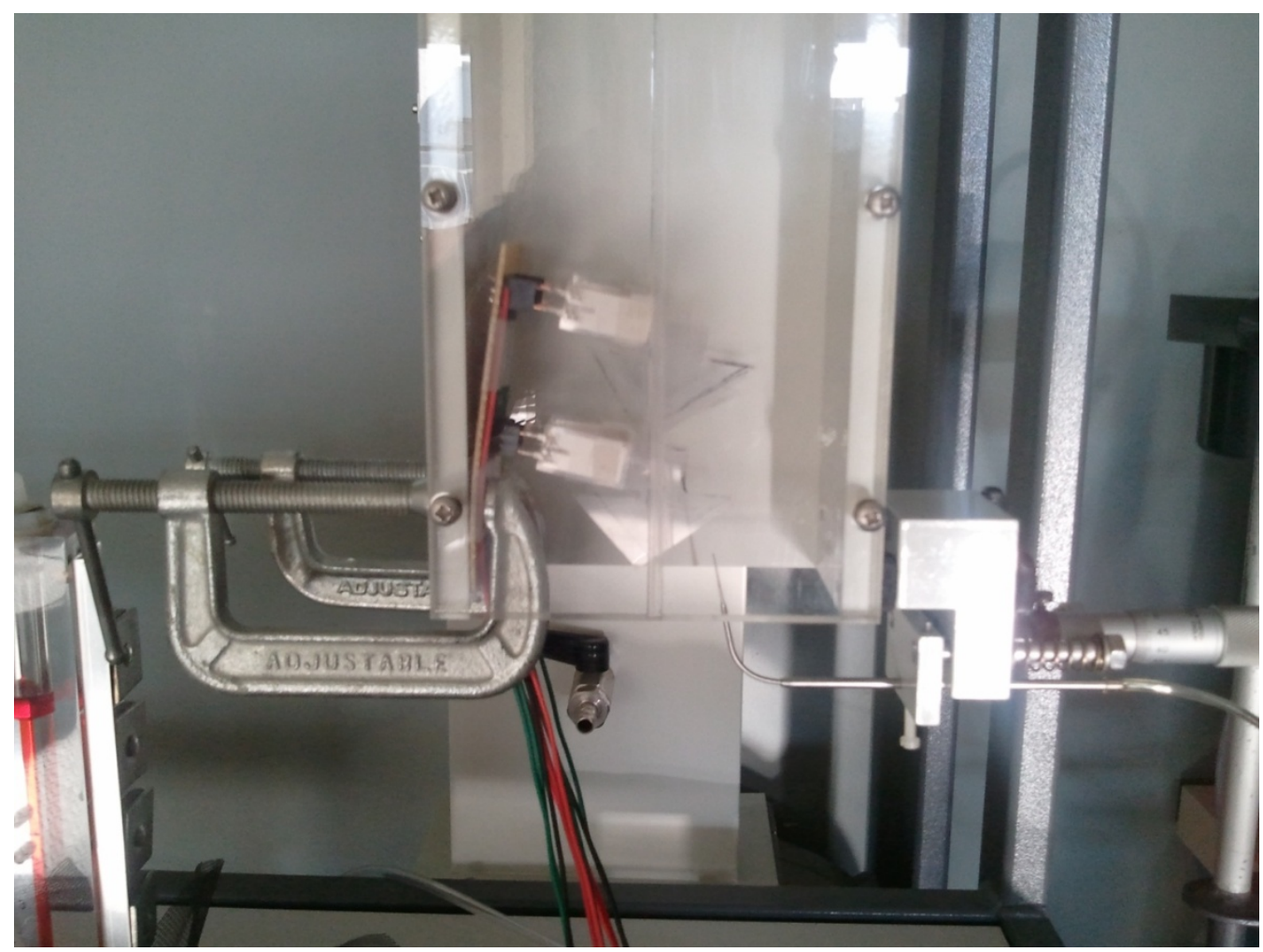

Figure 5-31: Assembly inside of wind tunnel

Initial tests of direct piezoelectric output were gathered to get a better idea of what voltage and energy might be available to the input of the energy harvesting system. Table 5-4 presents the results of these initial tests with Figure 5-32 providing a graphical representation of the results as well.

Table 5-4: Initial results for raw output of piezoelectric strips in wind tunnel.

\begin{tabular}{|c|c|c|c|c|}
\hline \multicolumn{3}{|c|}{ Wind Speed } & \multicolumn{2}{c|}{ Output Voltage } \\
\hline $\mathrm{ft} / \mathrm{min}$ & $\mathrm{m} / \mathrm{s}$ & $\mathrm{mph}$ & $\mathrm{Vmax}(\mathrm{V})$ & $\mathrm{Vpp}(\mathrm{V})$ \\
\hline 500 & 2.54 & 5.68 & 0.056 & 0.108 \\
\hline 1000 & 5.08 & 11.36 & 0.448 & 0.832 \\
\hline 1500 & 7.62 & 17.05 & 1.1 & 2.04 \\
\hline 2000 & 10.16 & 22.73 & 9.8 & 20.2 \\
\hline 2500 & 12.70 & 28.41 & 16.6 & 29.6 \\
\hline 3000 & 15.24 & 34.09 & 20 & 39.2 \\
\hline 3500 & 17.78 & 39.77 & 19.6 & 41.6 \\
\hline
\end{tabular}




\section{Output Voltage of a Piezoelectric Strip as a Function of Wind Speed}

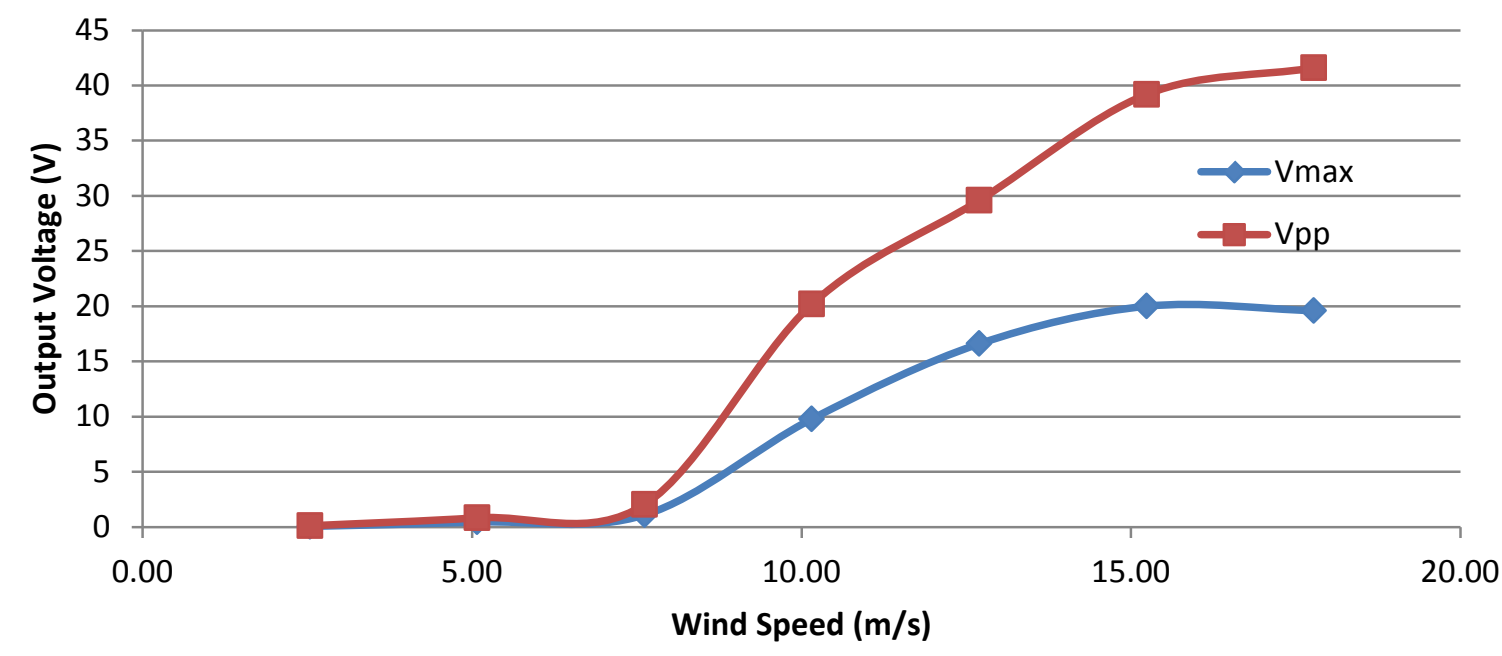

Figure 5-32: Output voltages of piezoelectric strips with varying wind speeds.

Remembering that the LTC3588-1 has a turn on threshold input voltage of around 4 volts it is easy to see that the system will yield no measurable results below $7 \mathrm{~m} / \mathrm{s}$ of wind speed input. This already precludes the desired wide input range. It may be possible to have some results at these lower wind speeds for a modified "sail” shape, perhaps much larger. This will not be tested here as a larger sail would push the size limitations of the available wind tunnel. Also, larger sails might perform better at lower wind speeds but may suffer greatly at higher wind speeds. Based on a maximum output voltage of $20 \mathrm{~V}_{\mathrm{pp}}$ the largest power yield we could hope for would be about $400 \mu \mathrm{W}$ (as viewed on a $10 \mathrm{M} \Omega$ Scope probe). This has already been tested by [25]. The real question is how much of this energy can we make actual use of once we have stored and conditioned it to a usable source? The next section will show the results of the tests performed. 
Figure 5-33 Shows the output of the system with all 5 inputs being utilized with an input wind speed of $3100 \mathrm{ft} / \mathrm{min}(15.75 \mathrm{~m} / \mathrm{s})$. The initial output desired was a periodic near-squarewave with an amplitude of about 9, instead the output is more akin to a series of voltage spikes with decaying voltage. While the waveforms are not as expected, this does not mean that the system is not performing as designed. Section 5.3 shows that the system works as intended, and in fact we see that in Figure 5-33 on the left side the first pulse actually has an immediate second pulse whose voltage adds on the already decaying first pulse. The problem lies in the variability and unsynchronized nature of the 5 independent inputs. For example, if Stage B has accumulated the required voltage at its input, the converter will transfer this energy to the output where it is quickly discharged through the scope probe due to the output capacitor's very low capacitance $(0.01 \mu \mathrm{F})$ and inability to sustain voltage even with a $10 \mathrm{M} \Omega$ load. By the time Stage D has gathered up its required voltage level, 1 or 2 seconds later, the energy at the output of Stage B has already been delivered to the load. While this was not the original intent of the design, it does not disprove its functionality as it still allows multiple inputs to supply a single load. Issues may arise, however, as the load may require a more fixed voltage. While this initial result shows many independent pulses, there is no way to guarantee that the voltage pulses will not occur at the same time thus producing a higher output voltage than desired in some cases. Additional conditioning may be needed for more sensitive loads. 


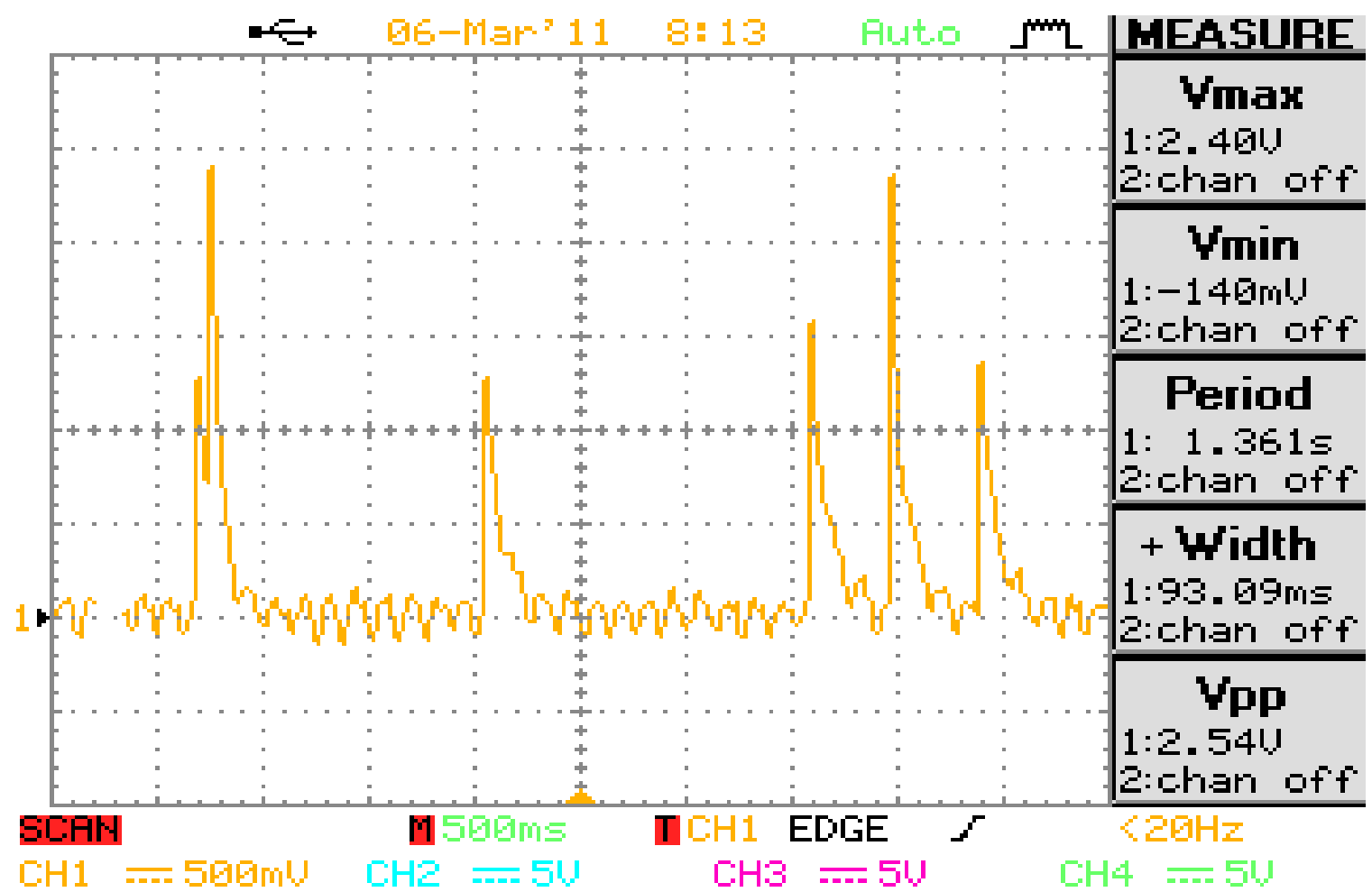

Figure 5-33: Output of system, wind speed $=3100 \mathrm{ft} / \mathrm{min}$

As it was the original intent of this thesis to measure the output power based on input wind speeds, a sample calculation will be provided to demonstrate the possibility of using this system.

Figure 5-34 shows two pulses taken from a single stage output of a single piezo input at a wind speed of $2100 \mathrm{ft} / \mathrm{min}(10.67 \mathrm{~m} / \mathrm{s})$. This provides us with a period of 12.2 seconds with which we may calculate the average power output. 


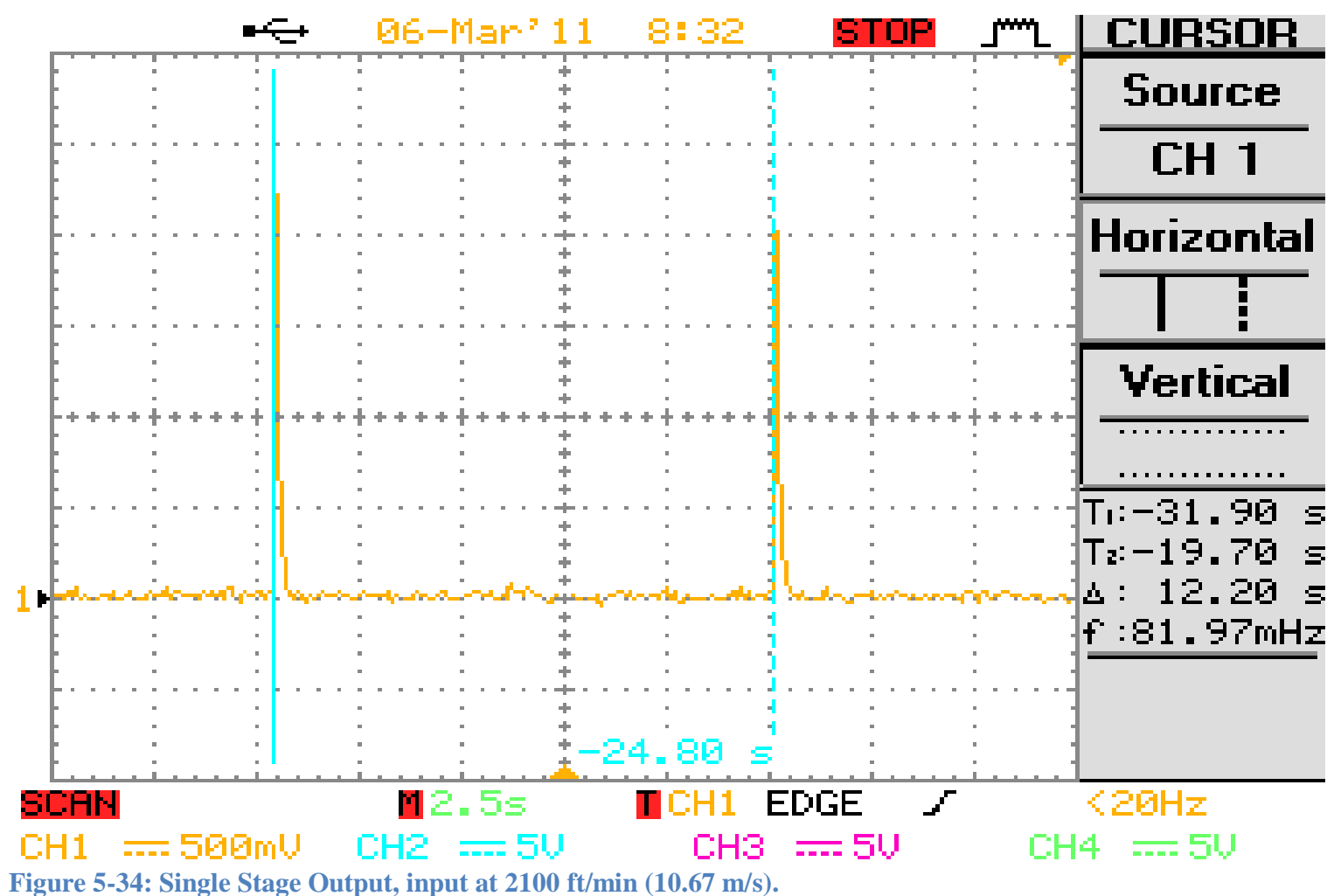

Using Equation 5-1 we can calculate the RMS voltage which can then be used to calculate the average power delivered to the $10 \mathrm{M} \Omega$ load (the oscilloscope).

Equation 5-1

$$
R M S=\sqrt{\sum_{n=1} \frac{1}{3}\left[V_{x n}^{2}+V_{x(n+1)}^{2}+\left(V_{x n} \times V_{x(n+1)}\right)\right] \times\left(\frac{t_{n}-t_{n+1}}{T}\right)}
$$

To utilize this equation we need a better view of the waveform (which is assumed to be approximately the same for each pulse). 


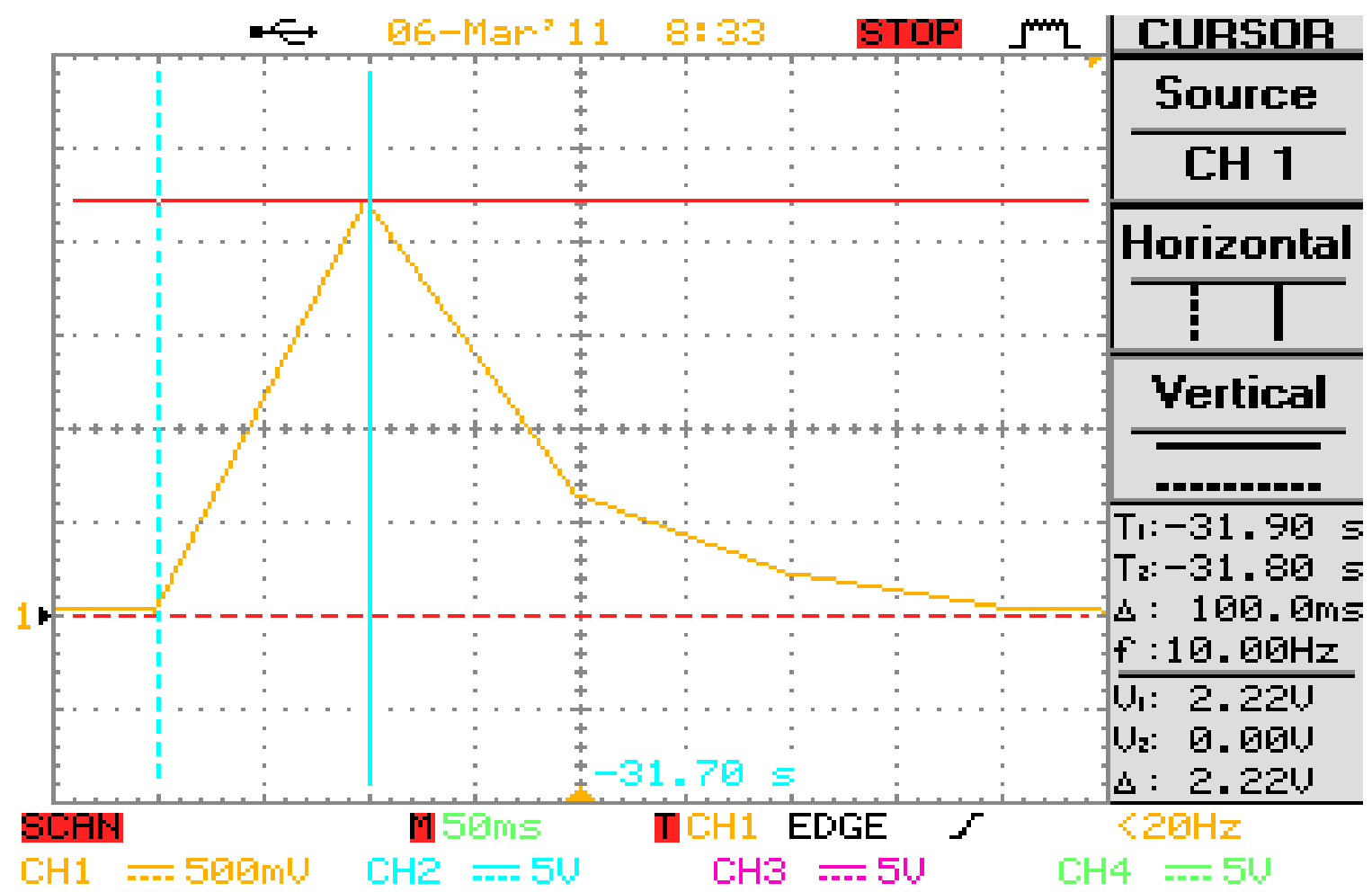

Figure 5-35: close up view of a typical output pulse

Using Figure 5-35 we can find several points with which we can then calculate the RMS voltage. Table 5-5 provides data points which can be used in conjunction with Equation 5-1 to obtain the RMS voltage.

Table 5-5: Discrete points of the piecewise voltage output

\begin{tabular}{|c|c|c|}
\hline $\mathrm{n}$ & $\mathrm{V}$ & $\mathrm{t}$ \\
\hline 1 & 0 & 0 \\
\hline 2 & 2.22 & 0.1 \\
\hline 3 & 0.62 & 0.2 \\
\hline 4 & 0.22 & 0.3 \\
\hline 5 & 0 & 0.4 \\
\hline
\end{tabular}

Using the above values the resulting RMS voltage is about 0.183 volts. With this value the average output power can be calculated and is about 3.34nW. Figure 5-37 through 
Figure 5-40 show additional outputs at $2300 \mathrm{ft} / \mathrm{min}, 2600 \mathrm{ft} / \mathrm{min}, 2800 \mathrm{ft} / \mathrm{min}, 3000 \mathrm{ft} / \mathrm{min}$, and 3300ft/min respectively. Table 5-6 provides a summary of the data taken.

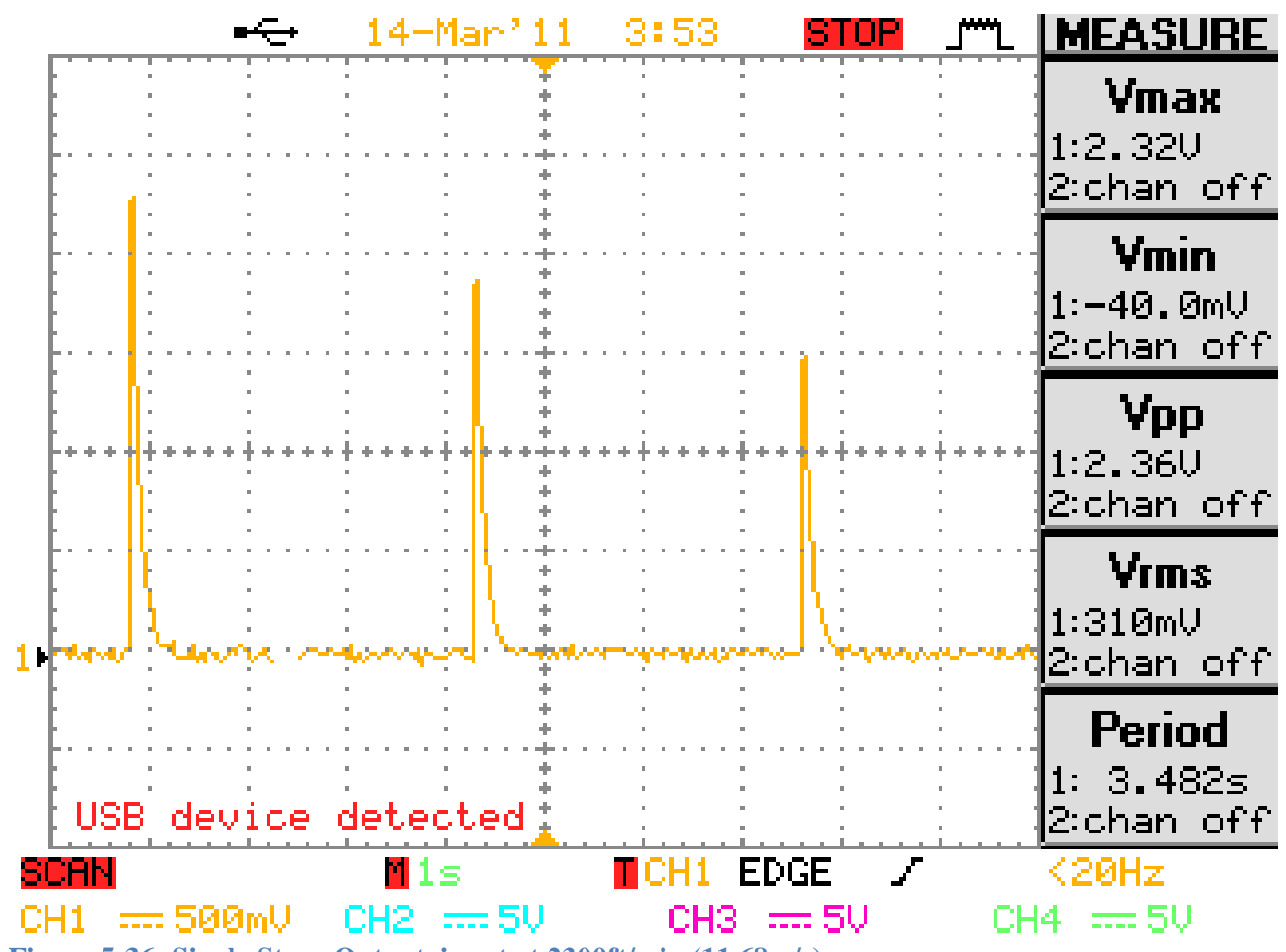

Figure 5-36: Single Stage Output, input at $2300 \mathrm{ft} / \mathrm{min}(11.68 \mathrm{~m} / \mathrm{s})$. 


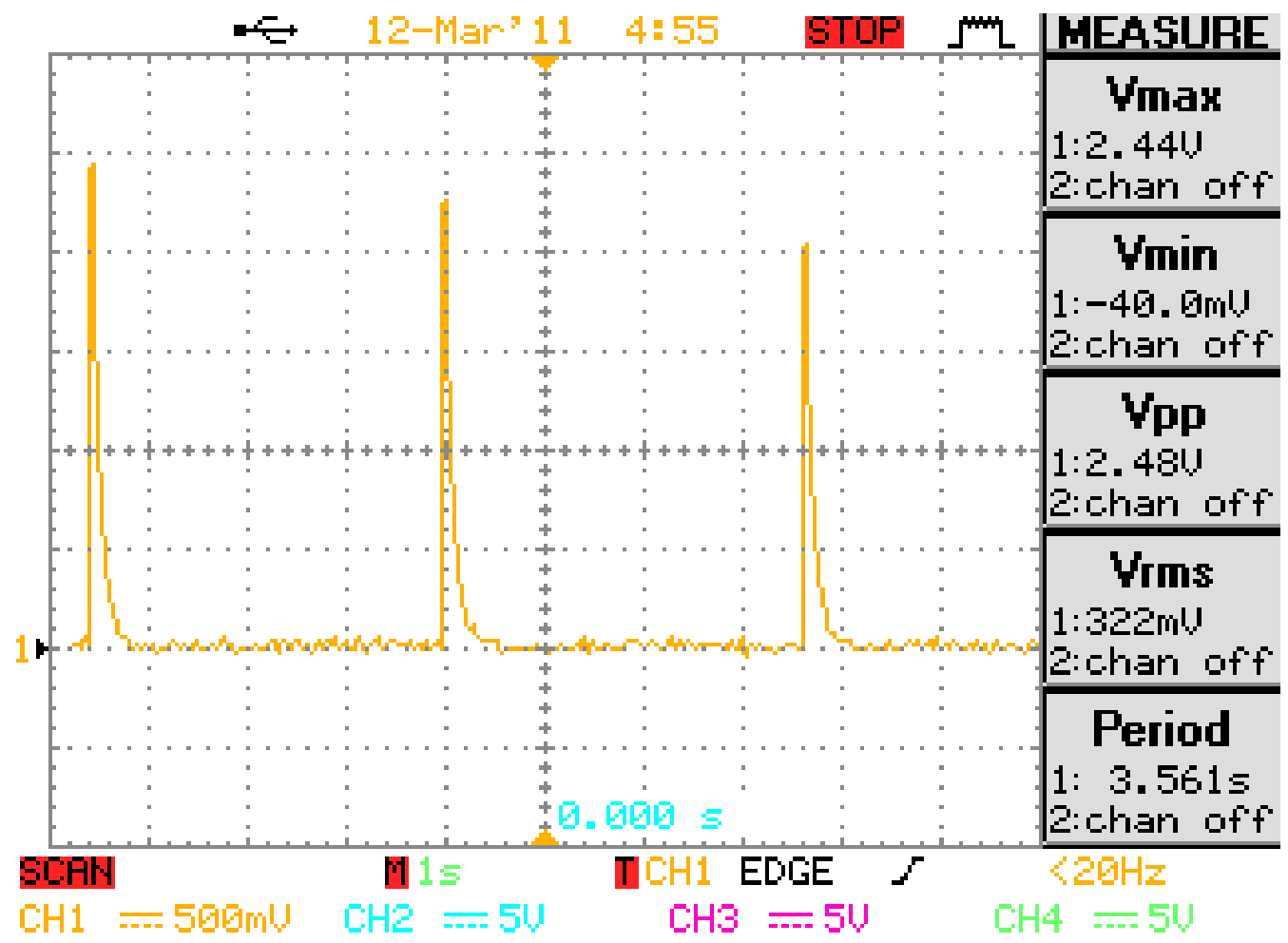

Figure 5-37: Single Stage Output, input at $2600 \mathrm{ft} / \mathrm{min}(13.2 \mathrm{~m} / \mathrm{s})$.

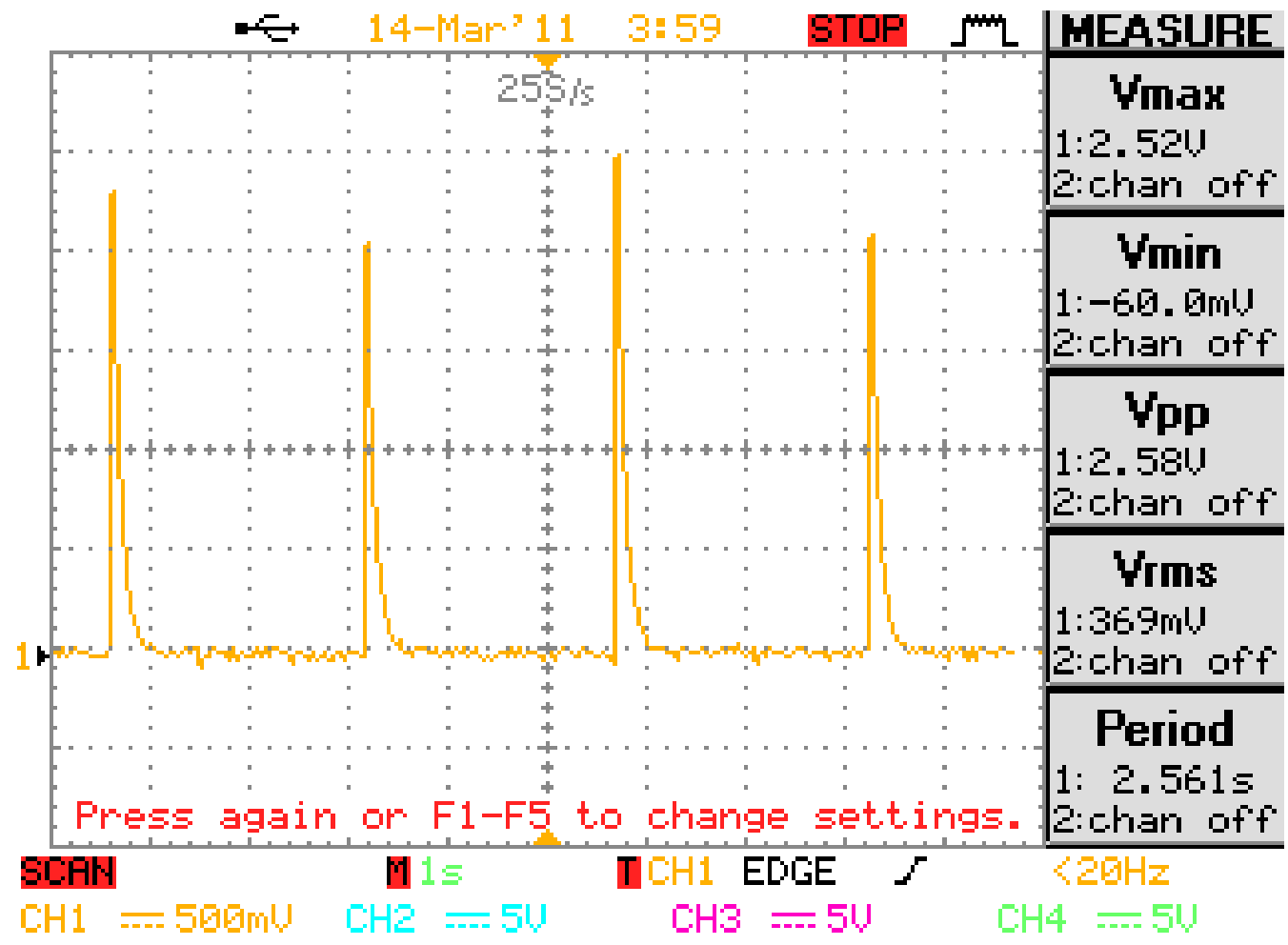

Figure 5-38: Single Stage Output, input at $2800 \mathrm{ft} / \mathrm{min}(14.22 \mathrm{~m} / \mathrm{s})$. 


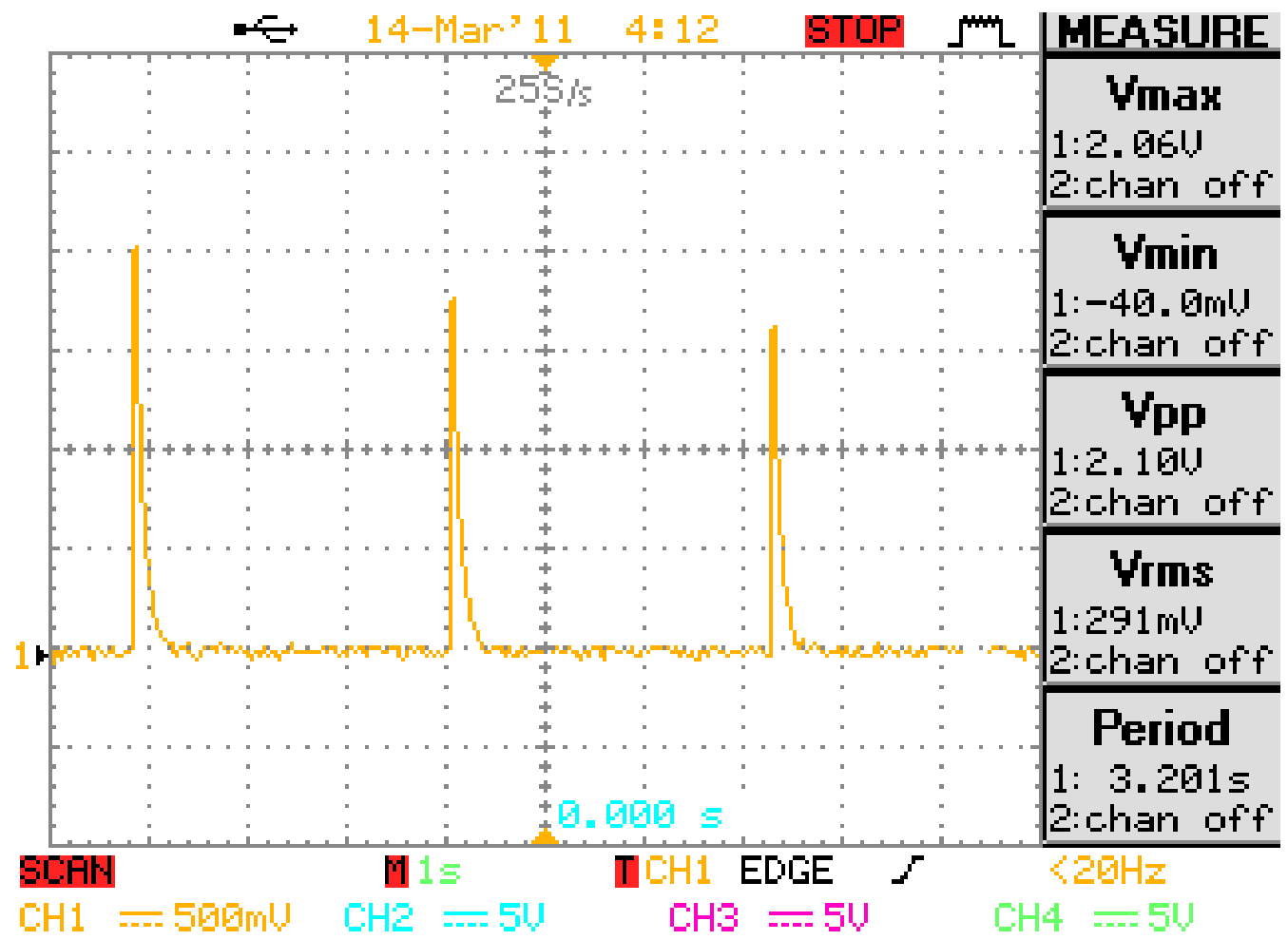

Figure 5-39: Single Stage Output, input at $3000 \mathrm{ft} / \mathrm{min}(15.24 \mathrm{~m} / \mathrm{s})$.

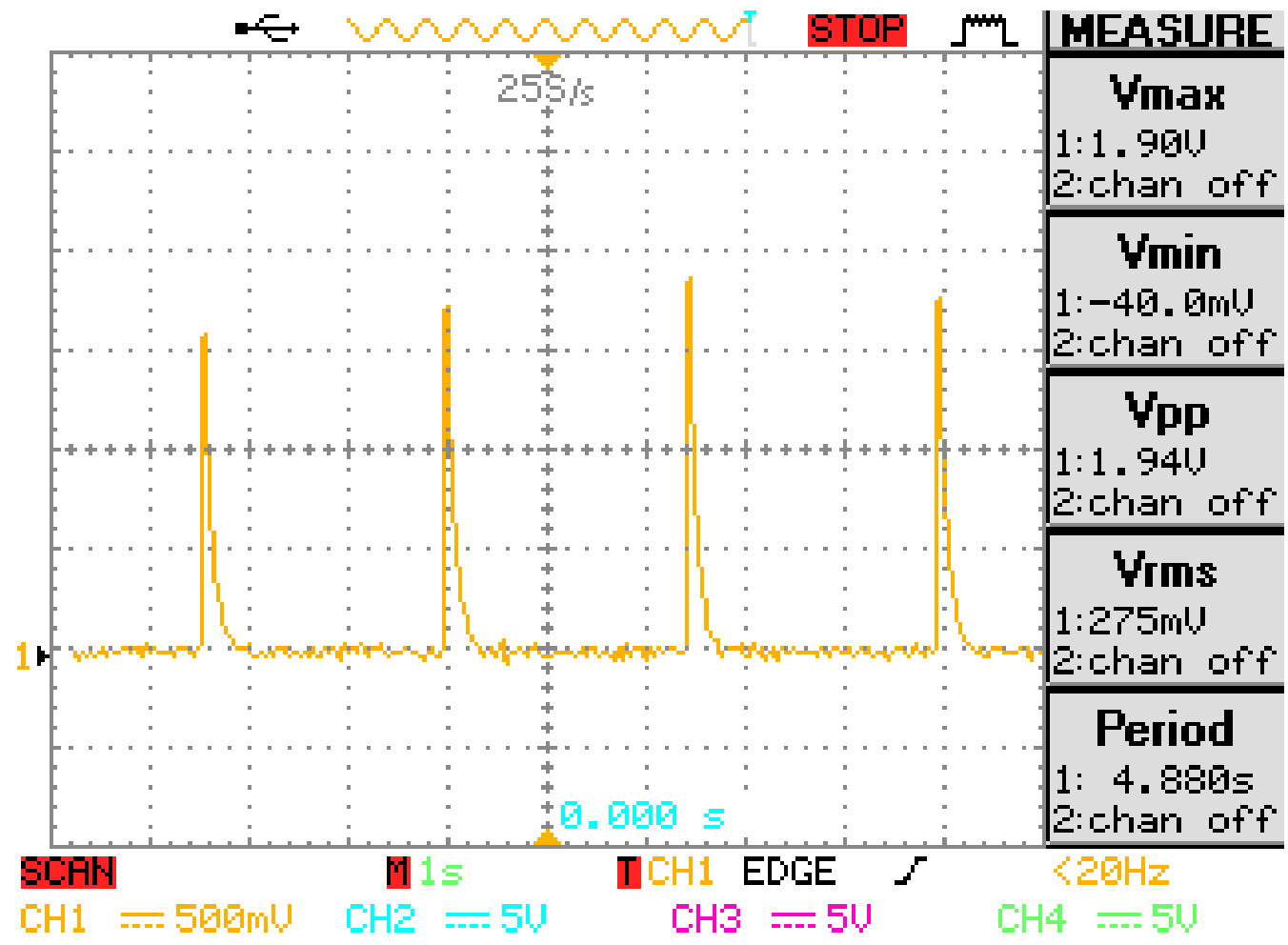

Figure 5-40: Single Stage Output, input at $3300 \mathrm{ft} / \mathrm{min}(16.76 \mathrm{~m} / \mathrm{s})$. 
Table 5-6: Summary of output power data

\begin{tabular}{|c|c|c|c|c|c|}
\hline \multicolumn{3}{|c|}{ Wind Speed } & \multirow{2}{*}{$\begin{array}{c}\text { Pulse } \\
\text { Period }(\mathrm{s})\end{array}$} & $\begin{array}{c}\mathrm{V}_{\mathrm{o}} \mathrm{RMS} \\
(\mathrm{V})\end{array}$ & $\begin{array}{c}\mathrm{P}_{\mathrm{av}} \\
(\mathrm{nW})\end{array}$ \\
\hline 2100 & 10.67 & 23.86 & 12.2 & 0.1828 & 3.34 \\
\hline 2300 & 11.68 & 26.14 & 3.52 & 0.2396 & 5.74 \\
\hline 2600 & 13.21 & 29.55 & 3.56 & 0.3004 & 9.02 \\
\hline 2800 & 14.22 & 31.82 & 2.56 & 0.3046 & 9.28 \\
\hline 3000 & 15.24 & 34.09 & 3.2 & 0.2456 & 6.03 \\
\hline 3300 & 16.76 & 37.50 & 2.4 & 0.2689 & 7.23 \\
\hline
\end{tabular}

Figure 5-41 shows a graphical representation of the data taken and shows a very nonlinear relation between wind speed and output power.

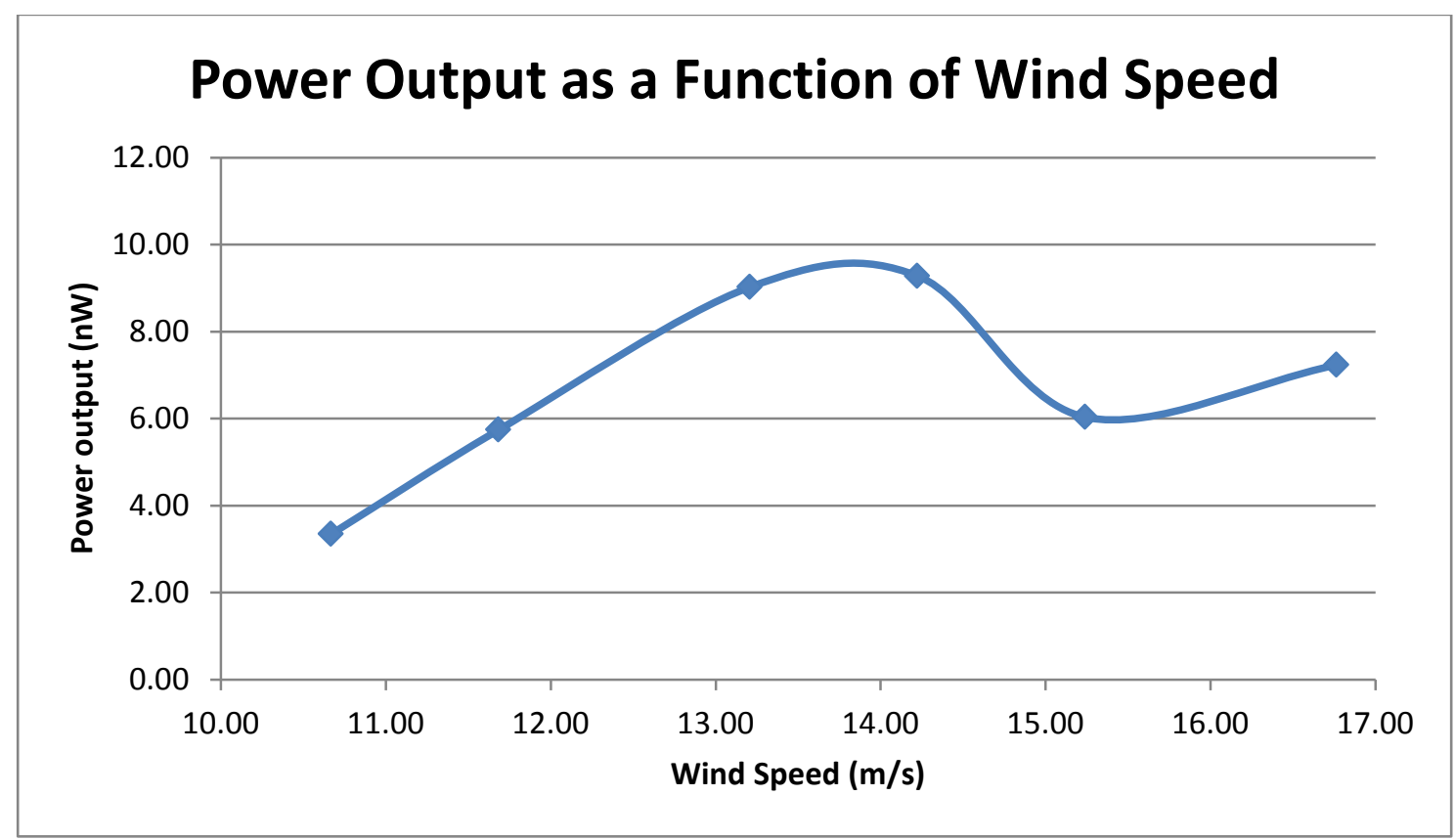

Figure 5-41: Output power as a function of wind speed

The initial expected values of output power were in the range of microwatts to tens of microwatts. The values obtained from the above test are about three orders of magnitude lower. While a small portion of this discrepancy can be attributed to the converter's 
efficiency (which is below $10 \%$ for load currents under $1 \mu \mathrm{W}$ ), this does not account for the other factor of 100 . The remaining discrepancy is perhaps an error of concept. To compute average power, the RMS voltage is needed. For an approximately sinusoidal waveform this would be the amplitude divided by the square root of two. However, this voltage is not applied directly to a linear resistive load. Instead it is fed through a nonlinear rectifier, accumulated on a capacitor, and then delivered in a non-linear manner to an output load. A major factor that was initially over looked is the fact that the charge delivered from the piezoelectric is related to the voltage level of the capacitor. Figure 5-42 provides an illustrative example of this. When the voltage on the capacitor gets close to the turn-on threshold voltage of the converter, if the peak voltage of the piezoelectric strip is not significantly higher, then the effective voltage is not a solid sinusoidal waveform. The effective voltage will appear to be more of a chopped sinusoid as illustrated by the red lines in Figure 5-42. Because of the larger periods of zero effective voltage the RMS voltage will drop significantly lower. Since the average power is related to the square of the RMS voltage the average power will be significantly affected as well. Thus it may not be entirely valid to assume that all of the energy of the sinusoidal output of the piezoelectric strip is available to be delivered to the converter.

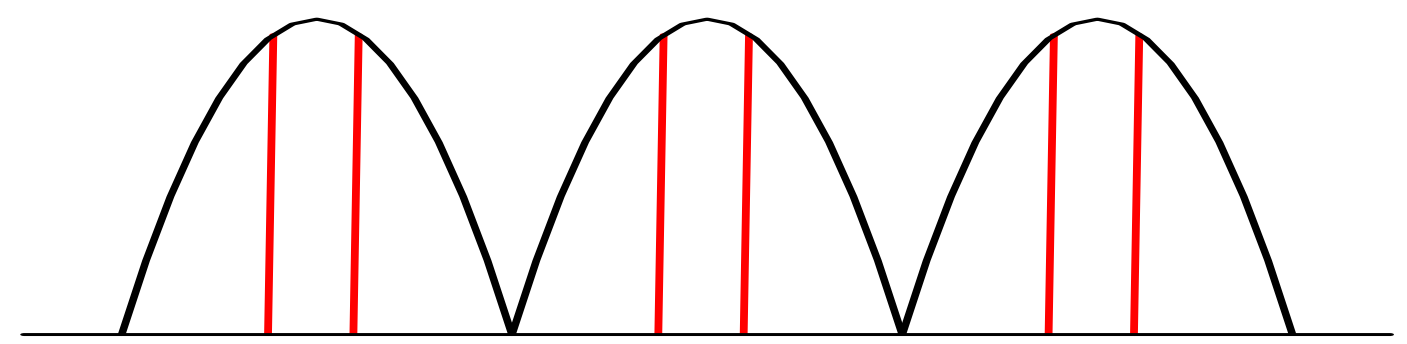

Figure 5-42: Effective input voltage with rectifier and filter capacitor. 


\section{Chapter 6 : Conclusions and Recommendations}

\subsection{Summary and Conclusion}

This thesis has two major objectives; to further investigate energy harvesting with piezoelectric polymers, and to show the "stacked buck" in a working application. Chapter 1, the introduction, showed a need for non-polluting renewable sources of energy, and how energy harvesting works into that need. Chapter 2 described why wind energy was of particular interest and the different methods for harnessing the energy. Chapter 3 detailed the major objectives of this thesis as stated in the first sentence of this chapter. Chapter 4 analyzed and simulated the newly proposed "stacked buck" to show that, in theory, it is indeed feasible. Chapter 5 tested a working hardware model in two scenarios; one in a laboratory with DC sources capable of supplying all the necessary power requirements to illustrate the working operation and performance of the "stacked buck", and an applications test, performed with the piezoelectric polymers as inputs with provided energy from a wind tunnel. The hardware verification test showed that the "stacked buck" works as initially proposed. It is capable of utilizing multiple inputs over a range of voltages to provide varying output voltages that are directly related to the number of inputs. The applications test also showed the working operation of the "stacked buck", however the resulting output was not as initially desired as the inputs have little to no correlation and achieve converter turn on times independently. The results showed that little voltage is available below $7 \mathrm{~m} / \mathrm{s}$ for this particular configuration. This short fall may be changed if the physical configuration of the sails were altered. The results did show that for increasing wind speeds larger amplitudes are produced by the 
piezoelectric strips. While initial estimates put the available power upwards of $400 \mu \mathrm{W}$, it is now thought that this analysis incorrectly assumes that this voltage is being delivered directly to a resistive source. In the case of rectifiers, capacitors, and buck converters, a linearly resistive source is not an accurate model. This is largely due to the voltage build up on the capacitor and turn on threshold voltage of the converter. The recovered available power was in the range of several nanowatts, at least 3 orders of magnitude less than initial estimates based solely on the raw output of the piezoelectric strip. While some of this can be attributed to the poor efficiency of the converter at very low loads, the remainder must be accounted for in an error of calculation or concept.

This thesis shows that the "stacked buck" works as predicted, but that wind harvesting with piezoelectric polymers, as configured here, is not a promising avenue for large scale power applications as the low available power and economic considerations make it impractical, but could be scaled to some smaller power applications.

\subsection{Future Considerations and Recommendations}

\subsubsection{Stacked Buck}

Some further considerations and analysis into the "stacked buck" would prove useful as it may relate to other energy harvesting interests. One major consideration would be to create a stacked buck with fixed duty cycles to demonstrate a working model of the simulation provided in Chapter 4 of this thesis that allows a single output filter instead of one for each stage. Additionally another worthwhile design would be to create a stacked buck out of more typical controllers with adjustable feedback to provide different voltages at each stage. A test comparing the power throughput of the "stacked buck" to a parallel buck converter may provide a test of merit for considerations as it 
pertains to multiple inputs. Other applications may be to test the "stacked buck" with other energy harvesting sources, or in other environments. Some other tests may be to see how it performs with a small solar array with each panel being an independent input, or to test vibration harvesting of piezoelectric crystals in different environments.

\subsubsection{Wind Harvesting with Piezoelectric Strips}

Additional tests should be performed on optimizing the material, size and shape of the sails used to enhance the piezoelectric strips' ability to harvest energy. One issue that was noticed was that sails had a tendency to tear due to repetitive stress from their intended vibrational flapping. This may simply be attributed to the material used as special considerations were not taken when choosing the material. Other points of interest would be to determine the optimum size and aspect ratios of sails (assuming a similar triangular shape) tailored to a range of wind speeds.

\subsubsection{Energy Harvesting Analysis of Available Energy}

This thesis revealed that a simple average power calculation of a piezoelectric source may not account for other limitations in an energy harvesting system. While the energy delivered to a passive, linear resistor is easily understood even for arbitrary waveforms it is not as easily equivocated to the non-linear system of energy harvesting. Further investigation into a more correct method of analyzing available power of a source and energy harvesting system would be beneficial for future decisions into whether or not a particular technology would yield promising results, or should be dismissed. 


\section{Chapter 7 Works Cited}

[1] U.S. Energy Information Administration, “Annual Energy Review 2009,” 2009. [online] Available: http://www.eia.gov/emeu/aer/pdf/pages/sec1_3.pdf

[2] “U.S. Primary Energy Flow by Source and Sector, 2009”, 2009 available: http://www.eia.doe.gov/aer/pecss_diagram.html

[3] L. Yount, Energy Supply. Facts on file, inc: New York, 2005.

[4] U.S. Energy Information Administration, “Energy Perspectives Overview”, 2009 http://www.eia.doe.gov/aer/pdf/perspectives_2009.pdf

[5] U.S. Energy Information Administration, “United States Energy History”, 2009 http://www.eia.doe.gov/aer/eh/eh.html

[6] California Air Resources Board. "Key events in the history of California air quality” 2010 http://www.arb.ca.gov/html/brochure/history.htm

[7] “History of Smog”, LA weekly, Sep 22 2005. [Online] Available: http://www.laweekly.com/2005-09-22/news/history-of-smog/ [Oct. 10, 2009]

[8] P. Asmus, Introduction to Energy in California. University of California Press: Berkeley, CA, 2009. 
[9] The California Energy Commission."Renewable Energy Transmission Initiative”, May 26, 2010. Available: http://www.energy.ca.gov/reti/background.html

[10] “Energy Harvesting”, http://en.wikipedia.org/wiki/Energy_harvesting. [Accessed: 725-10]

[11] D. Santschi. (2009, Sep. 11). "Workouts on 20 machines feed the Cal State San Bernardino rec center's power grid.” The Press-Enterprise. [Online]. p.5. Available: http://rerev.com/downloads/Articles/Workouts_On_20.pdf [Oct 1st, 2010].

[12] H. Ureh and C. Henry. (2009, Dec.) "DC-DC Converter for Harvesting Energy from an Exercise Bike” [Online]. Available: http://digitalcommons.calpoly.edu/eesp/20/ [Jan. 29, 2010].

[13] M. Lum and J. Yuen. (2009, Dec.) "Energy Harvesting from Elliptical Machines: DC Converter Troubleshooting.” [Online]. Available: http://digitalcommons.calpoly.edu/eesp/12/ [Oct. 1, 2010].

[14] Starner, “Human-Powered Wearable Computing,” IBM Systems Journal, Vol. 35 No. 3-4, 618-628. 1996 
[15] M. Fitzpatrick, “Vibration packs aim to replace batteries for gadgets” July 21, 2010. [Online] Available: http://www.bbc.co.uk/news/technology-10711202 [Accessed Sept. 29, 2010]

[16] D. J. Cliff and W. J. Young, The United State Energy Atlas. New York: Macmillan Publishing, 1986, pp. 251-281.

[17] J. Marshall. (2010, Aug 4). The State of the U.S. Wind Industry [Online]. Available: http://www.next100.com/2010/08/the-state-of-the-us-wind-indus.php

[18] S. Li and H. Lipson "Vertical-stalk Flapping-Leaf Generator for Wind Energy Harvesting,” Smart Materials and Structures, Sept 2009. [Online]. Available: http://ccsl.mae.cornell.edu/sites/default/files/SMASIS2009_LI.pdf [Accessed May 11, 2010].

[19] L. Ward. (2007, Oct 1) Windbelt, Cheap Generator Alternative, Set to Power Third World [Online]. Available: http://www.popularmechanics.com/science/energy/solarwind/4224763 [Accessed Oct. 1, 2010]

[20] American Wind Energy Association. Available: http://www.awea.org/faq/wwt basics.html [Accessed Oct. 16, 2010] 
[21] Humdinger Wind Energy LLC, http://www.humdingerwind.com/ [accessed Oct. 11, 2010]

[22] P. Proefrock, “Windbelt: Innovative Generator to Bring Cheap Wind Power to Third World”, Inhabitat 03/08/10. [online] Available:

http://www.inhabitat.com/2010/03/08/windbelt-innovative-generator-to-bring-cheapwind-power-to-third-world/ [accessed Oct. 11, 2010]

[23] Wikipedia, "Piezoelectricity”, Available:

http://en.wikipedia.org/wiki/Piezoelectricity accessed [Accessed July 25, 2010]

[24] H. Sodano and D. Inman “Comparison of Piezoelectric Energy Harvesting Devices for Recharging Batteries,” Journal of Intelligent Material Systems and Structures, 2005. [Online]. Available: http://institute.lanl.gov/ei/pdf_files/JIMSS2005.pdf [Accessed May 17, 2010].

[25] Piezoelectric Trees-aesthetically pleasing wind power, 2002, Available: http://www.halfbakery.com/idea/Piezoelectric_20Trees. [Accessed Oct. 1 2010]

[26]Measurement Specialties, Application Note 111398 “LDT0 Solid State Switch/Vibration Sensor”. [Online]. Available: http://www.parallax.com/Portals/0/Downloads/docs/prod/compshop/LDTOSensor.pdf [Accessed Oct. 1, 2010] 
[27] Linear Technologies Corporation, LTC3588-1 “Piezoelectric Energy Harvesting Power Supply”, Data sheet. [online] Available: http://cds.linear.com/docs/Datasheet/35881fa.pdf [Accessed May 17, 2010]

[28] Energybible.com, "Wind Speed and Wind Energy". Available: http://energybible.com/wind_energy/wind_speed.html [Accessed Nov. 7, 2010]

[29] Taufik, 2009. Introduction to Power Electronics, 7th Rev. @Taufik

[30] National Renewable Energy Lab, R. Wiser and M. Bolinger, Annual Report on U.S. Wind Power Installation, Cost, and Performance Trends: 2006, 2007. Available: http://www.nrel.gov/docs/fy07osti/41435.pdf [Accessed April 25, 2011]

[31] P. Harrop, The Price-Sensitivity Curve for RFID, 2006, Available: http://www.mindya.com/shownews.php?newsid=1615. [Accessed April 25, 2011] 